Portland State University

PDXScholar

$1-1-2012$

\title{
Informal Learning Choices of Japanese ESL Students in the United States
}

Brent Harrison Amburgey

Portland State University

Follow this and additional works at: https://pdxscholar.library.pdx.edu/open_access_etds Let us know how access to this document benefits you.

\section{Recommended Citation}

Amburgey, Brent Harrison, "Informal Learning Choices of Japanese ESL Students in the United States" (2012). Dissertations and Theses. Paper 755.

https://doi.org/10.15760/etd.755

This Thesis is brought to you for free and open access. It has been accepted for inclusion in Dissertations and Theses by an authorized administrator of PDXScholar. Please contact us if we can make this document more accessible: pdxscholar@pdx.edu. 
Informal Learning Choices of Japanese ESL Students in the United States

by

Brent Harrison Amburgey

A thesis submitted in partial fulfillment of the requirements for the degree of

Master of Arts

in

TESOL

Thesis Committee:

Nike Arnold, Chair

Lynn Santelmann

Kim Brown

Portland State University

2012 


\begin{abstract}
This study was designed to explore possible relationships between English language learners past formal language learning experiences and beliefs about language learning on the one hand, and their informal learning choices on the other. Six Japanese English as a second language (ESL) students participated in the study. Participants were interviewed and asked to complete an English study log for one week prior to their scheduled interview. The results of the study suggested that there were likely connections between experiences, beliefs, informal learning choices. For some participants, a singular experience or belief had an effect that seemed to outweigh other experiences and beliefs. However, there were also some differences in informal learning choices among participants that might be better explained by factors outside of the interest of this study, such as personality or goal of English study.
\end{abstract}




\section{Table of Contents}

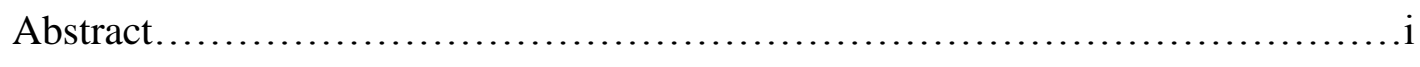

List of Tables................................................................

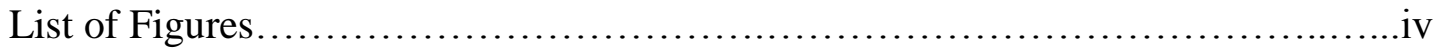

Introduction.........................................................

Review of Literature .........................................................

Forms of Learning ................................................. 3

Beliefs....................................................9

Methodology..........................................................20

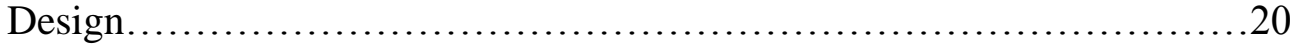

Participants and Context.........................................21

Data.........................................................25

Data Collection.................................................28

Analysis....................................................... 31

Validity and Reliability..........................................33

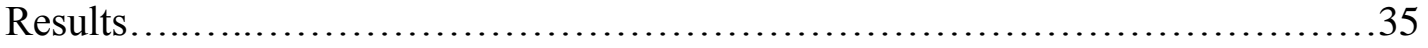

Honami...................................................... 36

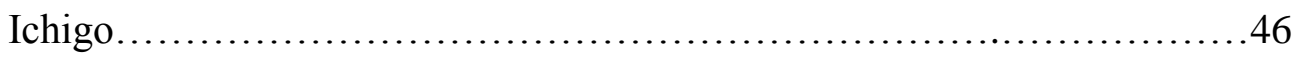

Norio.......................................................... 57

Natsuo..........................................................66

Hanako....................................................... 76

Yoshito.........................................................83

Summary ......................................................90

Conclusion.......................................................96

References......................................................... 102

Appendix A: Core Interview Questions.................................107

Appendix B: English Study Log...................................... 110

Appendix C: Interview Transcriptions \& Follow up Communication ..............111

Appendix D: Codes.................................................230 


\section{List of Tables}

Table 1: Participant Summary ...................................................

Table 2: Summary of Participants' Experiences, Beliefs, and Informal Learning

Techniques......................................................... $90-91$ 


\section{List of Figures}

Figure 1: Livingstone's Four Categories of Learning...........................4

Figure 2: Rogers's Continuum of Learning Types...............................5 


\section{Introduction}

Informal learning is a phenomenon that has been slowly gaining attention in the fields of education and applied linguistics over the last few decades. One aspect that separates informal learning from other types of learning is learners' ability to make their own choices in terms of their goals and the techniques and resources utilized for the purpose of learning. This research explores the relationship between the choices that learners make while engaging in informal learning, their past learning experiences, and their beliefs about language learning. The population for this study is Japanese university students, who are studying English in the United States.

I became interested in the topic of informal learning a number of years ago while talking casually with a group of Korean friends, who were studying English in the US. While discussing their English study habits, I found that they routinely spent several extra hours per day beyond what was required for their ESL classes.

Furthermore, once they transitioned from studying for classes to simply studying for their own benefit, their methods changed. One of the more interesting revelations was that they often used the TV show "Friends" as part of their study time. In fact, they reported that many of their fellow English students had purchased or borrowed box set DVDs of "Friends" or similar shows.

These discussions occurred before I had entered the field of applied of linguistics, and yet they stuck with me. When it came time to choose a topic for my thesis, I still had this fascination with informal learning habits. It was a natural 
choice for me to use this format to explore something that was both of great interest to me and potentially useful for my future career.

I chose to work with a Japanese population for a number of important reasons. First, I believed it likely that I would be looking for teaching positions primarily in Japan upon my graduation. This was due both to the availability of positions that fit my professional goals and to where I was in my own personal life and relationships. Also, I already had some familiarity with Japanese culture and language, which I felt might aid the process of finding participants and building rapport. Lastly, I was aware of the intensive study that Japanese youth do outside of formal education, often in the form of attending "cram" schools, and was hopeful that these experiences might result in a population with higher rate of informal learning practices that would be relevant to this study.

After establishing what is meant by and included in the term informal learning, I will examine the concept of beliefs, specifically with relation to beliefs about language learning. Having operationalized these concepts, I will report the findings of my study that examines the informal learning practices of Japanese students at the university level who are studying English in the United States. Through a series of interviews and the use of participant study logs I will explore possible relationships between the informal learning techniques used by the students, their previous learning experiences and beliefs about language learning. 


\section{Review of Literature}

In the following paragraphs I will position my operationalization of the term "informal learning" with regards to both other forms of learning and other researchers' definitions of the term informal learning itself, which have been somewhat varied. In addition, I will discuss the topic of beliefs, specifically with regard to language learning, which can play an important role in how students choose informal learning practices. Lastly, I will present some background information on the formal and "cram" school experiences that are typical for students growing up in Japan.

\section{Forms of Learning}

In the past, the term learning was generally associated with formal, institutionalized schooling. However, recognition of how much learning occurs outside of the structures of formal education during a lifetime has created a need to better differentiate between forms of learning. Rogers (2004) noted that since learning is an "activity which exists throughout life, then it becomes important to find new ways of breaking it into manageable units" (Non-formal education and lifelong learning/education section, para. 1).

As noted above, there are many different types of learning. Livingstone (2001) placed these different forms of learning into four categories based on who the

primary agent is and whether the learning is situational (tailored to student's needs) or comes from an established tradition (pre-set curriculum), as illustrated in Figure 1. 
As an example, non-formal education is when people are learning of their own accord and for their own purposes, but are submitting to the curriculum of an existing institution in order to do so. Livingstone's category of self-directed learning, in which the learner studies for his or her own purpose and at his or her own direction, falls closest to my functional definition of informal learning.

Figure 1: Livingstone's four categories of learning (2001).

\begin{tabular}{|l|l|l|}
\hline \multirow{2}{*}{ Knowledge Structure } & \multicolumn{2}{|c|}{ Primary Agency } \\
\hline Pre-Established & \multicolumn{1}{|c|}{ Learner } & \multicolumn{1}{c|}{ Teacher } \\
\hline Situational & $\begin{array}{l}\text { Non-Formal education } \\
\text { Further education }\end{array}$ & $\begin{array}{l}\text { Formal schooling } \\
\text { Elders' teachings }\end{array}$ \\
\hline & $\begin{array}{l}\text { Self-directed learning } \\
\text { Collective learning }\end{array}$ & $\begin{array}{l}\text { Informal education } \\
\text { Informal Training }\end{array}$ \\
\hline
\end{tabular}

Mocker and Spear (1982) divided their categories similarly, by establishing four types of learning in which the learner has a combination of control over two factors: learning means and objectives. Formal education, for example, is when the learner has control over neither means nor objectives; on the other end of the spectrum, selfdirected learning would be when the learner has control over both of those variables.

Rogers (2004) also sought to represent the differences between formal, nonformal, and informal/participatory education, though he only briefly mentioned informal learning and described all of the items on a continuum rather than as distinct categories, as depicted in Figure 2. His approach to distinguishing them was mainly based on how much each situation is adapted to the participants. 
Figure 2: Rogers's continuum of learning types (2004).

\begin{tabular}{|c|c|c|c|}
\hline \multicolumn{3}{|c|}{} & \multicolumn{3}{|c|}{ Formal } \\
education & $\begin{array}{c}\text { Non-formal } \\
\text { education }\end{array}$ & $\begin{array}{c}\text { Participatory } \\
\text { education }\end{array}$ & $\begin{array}{c}\text { Informal } \\
\text { learning }\end{array}$ \\
\hline
\end{tabular}

Formal education, as an example, is characterized by a curriculum that is preestablished and does not change depending on the learners.

Though the terms used and graphics employed to describe these forms of learning differ quite a bit between researchers, the main points are largely consistent. A variety of learning situations exist, some of which are highly controlled by an institution, while others give the learner more freedom. It is the latter that I will explore in this paper: informal learning.

\section{Informal Learning}

Informal learning, as it is currently defined, has several characteristics that are generally agreed upon: (1) The learner is the primary agent, meaning that learning results primarily from the actions of the learner rather than an organization or teacher (though the learner may make use of tutors or curricula from formal institutions); and (2) the learning will generally occur outside of the walls of formal education (Livingstone, 1999; Livingstone, 2001; Pemberton et al. 2004; Garrick, 1996). Marsick and Watkins (1990) argued that "informal learning can be deliberately encouraged by an organization or it can take place despite an environment not highly conducive to learning" (as cited in Pemberton et al., 2004, p. 28). Informal learning 
often takes place in daily life, sometimes happening in an unplanned or unorganized manner.

For the purpose of this research, I am most interested in what Livingstone (1999) refers to as explicit informal learning, which he argues is learning that "is distinguished from everyday perceptions, general socialization, and other tacit learning by peoples' conscious identification of the activity as significant learning" (p. 51). In other words, I am looking for active attempts at learning in which the learner maintains his/her agency.

Having established my operationalization of informal learning for this research, it is important to also address some of the other uses of this term in order to distinguish what is not meant by the term informal learning. The most complicating factor is that the term is used differently by different researchers, and even the simplest definition likely includes a few subdivisions. In some definitions the concept seems to be limited only to tacit learning. Rogers (2004), for example, describes informal learning as unpurposeful and as "learning that goes on outside of any planned learning situation" (Defining non-formal education section, para. 6). Such learning might be categorized as a subdivision of informal learning that is generally referred to as incidental or experiential learning (Comas-Quinn, Mardomingo, \& Valentine, 2009; Garrick, 1996; Livingstone, 1999, 2001; Pemberton et al., 2004; Rogers, 2004).

At other times, informal learning is used to describe a process of learning by accident or learning through the experiences and mistakes of everyday life. Comas- 
Quinn et al. (2009) referenced and elaborated on Kukulska-Hulme's term “stumble and learn" (p. 101) to mean that even when individuals are not actively looking for knowledge, they may still be cognizant of gaining knowledge from a situation. Garrick (1996) extended his definition of informal learning in a similar way by acknowledging that learners are at times adept at "apprehending experience, reasoning, or logically thinking through their direct experience and giving that experience meaning" (p. 24).

Despite some of the more restrictive definitions, it seems that most researchers, including Livingstone (2001), Pemberton et al. (2004), Comas-Quinn et al. (2009), and Garrick (1996), had room in their definition of informal learning to include both the explicit and tacit. In other words, they acknowledged two subcategories of informal learning and explicitly discussed whether a learner was consciously aware of the learning that was occurring.

The concept of informal learning has gained attention in a number of fields in recent years. However, it is not an entirely new concept. To some extent, the interest in informal learning can be traced back to the field of adult education (Rogers, 2004; Garrick, 1996; Livingstone 2001). Tough (1971) first delved into this subject with his exploration of self-planned/self-directed learning. The terms self-planned and selfdirected are not meant to give the impression that the individual is alone in the pursuit of knowledge. A self-directed learner is one who will "obtain the knowledge and skill from a variety of individuals, books, and programs without giving up the responsibility for deciding which resources and activities to use each time" (Tough, 
1971, p. 78). A self-directed learner can use many resources in his/her learning: books, videos, consultation with experts, conferences, and much more (Candy, 1991; Pemberton et al., 2004; Tough, 1971).

The progression of theory in second language acquisition and the resulting changes in teaching methods have also opened the doorway for greater appreciation of informal learning. As the influence of Behaviorism, Grammar translation, and Audio Lingual teaching declined, new theories began to replace them which were more interested in and conducive to informal learning. Krashen (1981) introduced his monitor model, which claims the superiority of acquisition, a subconscious process that occurs when being immersed in the language, over learning, which involves a more formal instruction in the language. In this way, the strict adherence to traditional classroom language learning began to loosen. Pemberton et al. (2004) also wrote that "successful language learning is... achieved through exposure to and interaction with language in authentic contexts" (p. 30). This focus on authentic contexts and social interactions is a perfect fit for informal learning, which often takes place in exactly those places. Indeed, Ellis (1980) argued that "there is... a substantial literature which suggests that where acquisition takes place in a formal learning context it is frequently less successful than when it takes place informally" (p. 30).

The importance of informal learning has also been recognized outside of language learning. While it has long been common knowledge that adults continue to learn throughout their lives, recent research by Livingstone (1999) and Garrick (1996) has shown that adults are increasingly looking to informal learning to gain skills and 
knowledge that are relevant to their professional goals. Livingstone (1999) even foresaw the possibility of some formal learning institutions becoming outdated or irrelevant in the face of rising informal learning, saying, "if the crews of our big educational and training ships do not increasingly look out for the massive, detectable icebergs of informal learning, many of their programs my sink into Titanic irrelevancy" (p. 50). Garrick (1998) made a similar claim about informal learning in the workplace, saying that it "has the potential effect of breaking the power of the formal education system" (p. 17).

One of the reasons that informal learning is becoming so popular with adult learners is that technology continues to make access to information and knowledge quick and convenient (Comas-Quinn et al., 2009; Egert, 2000; Pemberton, et al. 2004). Some technologies, such as Internet chat programs, blogs, message boards, or computer software, can just as easily be taken advantage of at home.

\section{Beliefs}

While finding out what students are doing when they engage in informal learning is interesting in itself, equally interesting is finding out why they make the choices they do. This is a question of beliefs, in this case, beliefs about language learning. At a surface level, it may appear that the construct of beliefs does not need explanation. However, the concept of beliefs is an abstract idea and deceptively complex. It is easy to take for granted what exactly it means to hold a belief about something. Bernat and Gvozdenko (2005) compiled a fairly thorough list of the 
different ways that researchers have thought about beliefs. Included were minitheories, insights, cultures of learning, learner assumptions, implicit theories, selfconstructed representational systems and reality filters. With this many different ways of thinking, it is clear that the concept of beliefs is more complex than a surface level investigation would reveal. Pajares (1992) even goes so far as to say that beliefs are often thought of as "messy" (p. 329). However, he continues on to say that "when they are clearly conceptualized...beliefs can be...the single most important construct in educational research" (p. 329).

Pajares (1992) also noted that part of the difficulty in defining the term beliefs is that it is often difficult to tell at what point beliefs end and knowledge begins. After all, at one point humans knew that the earth was flat and the center of the universe. It is this sort of mistake that has led to beliefs being labeled myths or misconceptions. However, humans are constantly theorizing to help explain the phenomena they experience and observe. The only difference between the theorizing of a scientist and a lay person is expertise. As Barcelos (2000) points out, at a base level, the process that occurs in the human mind is the same. Therefore we are left with beliefs lying somewhere between knowledge and misconceptions or myths. This is a very large gap, and the difference between being on one side versus the other seems to be completely dependent on having some sort of scientific proof, which may not be readily and immediately available. By this line of reasoning beliefs, without proof, are nothing more than a state of uncertainty. As this is not a particularly helpful definition, I will turn to a definition offered by Dewey (1933), 
who said that beliefs "cover all the matters of which we have no sure knowledge and yet which we are sufficiently confident of to act upon and also the matters that we now accept as certainly true... but which nevertheless may be questioned in the future..." (as quoted in Barcelos, 2000, p. 32). This seems a suitable working definition of beliefs.

Beliefs about language learning. Having defined what a belief is, we turn to the question of how beliefs are involved in the process of language learning. To that end, it is definitely important to consider the effects of beliefs on learning outcomes. However, it makes sense to first start at the beginning: how beliefs develop.

A large percentage of students' beliefs about language learning come from what they are exposed to from instructors who have taught their classes. Arnold (2007) revealed that student beliefs about language learning were "at times heavily influenced by teaching practices they had experienced..." (p. 131). While the beliefs and theories of language learning held and promoted by an instructor can have a definite impact on those they teach, students are also capable of holding their own unique ideas about language learning (Horwitz, 2008). Peacock (1998) found that students in his study held stronger preferences for grammar work and error correction. Meanwhile, teachers preferred communicative activities and group work. Peacock concluded that the students, all first year Chinese university students, were likely influenced by their past learning experiences. As such, it is possible that learners who had a history with communicative teaching might be more inclined to agree with teachers that communicative activities are useful. Peng and Woodrow 
(2010) agreed, noting that students who had positive experiences in communicative classrooms were likely to develop a language learning belief system that was communicative in nature. Some students may buy into the ideas and techniques they learn from their instructors, while others may have strong opinions that do not harmonize well with the techniques used in their classrooms.

The existing literature seems to confirm that students are likely to enter a language program with certain ideas about language learning (Horwitz, 1988). Arnold (2007) suggests that these ideas come from a developed "culture of learning" that is the result of environmental factors. In other words, past experiences can shape a set of expectations and beliefs that a language student carries into future learning situations. However, Allen (1996) demonstrated that a student with existing beliefs about language learning could have their beliefs evolve over time as a result of interaction with a teacher who holds different beliefs. Peacock (1998) suggested, furthermore, that teachers being overt about their rationales for exercises or strategies that students are unfamiliar with may impact student beliefs, or at least alleviate the anxiety caused by differing opinions. Mantle-Bromley (1995) even went so far as to suggest that teachers should actively seek to change errant language learning beliefs that students hold, calling it a "weighty responsibility" (p. 383).

White's (1999) study on self-instructed learners also demonstrated that beliefs can be shaped. In fact, in her study learners' beliefs changed as a result of a new experience, self-instructed language learning, even without the influence of a teacher with differing beliefs. Interestingly, some students did not adjust well to this new 
process. Those students were generally found to have trouble adopting an internal locus of control, and possibly were "less predisposed to being able to adjust to language learning in a less conventional context” (White, 1999, p. 456).

In discussing the effect of experiences on beliefs, culture can certainly not be ignored. Several researchers on the topic of language learning beliefs have talked about the impact of popular ideas about language learning on learner beliefs by using terms such as folklore or folklinguistics (Barcelos, 2000; Pajares, 1992). While these terms may at times be used in a way meant to belittle the beliefs that common people have about language learning, the researchers don't underestimate the impact that these popular ideas have on learners. A learner from a teacher-centric East Asian formal education setting, for example, will likely have quite different ideas about the roles of teacher and student in the classroom than a Western student. Peng and Woodrow (2010) wrote that a learner's "socially constructed beliefs... could profoundly influence learners' learning and communication behaviors" (p. 841). While the origins of learner beliefs are definitely important and relevant, it is the effects of those beliefs that display themselves tangibly in the classroom. It is clear that the beliefs that learners hold about learning techniques can have a strong impact, either positively or negatively, on their success with language learning. In Fernandez's (2007) study on the relationship between learner beliefs and persistence in foreign language, there were a number of interesting findings which relate to learning methods and techniques. First, language learners who planned to continue their study rated the importance of communicative activities more highly than those 
who did not plan to continue. Continuing students also disagreed more strongly that learning language is a matter of translating into the native language. Additionally, they placed a stronger importance on learning about the second language (L2) culture. Lastly, language learners who planned to continue their study were more likely to agree that they have an aptitude for language and also felt more strongly that anyone has the potential to learn a language.

While it is often true that some types of studying come easier to an individual than others, a feeling of lacking aptitude or potential may also be a reaction to a mismatch between a student's needs or expectations and the teaching methods they experience. Several researchers have argued that disparity between the beliefs of teachers and students regarding the effectiveness of learning activities may affect learning outcomes. Horwitz (1988) noted that learners may choose to study in the manner they believe most fit outside of class, regardless of their teacher's recommendations. She believed that these differences could have a negative impact on students' learning and confidence. Peacock (1998) interviewed teachers and found that the majority believed that these disparities in language learning beliefs between teachers and students negatively affect learning. Furthermore Peacock suggested that these differences could result in students leaving a language program or otherwise discontinuing study. Issues such as these led to Mantle-Bromley’s (1995) recommendation for actively seeking to bring learners' beliefs more in line with the current research to "increase both the length of time students commit to language study and their chances of success in it" (p.383). 
Peng and Woodrow (2010) conducted a study in the EFL setting in China, in which they explored various factors that might impact students' willingness to communicate (WTC) using a questionnaire that included a modified version of the Beliefs About Language Learning Inventory (Horwitz, 1983). They found that the Chinese students in their study who held more traditional beliefs about language learning, such as it being a matter of translating between languages, had lower scores on the motivation items on a questionnaire. They posited that the students' motivation was reduced when asked to participate in activities, such as the communicative activities typical of many EFL classrooms, which might clash with the beliefs they held about language learning. There was also a relationship between beliefs and confidence, in which students that responded negatively to items about the appropriateness of speaking up frequently in class also responded more negatively to the communicative confidence items on the questionnaire. The researchers posited that this too may result from anxiety that develops from being asked to behave in a way that classmates might view as culturally inappropriate.

\section{Beliefs, Experiences, and Informal Learning}

Up until this point, little research has been done on the interplay between beliefs, experiences and informal learning techniques. While White (1999) did explore these themes, that study was more interested in how beliefs changed as a result of experiencing self-instructed language learning for the first time. Cotterall (1995) also investigated learner beliefs and their effect on learner autonomy, but this 
was more geared towards what type of learner will be successful in independent study. The research indicated that confident, experienced language learners who do not have a strict teacher-centric view of learning or rely too heavily on teacher feedback will be the most successful autonomous learners.

Cotterall (1999) later expanded on her previous work on autonomy and, among other conclusions, indicated that future research should delve into the use of specific strategies by learners. She posited that learner strategy choices likely have to do with their "knowledge of that strategy, their confidence to adopt it, their willingness to use it and their acceptance of responsibility for adopting it” (p. 510). She then called for future studies to explore the relationship between strategy choices and learner's metacognitive knowledge.

However, the topic of how previous learning experiences and beliefs might shape language students' informal learning practices and the specific techniques they use is still relatively uninvestigated. To that end, I proposed the following research question: What is the relationship between Japanese ESL students' informal learning methods on the one hand and their past formal language learning experience and beliefs on the other? To discover these relationships, I sought to answer three subquestions:

a) What are the techniques and materials that Japanese students studying English in the United States use in informal learning situations?

b) What kind of teaching methods and techniques have these learners experienced in their English classes in their home country and in the US? 
c) What beliefs do these learners hold about language learning?

\section{Japanese Educational System and Cram Schools}

To better understand the population of this study, and why it was chosen, it is important to discuss some background information on the Japanese educational system and cram school system. The Japanese educational system is well known for its strength and rigorous nature (Guo, 2005). While formal schooling is mandatory only through the end of middle school, high school attendance rates are above 90 percent and college rates are above 40 percent (Guo, 2005). Though the education system is undeniably strong, the entrance examination culture of the Japanese system is quite strenuous for the youth of the country. For students wanting to attend schools with the best reputations, strong entrance examination scores are required to enter not only high school and colleges but often elementary and junior high schools as well (Guo, 2005; Roesgard, 2006).

Despite those criticisms, however, the Japanese educational system is effective. The Ministry of Education controls the standardization of everything from policies and textbooks to teachers' salaries and minimum education and qualification requirements; under this strict guidance, education across Japan has thrived. The standards set by the Ministry of Education are routinely above those of corresponding schools in the United States (Guo, 2005). Despite already high national educational standards, in 1993, entrance examinations for 55.8\% of Japanese middle schools and $74.1 \%$ of Japanese high schools tested potential students on material that was beyond the scope of these standards (Roesgard, 2006). The result has been a system that 
results in very well educated youth. As an example, a 1989 report by the National Research Council showed that the mathematics scores of the top $50^{\text {th }}$ percentile of Japanese students were matched by only the top $5^{\text {th }}$ percentile of their American counterparts (Guo, 2005).

In addition to traditional formal schooling, many students also attend juku (also commonly referred to as "cram schools") in the afternoons and/or evenings. In fact, in 1999 over $70 \%$ of public middle school students attended a cram school (54.9\% for private middle school students). Even $36.9 \%$ of elementary school students were enrolled at a juku (Roesgard, 2006).

Cram schools are non-formal institutions, meaning that while cram school students do follow a curriculum that is imposed on them by the schools, attending a cram school is in no way mandated by the Japanese government (Guo, 2005; Roesgard, 2006). Students who attend a cram school generally do so for one of two reasons: to get supplemental instruction that will improve performance in school or to get additional advanced instruction that is beyond the scope of school teaching but will prepare the student for entrance examinations (Roesgard, 2006).

Roesgard (2006) argues that there are both positives and negatives to the existence of cram schools and the way they have impacted education in Japan. On the negative side, they can be quite expensive. As an example, Roesgard (2006) stated that it could cost up to 1 million yen for a $6^{\text {th }}$ grade student's full exam preparation course. Cram schools may have also contributed to a hierarchy in education that can start as early as middle school. For example, two well respected 
boys' middle schools can boast that over $50 \%$ of their students go on to attend one of the three most prestigious universities in Japan (Roesgard, 2006).

An argument has also been made that the strenuous nature of cram schools (especially when combined with an already strenuous formal education system) has caused social issues in Japanese children. However, these claims are often anecdotal and as yet unverified (Roesgard, 2006). There has also been some evidence to the contrary. For example, a study of 2,000 respondents found that $68.4 \%$ felt that attending a cram school had helped them make more friends (Roesgard, 2006).

On the positive side, well respected cram schools do have a strong record of helping students achieve entrance at reputable universities (Roesgard, 2006). Families that can afford to send their children to a good cram school will likely see results from the money and time that is spent there. The widespread existence of cram schools also provides an easily accessible option for children who struggle with their school work; a 1997 survey showed that $62.5 \%$ of the cram school attendees questioned felt that their school work had improved as a result of going to a cram school (Roesgard, 2006).

While there are clearly positives and negatives to both the formal educational system and cram school culture in Japan, the result has been a country whose youth are generally receiving a very strong education. It is clear that to succeed in this system, most students will need to study extensively outside of class. In selecting a Japanese population for my study, it was my hope that this history of study beyond the demands of formal education would translate into a higher rate of informal study. 


\section{Methodology}

\section{Design}

The purpose of this study is to examine the relationships between English language learners' past language learning experiences, their beliefs about language learning, and the techniques they use for informal language learning. It is qualitative and exploratory in nature, with the hope of finding notable themes and relationships but no intention to make strong generalizations to a larger population.

Qualitative studies focus on the "quality of the information taken from the sample, not the quantity" (Perry, 2005, p. 57). As a result, they generally have a small number of participants from whom they seek to elicit think, rich description. In addition, qualitative research focuses on the participants' subjective view of the issue being explored (Creswell, 2007) and is emergent in nature, meaning that the direction of the research cannot be completely controlled by the researcher. Instead, the researcher must follow the flow of the data (Creswell, 2007). This is precisely what I looked for in my study: rich, thick description of experience, beliefs, and informal learning practices, from a small number of participants. This sort of detailed description is desirable because it helps in understanding the subjective experiences of participants. This was also the logical choice for an exploratory study, because thorough and detailed accounts are more likely to reveal interesting, relevant, and possibly unexpected themes than responses to a survey. Additionally, the emergent design allowed for the direction of the research to be determined by the information 
that participants share. This was appropriate as I could not have predicted the beliefs that participants hold or the experiences they have had based on prior research.

Perry (2005) describes a continuum on which a study is located somewhere between exploratory and confirmatory. He writes: "The main characteristic of this continuum is whether a study is trying to find evidence to support (i.e. confirm) a hypothesis or explore some phenomena prior to the development of any hypothesis" (p. 80). While there are definitely specific factors that I intended to explore, such as past language learning experience and beliefs about language learning, I was not presuming or attempting to prove any relationship between these factors and the informal study habits of the participants in the study. Nor did I use a large enough sample size to extrapolate the results to any population. I merely hoped to discover what relationship might exist. Therefore, this study is on the exploratory end of the continuum.

\section{Participants and Context}

The participants of this study were six Japanese students who were attending a large public university in the Pacific Northwest United States, either as degree seeking students or as part of an exchange program with a university in Japan. All six participants were actively learning English as a second language. As discussed above, a Japanese population was chosen with the hope that their strenuous educational background, and especially the extent to which study takes place outside of formal education, might translate into a higher rate of informal study. 
In addition, English language education in Japan is largely planned around preparing students for school entrance exams, which are required for admission into universities and are also common as early as elementary school. These tests are largely grammar based, with little or no emphasis on communication. As a result, Japanese students studying English in the United States, where they presumably learn in a more communicative manner, will likely have experienced a variety of disparate methods and techniques. By interviewing individuals who have experienced a variety of teaching methods, I hoped that there would be more opportunities to observe the effect of the interplay of experience and beliefs on informal learning technique choice.

Participants came from three sources within the university. The first source was a large, multilevel academic English language program which is generally attended full time by students who are studying English for a number of purposes: to gain admittance to an American university, to improve English skills for work or travel, or for personal benefit. The second grouping consisted of students from a Japanese university that offered an exchange program with the university at which this study took place. The students in this program also attend English classes, but these classes overseen by instructors from the Japanese university and take place outside of the American university's English language program. The third source of participants was the general student body of the university, meaning those students who are enrolled in an undergraduate or graduate degree program. It was my hope that using multiple sources would not only give me a larger base from which to 
recruit participants, but also provide me with a more diverse population of Japanese students.

Participants were selected on a volunteer basis. My status as a MA TESOL student at the university means that I have regular interaction with students and staff from the English language program. In addition to my interactions with this program, I have regularly volunteered as a conversation partner for students from the Japanese university exchange program over the last several years, and have introduced myself to the staff at the office they maintain on campus on several occasions. I was able to successfully parlay these relationships into assistance in finding participants. Finding participants from the general student body was more dependent on networking connections, word of mouth, or an introduction from another participant in the study.

There were several criteria that potential participants were required to meet. First, they had to be actively studying English. This requirement was not a problem for students from the English language program as they are, by definition, English language learners. In addition, the Japanese university exchange students have English courses as a core component of their program. With general members of the student body, this was more of a grey area. However, as long as they considered themselves active, practicing learners of English, the data they could provide was judged to be relevant for this study.

The second requirement was that the participant currently possessed enough mastery of English to be able to communicate effectively in an interview setting. For the English language program students, this was operationalized as a minimum class 
level (level 3 or above). For the Japanese university exchange students and general members of the student body, this was not a problem as their programs require sufficient English skills to take academic classes in English, so they all had sufficient ability for my purposes. In addition pre-interview meetings helped to assess English ability, and ensure communication would not be an issue.

The last criterion was that potential participants had to agree to take part in a one hour interview, which would be the main source of data collection, complete a study log, and be available for follow up questions via email communication. This provision was to ensure that I would be able to gain clarification or further explore a theme that arose during the coding and interpretation of the data from the interview.

The participants were a convenience sample, though I had hoped to have a sufficient number of volunteers to choose from that I could make an effort to represent both male and female equally, as well as drawing from all three of the sources of participant described above. In the end, I interviewed six participants. The largest source of participants was the Japanese university exchange program, with four students taking part. Two of these participants were recruited directly from an email that was sent out for me by the exchange program's staff, one was an acquaintance made through volunteering as a conversation partner, and the last was someone I was put in touch with by another participant. The staff at the English language program also helped me connect with one participant. The sixth and final participant was a general student, who I became acquainted with through various connections in the Japanese community at the university. There were three male and 
three female participants with an age range from 20 to 27 years old, and a mean age of 22.5 years old.

\section{Data}

Consistent with a qualitative study, I was looking for thick, rich description of the phenomenon. As the focus was on past experiences and beliefs, neither of which could be directly observed, the most relevant data available was determined to be in the form of participants' subjective description of their experiences and beliefs. I could not expect that participants would have the linguistic vocabulary to indicate that their past experiences in language learning were primarily teacher fronted, grammar translation, or communicative method, or that they believe that language learning is about lowering the affective filter, or being provided with comprehensible input. These types of categories and terms were likely unknown to the participants. Instead, I hoped for data in the form of participants' descriptions of past learning experience, how they felt about those experiences, what they believe is the key to learning, and which learning activities they feel are most effective.

Barcelos (2000) writes about three different approaches to studying beliefs in language learners. The normative approach relies on surveys, the metacognitive on interviews, and the contextual on an ethnographic or case study approach involving both observations and interviews. While praising the metacognitive approach for its ability to get information from students in their own words, she ultimately concludes that the contextual approach is the most thorough because of its ability to see the 
"dynamic and social" nature of second language acquisition (SLA) (p. 25). I agree with this evaluation. To a certain extent, I attempted to elicit contextual data by asking students to complete a study log, recording the activities they used to learn language for a one week preceding their interview. However, due to the constraints and reality of the thesis format, a full case study was not feasible and so an interview based approach was deemed more appropriate. Further bolstering this decision, Barcelos (2000) does praise interviews for their ability to elicit "information about learners' metacognitive knowledge as related to self-oriented learning" (p. 25), which is precisely what I hoped to learn about.

Therefore, the primary method of data collection for this study was interviews. As stated above, I was interested in the rich, thick detail that can be obtained by listening to people describe their experiences and beliefs from their own perspective and in their own words. Interviews accomplish this purpose much more readily than a Likert scale.

Two pilot interviews were done to help create and refine an interview guide. The results led me to 22 initial questions that I believed would elicit relevant data (See Appendix A). From this starting point, additional questions were asked as needed to elicit further data and to follow relevant themes as they emerged. Included in the interviews were questions that asked for descriptions of past learning experiences and current informal learning practices, evaluations of past learning experiences, and thoughts on the best way to prepare for a hypothetical test on each language skill area (reading, writing, etc.). Discussions of past experiences and 
current informal learning practices corresponded to my research questions directly, while the evaluative comments and thoughts on the best ways to study helped to reveal the participants' beliefs about language learning.

A semi-structured interview procedure was chosen, using the 22 question interview guide to open topics and then asking additional probing questions to further explore emerging phenomena. Dörnyei (2007) says that this is approach is best when the researcher wants to "develop broad questions about the topic in advance but does not want to use ready-made response categories that would limit the depth and breadth of the respondent's story" (p. 136). This fit my exploratory study perfectly, as I knew what I was looking for in a broad sense, but wanted to leave room for the participants' unique stories to emerge.

A secondary source of data was a learner study log (see Appendix B), on which participants were asked to fill in each time they studied English in the week leading up to their interview. They were asked to keep track of how long they studied, where and with whom they studied, what materials they used, and the focus of their study time. There was also a space provided for reflection and evaluative comments. A pilot test of the study log was done, in which three Korean international students logged their study for several days. Korean students were used in order to not shrink my potential pool of Japanese participants. The data I received was relevant and only minor tweaks to wording in the study log were made.

I understood that participants were likely busy enough that they may not remember to log all of their study, but I was decided that even a partially completed 
log could be used to inform the interview by helping me target my questions more efficiently and possibly revealing study techniques that I would not think to ask about. In addition, I hoped that drawing participants' attention to their study habits ahead of the interview may help encourage the right frame of mind and result in less warm up time during the interview.

In the end, I received study logs for only two participants. Though four students were given the log as scheduled, only two of them brought a completed log to their scheduled interview. The last two participants were not given the study log to fill out. The reason for this was that I struggled to find my fifth and sixth participants, and time was becoming an issue. As a result, when I did finally locate these last two participants, I had to schedule their interviews as quickly as they were able to meet. Additionally, one of these participants left the country within a few days of our initial email communication, so he did not even have a week's time to $\log$.

\section{Data Collection Procedures}

After initial contact was made with participants, which generally occurred through email, I attempted to set up a brief meeting time to talk about my research, give the individual a consent form, and explain the study log. In this initial meeting with participants, which lasted no more than 10 - 15 minutes, I also introduced myself and began the process of building rapport. Dörnyei (2007) emphasizes the importance of the first few minutes of an interview in gaining acceptance and 
showing an interviewee that you are interested in what they have to say. As I was already working with a sensitive population (second language learners), I attempted to begin the process of gaining acceptance early, in order to minimize the amount of time it would take for participants to feel comfortable in the interview.

The interviews were conducted in English and audio recorded. On some few occasions I took light notes when participants were physically demonstrating a technique that I wanted to be able to describe accurately later on. This was helpful, as the interviews were only audio, and not video recorded. However, my focus was always on the conversation. Participants were told to expect an interview that would last about one hour. This length was chosen because of the results of the two pilot interviews. The first pilot interview lasted roughly 35 minutes. However, this interview was serving mostly as a tool to refine the core questions that I would ask my informants. As a result of this first pilot interview, I found gaps in the data that led to the addition of a number of new questions. The refined set of questions was then tested in a second pilot interview, which resulted in a session lasting just over an hour. The results of this pilot interview were positive, as I found the gaps in data to be largely filled by the new questions. I also focused my attention on making sure that my questions resulted in relevant data and were worded well. The main wording concern was that I did not want to be overly leading (Dörnyei, 2007). The second pilot resulted in an experience that was consistent with what I hope for in the actual interviews. 
There was some concern that an hour would not be enough to have all my questions answered. However, it must be recognized that participants were communicating in a second language. To be sensitive to participants, given the potentially exhausting nature of an overly long interview, I chose to cap the sessions at one hour. After reviewing and reflecting on the recording and notes, I occasionally found that I was missing information that could be relevant to my study. In these situations, I followed up with the participants via email. However, every effort was made to use the initial interview period efficiently, so as to limit my demands on participants' time.

The actual interview times averaged right around 47 minutes in length. Four of the six interviews fell in the $45-50$ minute range, with one ending just short of the one hour mark. My most fluent participant was able to move through my questions in 36 minutes.

It was my intention to conduct interviews in a way that made the participants comfortable, and create an atmosphere similar to a conversation. In the pre-interview meeting I did my best to demonstrate my (at least intermediate) knowledge of Japanese language and culture. In addition, I introduced the process of the interview before starting. I also informed participants that at no point did they need to feel any pressure to answer a question if they were uncomfortable, didn't have an answer, or otherwise felt unable to respond. Participants were encouraged to mention any information they considered important or relevant that I might not think to ask about. 
Furthermore, participants were able to step out and take a break for any reason and at any time.

In addition to their completed study log, participants were asked to bring any study materials they have used to aid their English proficiency. These materials could include, but were not limited to: textbooks, English study guides from Japan, DVDs of English language popular TV shows, electronic dictionaries, and magazines. I briefly examined any materials during the interview, and asked questions about how they are used and their benefits. On a few occasions, participants mentioned a web resource that they used for informal study. In these cases, I used a laptop that I brought into the interview to browse the websites and ask questions. Often, I returned to the website after the interview to gain a better understanding of the content.

\section{Analysis}

Analysis was done by transcribing the interviews and looking for themes regarding learning experiences and learning beliefs. As a way of "contextualizing/ evoking the speakers' voices," (Dörnyei, 2007, p.248) transcription of interviews was done in a way that left in things like grammatical errors, false starts, and wrong word choices. By doing so, the transcriptions remain consistent with the way a non-native speaker of English communicates. Dörnyei (2007) also recommended the use of "standard orthography," which I largely followed in my use of punctuation (p. 248). I deviated from standard orthography for the sake of clarity in three ways. First, I used parenthesis to encapsulate false starts. This allowed me to keep all of the content of 
the interview, but add some clarity for the reader. Second, brackets were used when adding an aside from myself or describing physical action of the participant. Lastly, ellipses were used when a participant trailed off, rather than finishing an utterance. The conventions were necessary infrequently, and only for the sake of clarity. Otherwise, standard orthography was the goal of the transcriptions.

After transcription was finished, I began coding the data. I entered this process with three predetermined master codes: "informal" for anything that fit my operationalization of informal learning, "belief” for any explicit expressions or evidence of participant beliefs, and “experience" for participants' past English learning experiences. However, beyond these very basic codes, the process was largely inductive. An inductive approach made sense for an exploratory study, such as this, because it allowed for themes to emerge. In fact, Hatch (2002) said that "all qualitative research is characterized by an emphasis on inductive rather than deductive information processing” (p. 161). As the coding process continued, subcategories of my existing codes were created based on the themes that emerged (see Appendix D for a full list of codes). For example, I created the codes "informal TV" for the use of TV/Movies to study, "belief motivation" when a participant expressed that their choices were impacted by what motivates them, and "experience teacher fronted" when a participant mentioned a class that was largely devoid of student participation.

After coding each participant's interview transcript and building a larger base of codes, I recoded a fresh copy for each of the three master codes: experiences, 
informal learning techniques, and beliefs. Recoding in this way had two benefits.

First, I was able to take a second look at the data to confirm my initial coding and look for themes that might have been missed. Second, having individual coded transcripts for each section resulted in cleaner copies that made the transition from coding to writing much smoother.

It is important to note that due to the abstract nature of beliefs (as discussed in the literature review above), they were not always directly stated by participants. For this reason, it was necessary at times to analyze the data available to me and make a conjecture about a given participant's belief system. This was only done when there were multiple instances of data that pointed to an implied belief. When discussing beliefs below, I will not present my conjectures about belief as fact, and will include supporting evidence.

\section{Validity and Reliability}

Golafshani (2003) argues that validity and reliability are terms that have their origins in quantitative research, and need to be redefined for the purposes of a qualitative study, such as this. She suggests that reliability and validity can best be "conceptualized as trustworthiness, rigor and quality" for the purposes of qualitative research (Golafshani, 2003, p. 604). Golafshani (2003) further makes the case that triangulation, which is the use of multiple data collection methods, is a key part of reliability and validity in qualitative studies. To this end, I employed a study log to supplement the data collected from interviews. 
Being able to revisit the audio recordings of interviews and asking participants to be available for clarifications also helped enhance my findings with the sort of trustworthiness that Golafshani (2003) suggested as a replacement for reliability/validity in qualitative studies (as discussed above). I only found it necessary to follow up with a participant on a few occasions. Though participants rarely described their past experiences using terms like "teacher fronted instruction" or "grammar translation," they did say that classes were "mainly like teachers talking and students are really passive" (Honami) or that they would "translate English into Japanese" in class (Hanako). Determining participants' beliefs was a little more complicated, but I believe that this is simply due to the ephemeral nature of beliefs. In cases of both experiences and beliefs, I found following up with participants for clarification via email to be sufficient when questions arose. 


\section{Results}

In the following pages, I will discuss the content of participants' interviews, specifically with regard to their experiences, beliefs, and informal learning techniques. As mentioned above, this study draws on data from six English language learners whose profiles are summarized in Table 1 below. Participants will be discussed one by one, with a summary at the end of this section. All participants were asked to select pseudonyms, by which they will be referred to. To avoid confusion, I asked participants to provide a pseudonym that was a Japanese name (or word). All text between quotation marks below represents a direct quote from a participant.

Table 1: Participant summary

\begin{tabular}{|l|l|l|l|l|}
\hline $\begin{array}{l}\text { Name } \\
\text { (pseudonym) }\end{array}$ & Age & Gender & Data Sources & Program \\
\hline Honami & 20 & Female & $\begin{array}{l}\text {-Interview } \\
\text {-Study Log } \\
\text {-Follow up communication }\end{array}$ & $\begin{array}{l}\text { Japanese } \\
\text { university } \\
\text { exchange } \\
\text { program }\end{array}$ \\
\hline Ichigo & 20 & Female & $\begin{array}{l}\text {-Interview } \\
\text {-Follow up communication }\end{array}$ & $\begin{array}{l}\text { English language } \\
\text { program }\end{array}$ \\
\hline Norio & 24 & Male & -Interview & $\begin{array}{l}\text { Japanese } \\
\text { university } \\
\text { exchange } \\
\text { program }\end{array}$ \\
\hline Natsuo & 23 & Male & -Interview & $\begin{array}{l}\text { Japanese } \\
\text { university } \\
\text { exchange } \\
\text { program }\end{array}$ \\
\hline Hanako & 26 & Female & $\begin{array}{l}\text {-Interview } \\
\text {-Follow up communication } \\
\text { graduate student }\end{array}$ \\
\hline Yoshito & 21 & Male & $\begin{array}{l}\text {-Interview } \\
\text {-Study Log } \\
\text {-Follow up communication }\end{array}$ & $\begin{array}{l}\text { Japanese } \\
\text { university } \\
\text { exchange } \\
\text { program }\end{array}$ \\
\hline
\end{tabular}




\section{Honami}

Honami was a Sophomore studying in Portland on an exchange program from a Japanese university. She was outgoing and social, and probably spoke English with the most fluency out of my participants. In addition to the friends she made, she also had an American boyfriend in Portland.

Experience. For Honami, exposure to English began in junior high. In fact, she said in general that Japanese people “...start learning English as a second language from middle school. Yeah, so I think everybody in Japan started around that time." She recalled learning to write in cursive and some basic words in those classes, but thought the focus of the class was "basically grammar." She described a teacher-fronted classroom in which the only regular involvement students had was reading from the textbook out loud.

During junior high Honami was also attending cram school. She said that she attended in order to pass her high school entrance exams. English classes at cram school were similar to those in the formal education system, except they were close to twice the length. Honami said "I need to sit in the classroom for like two hours and listen to lecture." The focus was grammar and vocabulary, and she remembered being scared of the instructor because he would get angry if students didn't do well on their vocabulary exams.

High school classes were structured similarly to junior high classes, in terms of being primarily lecture; however, Honami said the focus of English instruction shifted more towards vocabulary. In fact, she said students were expected to learn as 
many as 100 words per week. Other than increasing her vocabulary, though, Honami didn't find those classes to be very helpful. Through junior high and the beginning of high school, she said she didn't particularly enjoy English or think that she was very good at it.

This changed her second year of high school after she studied abroad for a month in a UCLA summer program. The experience seemed to have a large impact. She remembered being nervous and unprepared to interact with native English speakers and said "I didn't make any friends at all and I felt really sad because I spent so much time studying English" and "I thought I learned a lot... but the actual native speakers speak really fast, and their pronunciation is different from Japanese speaker's English.”

After high school, Honami was accepted at a prestigious university in Japan. At this school students are required to take at least two years of English. Honami had a professor there whose classes she found to be more stimulating. She said "my professor studied abroad in the US. He's Japanese, but he's writing some New York Times articles and he's pretty fluent in English...I was really lucky and I learned a lot from him." In his class, the students used authentic materials like New York Times articles and popular English music. Honami also said students were more active participants than in her junior high and high school classes; they were able to "get up and actually talk in class."

After her first year of university, Honami decided to study abroad. She said "I felt like maybe I want to study abroad and see how well I can do in the US." She 
chose to come to Portland, both because the timing of the program was favorable and because her boyfriend, whom she met in Japan, was living in Portland. Initially, she said she found some aspects of life in an English speaking country challenging, such as talking in groups of people. However, she also admitted that "maybe other students say that my speaking is better than most."

Though Honami did attend ESL classes in Portland, she didn't seem to credit them much for any improvement in her English. Her classes in the US did have more student participation and she seemed to appreciate the fact that the teachers were native speakers of English. Unfortunately, class discussions often seemed like a waste of time because her fellow students were "not really active in the class, of course, because they are Japanese. So we end up like being silent and saying nothing." Other class activities included pronunciation work, presentations, and papers, but in general Honami found the classes to be too easy. She gave most of the credit for her improvement in English to "making new friends and hanging out with groups."

Informal study habits. Honami was one of the two participants who filled out the study log ahead of the interview, so I was able to get a large amount of information about her informal study habits. Honami used a large variety of resources, ranging from a TOEFL (Test Of English as a Foreign Language, http://www.ets.org/toefl/) study book to interaction with friends.

One set of materials that Honami used for her informal study could be grouped into the category of authentic materials, specifically from popular English 
language media. She regularly watched television shows and movies in English, which she thought were helpful, and even recommended as part of her advice to a beginning student of English. She also listened to popular English music, and tried to focus on the lyrics. This is a practice that she began when she was young, as her parents were Michael Jackson fans. Lastly, she read books, such as the Harry Potter series, to increase her reading skills.

Honami also used study guides and vocabulary books. Among these are a study guide for the TOEFL exam and a vocabulary book that she bought in Japan. To increase her vocabulary, she picked words from the vocab book that she didn't know and wrote them over and over until she remembered the word. She also sometimes used the audio CDs that accompany vocab books, listening to them in her free time.

One of the more interesting tools that Honami used is the Internet chat program Skype. She began this practice after returning from her one month study abroad program at UCLA in high school. She initially used text-based chatting, but eventually purchased a webcam and began actually speaking with conversation partners abroad. Of the transition to speaking, Honami said "a girl, like my friend, suggested me get webcam and mic. So, I got it. And then I started to seeing the faces and talking." Interestingly, when I asked Honami what has been the most effective tool for her English study, she said Skype. Skype also seemed to be an integral part of her plan to continue her English study after returning to Japan; she said "maybe I'm going to find some other people to Skype on the internet, or maybe I'm just gonna keep in touch with my friends that I meet here on Skype." 
The largest resource that Honami was using, however, seemed to be her interactions with people in Portland. She thought that her conversations with her boyfriend, a native English speaker, and her friends have improved her English. She especially stressed the importance of interacting with many people. She said that "the same person uses the same kind of like (you know) words and same kind of like expressions," so communicating with a variety of people is important. It could be argued that the type of learning that occurs while hanging out with friends is tacit learning, which is not the focus of this research. However, Honami's effort to maximize these interactions and the very choice to come study in an English speaking country to begin with were both conscious decisions for the improvement of her English skills. For this reason, I believe her interactions with friends are a relevant and important example of her informal learning habits.

Beliefs. There are a number of themes of belief that recur throughout Honami's interview. She discussed two factors that contribute to effective learning: motivation and repetition. In addition, there were signs of a preference for being taught by and interacting with native speakers of English. Lastly, Honami seemed to believe that a change in focus is necessary over the course of studying English. She talked about an early period of grammar and vocabulary study, best accomplished through rote techniques, followed by a period of speaking and listening study, best accomplished through social interaction and exposure to authentic materials.

Motivation was a topic that came up frequently in the interview. For the most part, it was intrinsic motivation that seemed to be a factor in Honami's study habits. 
Ryan and Deci (2000) define intrinsic motivation as when "a person is moved to act for the fun or challenge entailed rather than because of external prods, pressures, or rewards" (p. 56). An example of the importance of intrinsic motivation for Honami can be found in her evaluation of English classes at the junior high, high school, and university levels. There was a connection between whether a class was interesting for her and whether she felt like she learned anything. For example, she said about English classes at her university in Japan "it was pretty interesting" and "I learned a lot." In contrast, of junior high classes Honami said "they were not really helpful at all. I didn't like English at the time." Similarly, she reported both not enjoying high school classes and not feeling that they were helpful.

In my interview with Honami, there was also one reference to motivation of a different kind: extrinsic motivation. Rather than being based on an activity's inherent benefits, extrinsic motivation is the goal "to attain some separable outcome" (Ryan \& Deci, 2000, p. 60). Ryan and Deci (2000) give the example of "a student who does his homework only because he fears parental sanctions" to illustrate extrinsic motivation (p. 60). Bringing this back to Honami's beliefs, she said that her cram school English classes were "really helpful, but really intense," and described her teacher as both scary and strict. Speaking of the weekly vocabulary quiz in those classes, she said "I had to study and take a good score on the word exam because he like gets really mad if I don't memorize 100 words for a week." In this case, the motivation of not angering a teacher seemed to create a successful learning environment for Honami, which is quite similar to the example given by Ryan and 
Deci (2000). Interestingly, cram school was the only time Honami recalled a class being helpful, without mentioning that it was interesting for her.

Using repetition in study also came up throughout the interview. Honami talked about writing words over and over in order to work on both vocabulary and spelling. This is an approach that she seemed to first learn from her cram school instructor. She said "I did it when I was in cram school, so the teacher doesn't get mad. I had to memorize and I had to be able to write, to spell it." Repetition also came up when she talked about using audio learning tools. She spoke of putting audio tracks on her iPod and listening to them over and over "while I'm commuting or maybe I'm doing nothing."

Another theme in my interview with Honami was that she seemed to show a preference towards native English speaking instructors. Without being asked, she would volunteer information regarding whether a teacher was a native speaker. On several occasions, such as when she spoke of her junior high English teachers, she even identified instructors as "not native" as opposed to referring to them as Japanese. On the one occasion that she mentioned a very positive experience with a Japanese teacher, she identified him as "Japanese, but...pretty fluent in English," and described his classes as "American style lecture." Honami did describe a negative experience with ESL classes in Portland, which were taught by native English speaking instructors. However, she did not directly criticize the instructors and placed at least some of the blame on the Japanese students in the class because they "kept like really silent and say nothing" during group discussion time. 
Lastly, Honami seemed to believe in a certain order of skill acquisition and a progression from rote learning to authentic practice. For a follow up question after our interview, I asked what advice she would give to another student who was just beginning to study English. Her first piece of advice was to build vocabulary and basic grammar. For this, she recommended the use of things like textbooks, flashcards, and repetitive writing, which are rote learning techniques. After this she said "then, you wanna improve your speaking skills. However, speaking skills always comes after listening skills." For these skills, she mostly recommended hanging out with native English speakers, which is undoubtedly authentic practice, or watching English language TV or movies, which also skews more towards exposure to authentic English than rote learning.

\section{Connections between experience, beliefs, and informal study habits.} Many of the choices Honami made for her informal study can be explained by her beliefs and experiences. Her belief in building a grammar and vocabulary base and then moving the focus towards speaking and listening was reflected in her choices. The need for motivation, in the form of fun, also appeared to impact her choices. Lastly, her belief in the benefit of repetition could also be seen in her study habits.

Honami's belief in a progression from rote activities that build a grammar and vocabulary base to authentic practice focused on speaking and listening seems to explain a large portion of her informal learning choices. Many of her early learning experiences, especially in the Japanese education system and cram school, were geared towards grammar and vocabulary and were learning tasks. After her 
experience in the one month study abroad program at UCLA, where she found it difficult to communicate in English, her study habits seemed to shift.

It was after returning home that she researched online and "some people said that Skype studying is really helpful." She built some confidence in her ability to communicate orally on Skype, and decided to study abroad to "see how well I can do in the US." From there on, most of her study has been geared towards activities that heavily stress speaking and listening. Examples of this include watching TV and movies, listening to popular English music, and generally going out of her way to be social and communicate with many people in her daily life, all of which are activities that are oriented towards authentic practice. As part of the interview I asked how she might study if she felt she really wanted to improve her grammar skills. Honami believed strongly enough in the importance of shifting her study towards speaking and listening that she said she would improve her grammar skills by trying "to listen to people, native speakers, and what they are actually talking," as opposed to using a grammar book.

Some of Honami's informal learning choices also seemed to be impacted by her belief in the benefit of motivation. When I asked whether she felt watching the English TV show Gossip Girls was for study or just fun, she replied "It's both. I like Blake Lively, the main character... and also it's going to be my studying." Also, when I observed that very little of her informal study involved textbooks, she explained that "I'm not really interested in them, so that makes me not feel like studying." 
The most direct example of a connection between experiences, beliefs, and informal study habits could be found in Honami's use of repetition in study. This was a habit she first learned from a cram school instructor in Japan. After this, the importance of repetition seems to have made its way into her beliefs, and through the time of our interview she continued to study vocabulary through writing words repeatedly.

Analysis. The discussion above covers much of Honami's informal learning habits. However, there a few ways in which her stated experiences and implied belief system did not match up with her study habits. These items, as well as how personality may play a role in her choices, merit further discussion.

First, her use of a TOEFL textbook seems to defy her general opinion that textbooks do not hold her interest well enough to be useful. However, like many international students, Honami wanted to achieve a high school on the TOEFL exam, and few things are as helpful as a book designed specifically to prepare students for this test. Interestingly, Honami found the particular TOEFL textbook she used the same way she discovered studying using Skype, by reading recommendations online. So the recommendations of peers online may have some impact on her choices.

The second item to discuss from Honami's informal learning is her use of fiction books to improve her English reading skills. Honami stated clearly that she doesn't usually “like to read books, because I don't like reading in English. But (I think) I feel like I need to read something, so I started reading Harry Potter.” This statement makes it difficult to make the argument that she chose to read because she 
was motivated by interest. However, her choice of a leisure reading book like Harry Potter likely reflects that it is something she found more interesting than other options to develop her reading skill, which she felt needed work.

Personality and personal motivation may have played a role as well. As noted above, Honami is a social person who has been successful in making friends (and a boyfriend) in Portland. This may have led her to choose activities that are more social, instead of rote learning that might be done alone. In addition to this, part of her stated motivation for learning English was to build relationships, which requires a higher level of speaking and listening proficiency.

\section{Ichigo}

Ichigo was a second year university student from Chiba, Japan. She was able to communicate fairly well in English, and understood my questions easily. Ichigo seemed quite shy, but answered my questions thoroughly. She declared a very clear goal for her study of English. Her house is close to Narita International Airport, Japan's largest international airport which serves most flights coming into Tokyo. It was Ichigo's intention to work at the airport, which requires its employees to have a strong mastery of English in order to communicate with the many international travelers.

Experience. Ichigo was exposed to English at an earlier age than many Japanese children. There was an American woman who lived with her Japanese husband near Ichigo's house. After receiving an invite from one of her childhood 
friends, Ichigo began attending a children's English class that the American woman taught. Ichigo went once a week, and described the experience as being fun. She said "we started from like $\mathrm{ABC}$, and A, apple; B, bear. Like simple things like that." They also played games that involved basic English vocabulary skills. Ichigo continued to study with the American woman "maybe like 5 years. Until I was $5^{\text {th }}$ grade or maybe before $6^{\text {th }}$ grade."

Ichigo began formal English classes in junior high school. She said these classes started with learning the alphabet and then moved on to basic sentence structure. Ichigo described the classes as "grammar. Just grammar." However, she did have an assistant language teacher (ALT) who came to teach once or twice a week. His classes were more focused on speaking, but Ichigo said "we don't do listening/speaking that much, and he's the only teacher. So it's a little difficult to do speaking."

During junior high, Ichigo also studied English at a cram school. She described cram school English classes as primarily grammar focused, like her English classes at school. However, cram school was a much more individual experience, in which students don't have time to get to know each other. Ichigo said "it was a class, but we do it by ourselves." Outside of checking homework, students mostly worked quietly by themselves.

In high school, Ichigo said that she chose to take many English courses. She described her high school English classes as similar to the English courses in junior high. There were two ALT's, one from the US and one from Canada, who taught 
more speaking/listening oriented classes a few times a week. However, most classes were taught by Japanese teachers and were primarily grammar focused. Ichigo did mention one Japanese teacher who taught her classes in English and discouraged students from using Japanese. She said of this teacher "she liked talking so much...she thinks talking is more important too." Ichigo also spent a month abroad in high school during summer break. She went to Michigan and though she didn't study English formally there, she was able to practice speaking with her host family. Ichigo studied English at her university in Chiba as well. Her experience there seems to have been very similar to her junior high and high school English classes. Ichigo said "most of the teachers are mostly Japanese, so we focus on grammar." In those classes, they read passages from a textbook, and the teachers explained how the grammar works. Sometimes they had to answer content questions about what they read.

Four days a week, Ichigo had class with an ALT from Canada. She said of his classes "we focus on speaking very much." The students often split up into small groups. In these groups, the students did activities such as using flashcards to quiz each other. Ichigo said "you make (the flashcards) yourself and you write the words in textbook or the reading that you don't understand." The ALT also taught a reading class. As part of the homework for that class, the students were required to read two short books a week. The library had a selection of easy English books that were divided up into different difficulty levels. The level 1 books were only around 20 pages, and level 5 could be as long as 100 pages. Ichigo read the higher difficulty 
books, and even though she was only required to read two books, she often read as many as four per week.

Ichigo had been in the US for about one month at the time of our interview, so she was just beginning her ESL classes in Portland. After taking a placement test, she was put into Grammar/Writing level 2, Reading level 2, and Speaking level 3, which could be described as lower intermediate to intermediate level classes. Ichigo struggled with some of the English terminology in her Grammar/Writing class, such as "process paragraph" or "simple past." However, she often felt that she knew these terms in Japanese, and just needed to learn the equivalent in English. She didn't report having any trouble with the content of the class outside of difficult terms.

In her reading class, Ichigo said that the "teacher thinks that reading you need a lot of vocabulary if you want to read good. So we focus on vocabulary very much." She said that she already knew a lot of the vocabulary, so the class was somewhat easy for her.

In speaking/listening class, Ichigo said that students were sometimes required to give a speech. As an example, she said that students were asked to interview someone about their job and then give a speech to the class about that person's job. However, she said "we have to make up speech, but we can't write like everything we want to say. We have to write only like key words or something like that." Ichigo said she thought that this speech exercise was good practice. In another exercise, students listened to audio of someone talking about various subjects and had to take notes about the important points. After the audio was finished, students were able to 
use their notes on a quiz. Ichigo described the topics as being challenging, such as whether shyness is genetic, so students had to listen carefully for key points and take notes quickly.

Informal learning. Ichigo did not fill out the study log; however, I was still able to get a fair amount of information about her informal study habits from our interview. For the most part, Ichigo used a lot of materials that she was exposed to in school, or were recommended by teachers. She did use some authentic materials from English language popular media, and also tried to create opportunities for casual conversation with native speakers of English.

Ichigo's earliest report of informal learning was in high school, when she would sometimes study for English proficiency tests like the TOEFL or EIKEN (Test in Practical English Proficiency, http://stepeiken.org/). She used textbooks and materials specifically designed for those tests. While in Portland, she continued to study for the TOEFL using a CD that she got from the university for free.

I asked Ichigo a series of questions regarding the best ways to study to improve specific skills. She said that she preferred to use textbooks when trying to improve her grammar. However, if she couldn't understand something from the textbook, she thought it was best to "go to the learning center or ask your teacher or something like that." To improve her vocabulary study, she sometimes used flashcards. Ichigo felt that it was important to review the flashcards every day. She also thought that writing words repeatedly can help with memorizing new vocabulary. To improve her listening skills, she said that she sometimes used the audio CDs that 
accompany some textbooks, and also liked a website called "Breaking New English" that one of her teachers recommended.

When I asked Ichigo what in her experience has been the best thing for improving speaking skills, she replied that studying abroad is the best way. When it is not possible to be abroad, she said it is a good idea to take advantage of native speakers of English in your own country. As an example, she said one of her classmates in Japan “wanted to improve his English skills. So even when he doesn't have class he goes to the ALT's room and try to talk to him a lot." While in Portland Ichigo also signed up for a conversation partner, and was just starting to meet with her at the time of our interview. This seemed to have been a good experience, as she said "it's fun talking with her." Additionally, Ichigo mentioned that she wanted to get involved in some kind of club, in which she would have the opportunity to interact casually in English with other members.

Ichigo also made use of some authentic matericals. She reported occasionally watching an English education TV program on NHK, a major Japanese television network. She also said that she enjoyed watching TV and movies in English and tried to learn while doing so. However, when I asked her if she thinks those programs are helping to improve her English, she said "maybe" and then added "I watch because it's fun."

Beliefs. Ichigo displayed signs of several beliefs that could be impacting her informal learning choices. She seemed to believe in the effectiveness of formal English education and instructional materials, such as textbooks and study guides for 
exams. Also, Ichigo appeared to believe in the power of repetition and the benefit of being taught by and interacting with native speakers of English. Lastly, she professed a belief in the importance of speaking to improve her English skills.

The first belief that Ichigo seemed to display was a belief in the effectiveness of both the techniques she has learned from teachers in formal English education settings and prepared materials like textbooks and study guides. Ichigo repeatedly mentioned textbooks, study guides for exams like the TOEFL, and English instruction audio CDs as tools for her informal study. She also reported utilizing techniques like flashcards and repetitive writing, which were initially taught to her by teachers. In addition, the only web based resource she used in her informal study was one that was used in one of her ESL classes.

Ichigo seemed to believe strongly in the power of repetition in language learning. As an example, she used the technique of writing words repeatedly to help acquire new vocabulary and remember how to spell words. In our interview, Ichigo used phrases like "over and over," "just try to write a lot," and "write, write, write, write." These quotes also suggest that the she believed in the value of physically writing for stimulating memory, as opposed to simply looking at words over and over.

Ichigo also believed in the power of repetition on a scale larger than just a single exercise. Throughout the interview she emphasized the importance of studying every day. When asked the best way to study vocabulary, she talked of making flash cards and "check it every day before bed or something like that." A little later she 
said even more firmly "you have to see it every day." When I asked about how she studies grammar, she said the best way is to use a textbook and "just look every day." Similarly, for speaking practice she said it was best to find native speakers of English and speak with them as often as possible. Lastly, when I asked Ichigo in a follow up email what advice she would give to future English learners, one of the things she recommended to improve listening skills was to "try to listen many times as possible. (anything is ok, recording, TV, radio)."

Ichigo also displayed a preference towards being taught by and interacting with native speakers of English. At several points in the interview, she mentioned the importance of talking with native speakers, even saying "talking to native speakers is the best way to encourage your English.” Throughout the interview, Ichigo also identified whether her teachers were Japanese or native speakers. In many cases, there seemed to be a positive relationship between her enjoyment of a class and whether it was taught by a native English speaking ALT. However, at one point she almost acknowledges that this may not be the fault of the Japanese teachers. Of the classes taught by Japanese teachers, which were often the less stimulating, more grammar focused classes, she said "maybe we have to teach it, and Japanese teacher has to teach it, so."

Lastly, Ichigo professed a belief in the importance of speaking. She said "I think (um) try to speak a lot is the most way to study English.” In addition, when I asked her to talk about her English classes at various levels (junior high, high school, etc.), Ichigo consistently reported how much speaking practice was involved. For 
example, of junior high English classes with an ALT she said "we don't do speaking/listening that much, and he's the only teacher. So it's a little difficult to do speaking." Similar evaluations of the amount of speaking practice were made as we discussed English classes in high school, university, and in Portland.

Connections between experience, beliefs, and informal study habits. For Ichigo, many of her informal learning choices can be traced to her past formal English learning experiences and the belief that they have been effective. This is clear from her continued use of study techniques and materials that were introduced to her in school. Writing words repeatedly to remember their meaning and spelling is an example of a technique from school that she continued to use. Ichigo said of one of her teachers "she said how to study is like write, write, write, write. She thinks that if you don't write, you can't learn. She taught me that way." Similarly, Ichigo reported using flashcards as part of her informal learning to study vocabulary. When I asked where she learned this, Ichigo replied "I think maybe teacher first. My junior high school teacher." Students in her university English classes also used flashcards to quiz each other in small groups during class.

The materials that Ichigo used in her informal English study are another example of not straying far from formal education. While at university in Japan, she did additional homework to help improve her English skills. An example of this can be found in her reading class, where she was only required to read two books from the library a week, but she regularly chose to read as many as four. She also said she 
used textbooks to study informally, and specifically mentioned that she thought they were the best way to study grammar.

Even when Ichigo wasn't using study materials directly from formal education, her teachers still appeared to have a large impact. For example, as mentioned previously, the only website Ichigo reported using to study was a site that one of her Portland ESL teachers used in class. In addition, Ichigo frequently mentioned using study guides for the TOEFL or other English proficiency tests as study tools. When I asked Ichigo how she found out about the test and study guides she replied "my teachers tried to say good for taking. And some of my friends took it, so I tried to too." Ichigo's teachers seemed to have at least some role in her decision to study for and take these English tests.

Interestingly, though Ichigo professed speaking to be a very important part of learning English, there were only a few examples of study that was focused towards developing and using that skill. She did sign up for a conversation partner through the university. However, this is the only activity aimed towards speaking that she currently participates in, outside of a desire to join a club where she could use English casually.

Analysis. As explained above, a lot of Ichigo's informal learning habits can be explained by her belief that the techniques and advice given to her by teachers will lead to successful English study. There is definitely some truth in that belief, as Ichigo's English was fairly good. She could communicate well, and didn't ask for 
repetition or clarification very often. It may be that this success led her to continue studying in the manner that got her where she is and to use the same study materials.

However, there were a few things about her informal study habits that didn't seem to be fully explained by her experiences and beliefs. One of those things was her frequent use of study guides for proficiency tests. As mentioned above, it was at one point recommended by her teachers that she study for this type of test. However, Ichigo mentioned these tests and the study materials associated with them more than any of the other participants I interviewed. I think the best explanation for this lies in her goal for English study. In order to get a job working at Narita Airport, Ichigo will be required to score very highly on an English proficiency test. Regardless of whether a TOEFL study guide was the best way to improve her English, it was likely the best way to help her achieve her goal of getting a job at the airport by her house.

Another interesting point is the difference between Ichigo's professed belief in the important role of speaking, but lack of specific action to create speaking opportunities. To be fair, her decision to study abroad shows that she was making effort to set herself up for these opportunities. However, I did not get the impression that she spent much time each day interacting in English outside her classes. I believe this discrepancy is likely due to her shy nature. She acknowledged this to a certain extent, saying “I'm trying to speak a lot, but it's a little difficult for me to go to a person I don't know and speak "how are you?" 
Norio

Norio was in the US on an exchange program from a university in Japan, where he was a senior. He presented himself as very outgoing and confident compared with many international students. From our discussion, I gathered that Norio made many American friends while in Portland. He also met and began dating an American girl. When I asked about his reasons for coming to Portland, he did mention part of the reason he came was to improve his English, but it felt almost like an afterthought. It was more important to him that he get a chance to "have wide thinking." After some of negotiation of meaning, I understood that he meant it was very important to him that he developed into an opened-minded person. Norio felt that interacting with people from other countries would help him develop into such a person. At the time of our interview, Norio was set to return to Japan within a few days. He had been in Portland for about nine months.

Experiences. Norio was exposed to English at an early age. In kindergarten, he was in what he described as an English club. Norio said that he mostly just learned very basic English words at that time. After that experience, he did not have any English instruction again until junior high school, when most Japanese students begin compulsory English education.

Norio attended a private junior high school in the Tokyo area. He said that English classes there were focused around reading, grammar, and some pronunciation. Norio's described the class as very teacher fronted. Sometimes the 
teacher would call on students, but they were only expected to "just answer and no conversation." Norio said that initially he enjoyed the classes, but "gradual it was like boring, because always reading and then pronunciation. But pronunciation is not conversation." When I asked Norio if he felt like he learned anything in these classes, he said "I think I just learned grammar and reading. Listening is not so helpful for me, because I can hear and listen English, but it's not working."

The junior high that Norio attended was connected to the high school he attended. Norio described the school as being set up "like steps. Junior high school and then step." The ultimate purpose being to "enter the good university." Because of the schools being connected, high school English classes were very similar to junior high classes. One difference between the two was that junior high classes were more strict. Norio said that in junior high they wanted "to teach English and they wanted to teach manner." High school classes were focused more on making students "study more for university." Outside of that difference, classes continued to be focused mostly on grammar.

I asked Norio if English classes at his junior high or high school were ever taught by ALTs. He struggled to remember for a while, and ultimately decided that he thought there was one teacher from the US at his junior high school, but he couldn't remember any ALTs at his high school. When I asked if he remembered how often the ALT taught, he said “once a week. Actually I don't really remember very much." So it seems that he did not have much experience with native English speaking instructors. 
During high school, Norio also attended a cram school where he studied English. He described English classes at cram school as "only studying for university. So like grammar, reading, little bit listening." When I asked if cram school English classes were similar or different than high school English classes, Norio said "the content is almost the same. But the difference is like long. So in high school our class is like 50 minutes, but in cram school it's like two hours per one class." He also said that the classes were strictly lecture. Students were able to ask some questions, but otherwise were passive participants in the class.

English classes at university in Japan were different than Norio's previous classes. He said there was "more attention to conversation. So I was really happy to talk." In one class, which Norio said was called "tutorial English," there were only four students and one native English speaking instructor. His junior high and high school English classes generally had about 50 students, and cram school English classes had about 100 students, so a class with a four to one ratio of students to teacher was a real change of pace for Norio.

Norio also took a more traditional English class at university, which was focused on grammar and reading skills. However, the teacher made use of authentic materials, like English language newspapers. Despite a similar focus on grammar, Norio described this class as being more fun than junior high and high school English classes. 
When Norio first arrived in Portland, he was not confident about his ability to communicate in English. He attended ESL classes with the other exchange students in his program. He said "even though it was not so hard, it was really hard for me. I could not hear anything. So I thought "I don't know, I can't catch this class and this life in America." Eventually, both class and American life got easier for him.

In his ESL classes in Portland, Norio said they used a textbook that introduced basic American culture while also teaching English. He felt the first quarter of his exchange program was fun, because they primarily learned about American culture and watched American movies. In the following quarter, they began listening to NPR radio to help develop listening skills. Norio said it was difficult, but helpful. Other activities he felt were helpful included giving presentations in English and receiving instruction in pronunciation. It seems that his teachers used minimal pairs to emphasize vowel pronunciation because Norio said the teachers helped students "understand the difference between "set" and "sit." When I asked Norio what, in his broad experience studying English, was most helpful, one of the things he mentioned was these ESL classes.

Informal learning. Norio used a mix of traditional techniques, like flashcards and vocabulary books, and more creative techniques, like joining a club and using websites and other authentic materials as a resource.

Norio reported using flashcards to help learn new vocabulary. Interestingly though, he made two different kinds of flashcards. At times he wrote English on one 
side and Japanese on the other side. Other times he used flashcards that have the English word he is trying to learn on one side, and the other side had the English definition of the word or a few synonyms. Similarly, he reported using a variety of dictionaries to help learn new words. He used English-Japanese dictionaries, English-English dictionaries, and thesauruses. Norio said the reason he didn't rely strictly on English-Japanese resources is that "if I use just English and Japanese, I think I have to change the word in my brain." Norio also used TOEFL resources to study. He said "TOEFL is really helpful. TOEFL has many vocabulary, so I can learn."

Norio also made use of a non-compulsory class at his university in Japan. As discussed previously, Norio took a class at his university in Japan called Tutorial English. Norio found it to be so helpful for developing his English skills that after finishing the class, Norio opted to take it again the following year. This class was part of his required curriculum the first time, but his decision to take the class a second time was completely voluntary.

Authentic materials are another resource that Norio used to study. One of the more interesting examples of this was FIFA.com, which is the website of the international governing body for professional soccer. He has a strong interest in soccer, so he found reading FIFA.com to be intrinsically motivating. In addition to motivation, the familiar content was also easier for him to navigate, possibly because his understanding of the game helped him fill in linguistic gaps. Norio said "I like soccer, so it's easier to understand. I tried to do the Time magazine but that was kind 
of difficult and kind of boring. I think for me, the fun thing is helpful." Norio also said he often watched TV or movies in English. He did think this was helpful for his listening skills, though he thought having conversations is more helpful. Norio said "conversation is only one time. TV and radio is, I can repeat them. So yeah, conversation is important for listening skill."

Norio also took full advantage of his time studying abroad. He reported frequently hanging out with American friends and being deliberate about avoiding situations where he would fall back on using Japanese. He said "I didn't want to hang out with Japanese friends, because maybe I knew I will use Japanese. So I try to spend it with my American friends, soccer mates, or host family." Soccer was part of his motivation for coming to Portland. Norio played on the team at his university in Japan, and had heard from a Japanese friend that he would have an opportunity to play at the university in Portland. He seemed to feel that his time playing soccer also helped with his English improvement, saying "even play soccer I have to explain the situation or something I need to speak English."

Beliefs. In our interview, Norio stressed the importance of persistence. This came up at the end of our interview, when I gave Norio the opportunity to express anything he felt was important about language learning. He responded "maybe the important thing is attitude for English. So at the beginning I really don't understand anything in English. But I always try to understand English.” Earlier in the interview he also talked about having trouble in one of his classes, but being able to push through it because his attitude was "I want to understand." 
Norio also talked about motivation on multiple occasions, specifically intrinsic motivation. As discussed above, Norio read the FIFA.com website in English, because the content gave him extra motivation to improve his skills. Similarly, he was motivated by wanting to talk with women in the US. Norio spoke of situations where he saw an American girl and thought "Oh, she is pretty. I should talk with her, but I need to talk with her naturally. So I should study.”

Another belief Norio appeared to have is the importance of developing an aspect of language fluency that is referred to as automaticity. Automaticity is a term that is operationalized in many different ways depending on the researcher, but often is a reference to efficiency and speed of processing. However, Segalowitz (2003) suggests that the term automaticity should instead be regarded more specifically as "a significant change in the way processing is carried out" (p. 403). Norio's concern with this sort of automaticity was apparent when he talked of not using strictly English-Japanese dictionaries out of fear that he would always "have to change the word in my brain." What he was talking about is wanting to process language in a different, more efficient way. It was unclear whether this was something that a teacher told him, or his own opinion that developed over the course of his English study. Unfortunately, a message sent to Norio seeking more information about this belief was not returned.

Lastly, Norio seemed to believe in the importance of authentic practice for developing speaking skill, as opposed to rote study. As part of the interview, I asked Norio what he felt was the best way to study for the various skills involved in 
language. When I asked him the best way to improve speaking skills, he said "I didn't train to speak in English, I just spent the time with friends. And then maybe naturally more I could talk with my friends."

Connections between experience, beliefs, and informal study habits. One of the most evident connections is between Norio's belief that speaking and listening skills are developed through authentic practice, and his approach to improving those skills. He did not mention doing any specific exercises to improve his speaking skills, but rather repeatedly mentioned various ways that he tried to maximize his use of spoken English in daily life. Some of these included eschewing situations in which he knew he would use Japanese and making an effort to spend more time with American friends than with Japanese friends. He also joined a soccer club, in which he frequently used English.

It may also be relevant that Norio did not have much experience learning from ALTs in Japan. ALT taught classes are generally the only classes in Japanese formal education that focus on speaking skills. The one speaking based class that Norio did take was the Tutorial English class at his university in Japan. However, this class was very unique, and seemed to be very conversation based as opposed to drill or lecture based. Had he experienced more ALT instructed classes, he might have been exposed to speaking drills that could have made their way into his informal learning practices.

Norio also appeared to generally prefer the use of authentic materials to textbooks in informal study. This is consistent with his experience in formal English 
learning. Norio reported enjoying a grammar based class at university, even though the content was very similar to the grammar based classes he took in junior high and high school. The reason he gave for his greater enjoyment is that the instructor used authentic materials.

Lastly, Norio's expressed a belief in the importance of developing automaticity has impacted some of the materials that he uses. Instead of relying strictly on an English-Japanese dictionary or electronic dictionary, Norio also used English-English dictionaries and a thesaurus. As discussed above, he had a similar practice when preparing flashcards, using both English-English and English-Japanese. By doing so, he hoped to avoid the need to translate words between languages in his brain.

Analysis. As discussed above, many aspects of Norio's informal learning could be explained by his experiences and beliefs. However, there were a few practices that weren't directly addressed in the course of our interview. For the most part, this likely had more to do with the time constraints of the interview and Norio's lack of response to follow up communication. A few the techniques he used but did not provide explicit explanation of were flashcards, TOEFL materials, and a variety of dictionaries. It can be surmised that Norio was likely exposed to the use of flashcards in some of his early English classes. Though he never mentions it directly, flashcards tend to be a staple of language learning. Additionally, several of the other participants I interviewed mentioned using them to study for the heavy vocabulary learning demands of their cram school and formal English education classes. 
Norio's use of TOEFL materials were also not specifically addressed in our interview. Several other participants mentioned that these were recommended by various teachers, and it is a likely that Norio also had this experience. Additionally, Japan is a country that makes extensive use of proficiency exams, both as entrance into schools and as a demonstration of language skill when applying for jobs that require English. It is highly likely that Norio was exposed in some way to tests like the TOEFL, TOEIC (Test Of English for International Communication, http://www.ets.org/toeic), or EIKEN, whether it was a recommendation from a teacher or knowledge that a friend had taken one of the tests. As a result of this exposure, it is natural that Norio would look to these types of test preparation materials as part of his informal study.

\section{Natsuo}

Natsuo was a junior on an exchange program from a Japanese university. He was outgoing and social, and was successful at making friends while in Portland. Natsuo's formal English education began much earlier than the other participants of this research, and he spoke English very well. He came to Portland to improve his English skills, both for the sake of getting a good job after graduating from university and because he really enjoyed using English.

Experience. Natsuo had the least typical experience studying English out of the six participants that I interviewed. The reason for this was that his father's job 
resulted in Natsuo spending some of his early years in the Philippines. While living in the Philippines, he attended Manila Japanese School in Taguig City, just south of Manila. While this school does cater primarily to Japanese youth living in the Philippines, the curriculum differed from the Japanese education system in that English education starts much sooner. Natsuo said that his formal English education began in first grade. These classes began with basic greetings and he said "the professor didn't taught me like grammar or reading skill. Just speaking." Natsuo attended this school until fifth grade, when his family returned to Japan.

Once he returned to Japan, Natsuo's experience with English was similar to other Japanese students. He began studying English at school again in junior high. Junior high classes were focused primarily on learning the alphabet, then writing and grammar. His teachers were Japanese, and they taught out of what Natsuo referred to as an "easy textbook." They also had a grammar book, which was used primarily for homework assignments.

Natsuo said that high school classes were "similar to junior high, but the content is more difficult." When I asked if they were still grammar focused, he replied "not anymore. Almost reading and writing. So, I think Japanese people can't speak or hear English. Just focus on reading and writing. Sometimes listening." There was an ALT in high school, who taught some basic speaking courses. However, Natsuo found these classes to be too easy and a little boring. He said "sometimes we had a conversation, but not really." 
During high school, Natsuo also attended a cram school. He said the English classes there were "more focused on English that is used to entrance exam." When I asked him to describe the typical entrance exam, he said that it is "basically $80 \%$ reading section and 20\% writing section." Cram school classes were very strictly lecture and were meant to give students the reading and writing skills necessary to do well on college entrance examinations.

After being accepted at university, Natsuo also took English classes to fulfill the university requirement of two years of English instruction. He described the classes there as "super boring." Natsuo said there was hardly any homework or assignments. The professor would lecture by reading from a textbook or article and occasionally call on students to have them answer questions. Natsuo did take a speaking class, which was taught by an American, but described this class as boring too, saying "the content is so easy." In this class, the students occasionally gave short presentations, but otherwise they would listen to the professor lecture and answer questions. Natsuo said "in Japan group work was not usual."

While at university, Natsuo decided that it would be beneficial for him to study abroad in the United States. His goal was to work at a trading company after graduating, like his father and uncle. Natsuo's father told him “in order to enter the trading company you have to train your English skill in university. Like after you graduate from university, it is too late." In addition to this motivation, Natsuo also said that he really enjoyed English and wanted the opportunity to further hone his 
skills and have an exciting experience. After talking with a friend who had studied abroad on the same program, Natsuo decided to come to Portland.

Natsuo had taken ESL classes in the US for one quarter at the time of our interview. He said that there was more focus on group work, and that the textbook used in the class was focused more on teaching American culture and politics than on teaching English. The skill focus was also different than his past classes; Natsuo said "maybe the professor don’t care about the grammar. Mostly like reading." He also said they worked on "how to write a paper: introduction, summary, and response."

Informal learning. Natsuo had one informal learning experience that was very unique, when he learned about a café called Leafcup from one of his friends. Leafcup is an English conversation café at which a person pays an entrance fee to sit and talk in English. There are tables set up, each of which has one English teacher, and the rest of the seats are available for people to drop in and talk. Natsuo said "it's very cheap. $\$ 10$ for one hour and free coffee, free tea. And sometimes free snack." His experience at this café was very positive, and was a tool that he used to prepare himself for studying abroad in Portland. When I asked him what kind of advice he would give to new students of English, part of his advice was that they go to a café like Leafcup.

Natsuo credited the need to communicate in English in his daily life in Portland for some of his English improvement. However, he was not passive about his study abroad experience. Natsuo was deliberate about avoiding situations where 
he would fall back on using Japanese. He said "I avoid Japanese people recently, because if I hang out with them, I speak Japanese." He even went so far as to say that "just hang out with foreigner is the best way" to improve English skills.

Authentic materials were another way that Natsuo studied. He enjoyed reading English novels, saying that "now I am reading a really easy one for like elementary or junior high school." He also watched TV and movies in English and sometimes listened to music, often doing these activities before going to bed at night.

Natsuo also used some traditional methods of studying. One example of this is his use of flashcards to study new vocabulary. Sometimes he wrote English on one side and Japanese on the other. However, sometimes instead of Japanese he used the word in an English sentence on the back side, to remind him of how to use the word.

Lastly, when I asked Natsuo what he felt the best way to study English grammar was, he responded very quickly "grammar textbook." He said he thought reading through the textbook and then making grammar flashcards was an effective way to improve grammar. He described writing the grammar pattern on one side of a flashcard and then an example of how to use that pattern on the other side.

Beliefs. Natsuo showed signs of several strong beliefs about language learning during the course of our interview. Among these were the belief in an order of skill focus, a preference for authentic practice over rote learning, and a belief that noticeable improvement is most important when deciding how to study. 
Natsuo expressed a particular order in which he believed an English student should focus on skills. When I asked him what advice he would give to new students of English, he said "first you need to remember the word and grammar, because that is really basic one" and continued "after that you have to go to some kind of café, like Leafcup, and you have to do output." So it seems that Natsuo thought grammar and vocabulary come first, and speaking and listening come after that.

Natsuo also showed a preference towards authentic practice over rote learning. The quote in the paragraph above demonstrates that he understand the place of grammar and vocabulary learning, which he referred to as "input." However, throughout the interview he made it clear that, at least at this stage of his English education, he believes authentic practice activities are most effective. As an example, when I asked Natsuo if he did anything outside of class that he felt was helping improve his English skills, he replied "I hang out with American people. Just only American people, not Japanese people. To train my English.” He also said the most helpful thing for his English improvement, out of all his experiences, was living in the US because "here, I have to speak English in everyday life." He gave similar responses to questions of how best to hone speaking and listening skills, saying that talking with Americans was the best way. This was reiterated several other times during the interview.

Another unique aspect to Natsuo's belief system was that rather than gravitating towards activities that are fun, he seemed to only concern himself with what was most effective. When I asked what the most fun study activities were, he 
replied "what is fun for me is if I feel that my English skill is improving." His concern with effective study could also be seen when I asked him the best ways to study the major skill areas: speaking, listening, reading, writing, spelling, etc. When he was confident, he answered quickly, but with some skill areas he thought long and hard before answering. One of the skills about which he thought a long time was spelling, and he ultimately admitted he did not know the best way to study, rather than making something up. Lastly, the importance he placed on effective study and skill improvement could be seen when our interview went off on a sort of tangent and he expressed concern that his English skills were hitting a plateau.

Connections between experience, beliefs, and informal study habits. One of the most obvious connections with Natsuo's informal study habits came from his belief in a particular effective order of skill focus. He believed that the best way to study English is to build a vocabulary and grammar base, and then work on speaking and listening skills. In his own experience, the years spent studying English in the Philippines were more speaking/listening oriented than the other participants of this study. However, once he returned to Japan, his English study was very focused on vocabulary and grammar. Having built a solid foundation, he refocused most of his studying on speaking and listening skills, whether it was through hanging out with American friends or watching English language programming. This was consistent with his belief in what order language skills should be studied.

Similarly, Natsuo's informal study habits are impacted by the belief that grammar and vocabulary are best developed through rote learning activities, while 
speaking and listening are best developed through authentic practice. Natsuo preferred the use of flashcards for vocabulary study (and sometimes to memorize grammar patterns). In addition, when I asked him the best way to study grammar, he replied "grammar textbook" almost before I could finish the question (it was likely his fastest response of the interview). On the other hand, Natsuo's belief that speaking and listening skills are best developed through authentic practice was apparent in his lack of drills or exercises to develop these skills. Instead, he intentionally spent time in authentic situations where he needed to use English extensively.

Lastly, some of the study techniques that Natsuo was exposed to in school have made their way into his informal English study. Examples of this included the use of flashcards and textbooks. He continued to use both of these and called them the most effective tools for vocabulary and grammar study.

Analysis. Many of Natsuo's informal study choices are explained by his beliefs and experiences, as explored above. However, there are some aspects of his study habits that are not so easily explained. First, while some techniques and materials from his formal English educational experience made their way into his study, others did not. One example is repetitive writing for vocabulary or spelling memorization. Natsuo said that he does not use it because "I don't like that. I use flashcards." 
Also of interest is that Natsuo did not talk about using study guides for English proficiency examinations like the TOEFL. His only mention of the TOEFL came while discussing his choice of Portland for studying abroad, for which American universities require a certain level of TOEFL score. It is possible that this is related to his career aspirations. Natsuo said that his father and uncle advised him that improving his English skills would improve his chances of employment at a trading company. The fact that he referenced advice from relatives in the field is of relevance. It is likely that if there were a proficiency exam to enter this field, he would have mentioned that instead of bringing up the advice his relatives gave. For Natsuo, who is done with entrance examinations and has already come to study abroad, it is possible that tests like the TOEFL are in the rearview mirror.

Lastly, while his emphasis on speaking and listening skills can be explained by his philosophy of building a grammar and vocabulary base and then focusing on "output," there may be other factors at play. After all, most Japanese students go through the education system, studying primarily grammar, vocabulary, and reading, and never feel the need to develop speaking skills. It makes sense for there to be a distinct reason to make this effort. For Natsuo, the experience of first being exposed to English at a school in the Philippines, which focused more heavily on speaking skills than the Japanese educational system, may have strongly impacted his beliefs about language learning. Our discussion of English courses at junior high, high school, and university were peppered with comments from Natsuo about being "pretty easy," "kinda boring," "really boring. Super easy," and "not beneficial." The 
only class to escape these designations was Natsuo's ESL classes in Portland. And while he didn't go out of his way to compliment them either, he did mention that "the professor really focus on group work," and there is a lot of discussion time. It may be that Natsuo's time studying English in the Philippines affected his outlook on language learning.

\section{Hanako}

Hanako was the only participant who had already completed her undergraduate degree. At the time of our interview she was getting ready to enter graduate school at the university where this study took place. For the last several years she had been at three different universities in the United States teaching Japanese and taking classes. However, despite being further along in higher education and having spent more time in the US, I would rate Hanako's spoken English ability as definitely in the bottom half of my participants. For that reason, and because she was still actively trying to improve her English skills, her experiences were still very relevant to this study. In terms of personality, Hanako was a very social person and it was easy to feel comfortable while talking with her. Our interview took place shortly after she arrived in Portland for the second time, after spending time in Boston and Tennessee in between.

Experiences. Hanako began formal English classes in junior high, like most Japanese students, and this was her first real exposure to English. She said that in these early classes, students did not "participate, more like lecture." The focus was 
on learning the ABCs and basic grammar, and Hanako remembered a lot of the activities being based on translating between English and Japanese.

High school English classes for Hanako were also grammar focused, and she added "I don't remember story or anything." I asked Hanako if she felt her junior high and high school classes were enjoyable or if she learned anything; she replied while laughing "I learned that I hate English." She said part of this was due to the classes being mandatory and that her "score is always low." There was an ALT, who taught speaking and listening oriented classes, but Hanako said it mostly just drills and it was "so boring."

Hanako attended cram schools twice while in junior high. The first time, she didn't recall getting any English instruction at cram school. However, she said "before entrance exam for high school, I went to summer term. Like short period cram school. So, I studied English too.” Hanako said these classes mostly involved taking practice examinations to prepare students for the sort of English content found on entrance examinations.

At university, English classes were "something more meaningful" for Hanako. She had a conversation class, a class that taught formal English writing, and also remembered reading the children's book Matilda. Still, Hanako said "if the English teacher can speak Japanese, I didn't want to speak English. Because I cannot see point why I have to use English.” She also said that she didn't feel that her professor actually expected students to speak English. Hanako did say that she enjoyed using internet audio programs that were part of the curriculum to work on listening skills. 
After graduating from university, Hanako worked at a hotel for a year, but came to the decision that learning English and going back to school could benefit her career prospects. She thought about "going to graduate school, US. I wanted to study social psychology." However, she found an opportunity for a program called ALLEX (Alliance for Language Learning and Educational Exchange, http://www.allex.org/) that would allow her to come to an American university and take classes while teaching Japanese classes. She interviewed to be a part of the program, and was accepted.

The first stop on the ALLEX program was the university where this study took place, where the participants received training to teach Japanese. After spending the summer together, the participants spread out to universities across the US. Hanako was initially placed at a university in Boston, where she took only undergraduate courses. However, she said that after she moved to a university in Tennessee "the first year I took ESL" and also a TOEFL preparation course. Hanako said these classes were "so much better than junior high or high school class." She learned how to organize written English, working on pronunciation and grammar, and got some speaking practice.

However, at the same time she took a non-ESL public speaking course, which she thought was even more helpful. Hanako said "I think this class was so much better, because I had to research what I wanted to say" and "then I had to memorize like sentence script. So I had to practice before class." Throughout these classes, 
Hanako felt that her English development was supported by friends that she made. Among other things, they would check her "grammar or how I say these sentence."

Informal learning. One strategy that was unique to Hanako was her heavy use of friends to help her study. When she was preparing for her interview for the ALLEX program, she had a friend ask her practice questions and help her formulate responses in English. She also had a friend help her to prepare for the spoken portion of the TOEFL exam. After arriving in the US, Hanako had friends help her prepare for class presentations by checking "my grammar or how I say these sentences." Also, while in Tennessee, Hanako said that she "tried to read a children's book out loud, and then somebody corrected me." When I asked the best way to study unfamiliar vocabulary, she replied that having a friend describe the word or give examples would be helpful.

Many of Hanako's other study techniques were shared with the other participants of this study. One example was how she made use of authentic materials. Included in this category was how she tried to read books in English, and watch movies and TV in English. Hanako thought that these materials could be helpful, and gave the example of how she learned the word "legendary" by watching the TV show "How I Met Your Mother."

Lastly, Hanako also used some more traditional study methods. Like several other participants, she made use of repetitive writing. This technique did not come up while discussing the study of vocabulary, but she did mention it as a tool for memorizing the spelling of difficult words. She also has made use of "grammar 
structure notebooks" in the past, though she admitted to not liking them very much and seemed to have stopped using them.

Beliefs. Motivation seemed to be a very important factor for Hanako. However, the themes in Hanako's interview had more to do with a lack of motivation. Throughout our discussion, she made comments about not studying English, or not using certain techniques, because she couldn't see the point. Hanako said of junior high English classes that "my score is always low" and that she hated it, because it was mandatory. Of her high school ALT teacher, she said "if the English teacher can speak Japanese, I didn't want to speak English. Because I cannot see the point why I have to use English." Hanako even said that this teacher was not supposed to use Japanese with students, but "he finally gave up. He talked to me in Japanese." She again referred to high school classes as "just requirement."

Similarly, Hanako struggled with study techniques that did not motivate her. Of using flashcards she said "after I finish making flashcard, it's done" and added that she was "just satisfied making them." She never actually got around to using the flashcards, and said that this technique was good for students who are more patient than her. Motivation was also the reason that she didn't like using textbooks or grammar notebooks. Hanako said she used to use a grammar book but "hated it. So I stopped." She added that using these types of books "might help" but "it's so boring." Hanako had a strong negative reaction to study activities that were not inherently fun or entertaining. Interestingly, the first English class in which she reported actually making an effort was at her university in Japan. She described these 
classes as more meaningful and said that she thought "ok, I have to speak English now because we have conversation class." The social aspect of a class centered around conversation made learning intrinsically motivating.

Hanako's lack of enjoyment of traditional techniques and quickly developing boredom is a sign of lacking intrinsic motivation. Meanwhile, her inability to see any benefit that learning English might bring to her life is representative of a lack of extrinsic motivation. Interestingly, the latter motivational issue seemed to be rectified after entering the working world. Hanako said "after I graduated from university I decided maybe I need English skills, if I get a job.” So she set a goal of getting a Master's degree in the United States, and that seemed to be the end of any major extrinsic motivational issues. She even acknowledged the change in herself, saying "I'm now a good student, but I was not a good student."

Hanako also seemed to view language learning as a social endeavor, especially with close friends. At one point, I asked her how she would study for a speaking/listening exam that is set up as mock interaction, and her initial response was that she would practice with friends. However, she stopped herself short and said “I don't want to use friends for study. I'm gonna ask friend if I need help, but I don't want to use them only my study." When I pressed her by asking whether she thought using friends is helpful, regardless of whether it is nice or rude to do so, she answered "I think so, yeah." Later, she said that interactions with other people are helpful for developing speaking and listening skills. As an example, she said "If I go to Safeway and interact with cashier, I can learn something," but then she hedged this by adding 
"but friends is really important. Not acquaintances, friends." Hanako's belief in the importance of having the support of friends can also be seen in her experiences. She said the biggest factor in the improvement of her English while in the US was the friends that she made at her university in Boston. Hanako said they offered motivation because "I wanted to communicate with (them)." These same friends also helped her study or prepare for oral presentations.

The last belief was brought up directly by Hanako. She said "I think studying language has goal for me. Ok. You want to go to graduate school in the US or just travel conversation for fun or you want to get a job.” Essentially, Hanako believed that what you study and how you study are likely impacted by why you study.

Connections between experience, beliefs, and informal study habits. It is easy to see how the importance that Hanako placed on motivation affects her study. If she found a study technique to be too boring or frustrating, she simply did not use it. She was very direct about this on several occasions. Even if she felt that the given technique could be effective if she was diligent, without the motivation, she wouldn't do it. This likely extended to the amount of time she studied informally. If Hanako was not feeling motivated to improve her English, she probably won't put in the time. This is consistent with her report that her grades in English class as a child were always bad; she wasn't motivated, so she wasn't putting in the time.

Hanako's belief in language learning as a social experience also appeared to greatly impact her informal learning habits. As we talked about how she has studied in the past, or what she thinks is effective, friends kept entering into the equation 
unexpectedly. For example, Hanako made a comment about trying to read books in English in her free time, something several other participants also do. However, then she would add that she liked to read the books out loud so that a friend could correct her. She also made use of friends to prepare for interviews, presentations, and tests. For Hanako, friends were both a great motivation and a great tool in language learning.

Analysis. As discussed above, the need for motivation and the desire to have a very social language learning experience seem to explain a lot of the choices that Hanako made in her informal study. Supporting the importance of these factors is that Hanako eschews several techniques that almost all of my other participants use. These include using flashcards to study vocabulary and textbooks or grammar notebooks to study grammar.

Hanako's experiences with formal English study in the past were not a good predictor of informal study habits at the time of our interview. The only technique that she had definitely retained from her classes was repetitive writing. Hanako had replaced flashcards and dictionaries with talking with friends about the meaning of difficult vocabulary. She also replaced textbooks with leisure reading, and listening practice from TV and movies supplanted audio CDs from textbooks.

The reliance on friends and need for fun study activities may make it easy to dismiss Hanako as a poor student, but I believe she is simply studying in a way that motivates her. Hanako herself said "I told you I'm not good student. I'm now a good student, but I was not a good student." In support of this, it is relevant to note that by 
Hanako's own description, she was completely unable to communicate in English when she first joined the ALLEX program and arrived in the US. Several years later, she may not have had perfect pronunciation or grammar, but she never once had to ask for me to repeat a question in our interview. This kind of progress would not occur without some effort on Hanako's part.

\section{Yoshito}

Yoshito was a junior at his university in Japan. Unlike other participants, who came from more urban areas, he grew up on the small island of Amami. Yoshito was an active participant in the interview, and answered my questions thoroughly. His general demeanor was quiet and soft-spoken, though it was unclear to me whether this was a manifestation of a shy personality or more of a testament to his English skills, which were not as advanced as several of the other participants of this study.

Experiences. Yoshito grew up on a small island located between the wellknown island of Okinawa and Kyushu, which is the southernmost part of the main body of Japan. He agreed with the other participants that "most Japanese start English from junior high school, because it's compulsory." Yoshito described junior high classes as "very beginner grammar" and listening practice. There was a native English speaking ALT, who occasionally led the class in games to learn English, but otherwise teachers were mostly Japanese. Yoshito said that he enjoyed the classes, because they were easy, but didn't have a strong desire to learn English beyond what 
would be necessary for entrance examinations, which is what Yoshito felt the classes were designed to help with.

In high school, class was "more complicated, but still focused on grammar and reading. Then a little listening." Yoshito felt that these classes were also aimed at helping students pass entrance examinations. He described these examinations as "half of grammar and half of reading, and a little listening." The classes mirrored these examinations, and Yoshito added "It's not exam speaking and writing. So, most of us don't study speaking and writing."

Yoshito did not attend a cram school. He said that because his hometown was “really countryside," there were not very many cram schools available. Instead, students could ask their high school teachers to give them practice examinations to help prepare for their entrance examinations. Yoshito said his teacher would give him a practice exam and then he would return it for grading and receive a new practice examination. When I asked if taking on this extra work was something his parents suggested, he replied that it was "my idea."

Yoshito's preparation paid off, and he was accepted at prestigious university in Japan. While at university, Yoshito took two years of compulsory English classes, which he described as being focused on reading, without much emphasis on speaking and listening skills. However, the professor was an American and the classes were taught entirely in English. Yoshito said of these classes that they were "a little difficult, so I was supported by my friends." A few of Yoshito's friend were what he referred to as "returning students," a term that means they had attended high school 
abroad, usually in the US or Australia. They found the classes much easier, and were able to help Yoshito when he struggled.

I asked Yoshito why he chose to study abroad, and he answered to "improve English." However, I followed up by asking what percent of his motivation was studying English, compared with other factors, and he replied " $60 \%$ improve English and others is I want to experience foreign living." After arriving in Portland, Yoshito began ESL classes with the other members of his exchange program. He also attended classes on the topics of sustainability and other environmental issues, which were the focus of his exchange program. These sustainability classes were part of the American universities curriculum, so he had American classmates. Yoshito said that the ESL classes served to "support class content" of the sustainability courses. Students were able to ask questions about things they didn't understand from their core classes. In addition, the ESL classes focused on developing pronunciation, conversation, and reading skills.

Informal learning. Yoshito's informal learning habits fell on the traditional side. I first asked him about what he felt was the best way to study vocabulary, and his answer was to "look many times. In the bus or before sleeping, I look many times." Yoshito said that he wrote a word on a piece of paper, with the Japanese meaning next to it. Over the course of days, weeks, or however long it takes for him to memorize, he looked at the word repeatedly throughout the day. He added "then when I remember the meaning, I write again" in English. Yoshito also said he used flashcards, and felt both methods were effective. 
Yoshito found talking with native English speakers to be the most effective way to improve his speaking and listening skills. He did watch movies and television in English, with subtitles to help, but did not feel that it was helpful for his English development. In additional to these activities, Yoshito also took two non-compulsory English classes at his Japanese university that focused on developing speaking and listening skills. He did this in preparation for studying abroad in Portland.

To improve his ability to read English, Yoshito's said that "firstly, I read first sentence of each paragraph. After that we read all of them. I think it's a correct way." He said that this method was taught to him by his high school English teacher. Yoshito also thought it was a good idea to simply try to read often and to focus on learning relevant vocabulary if you are trying to improve reading skills for a specific purpose.

Perhaps the most interesting study technique used by Yoshito involved the memorization of English spelling. We discussed how it can be difficult to remember the spelling of some words in English, because a given sound can be often be spelled in multiple ways or could contain a silent letter. To mitigate this difficulty, Yoshito used a Japanese pronunciation to help him remember difficult words. As an example, Yoshito wrote the word "line" on a piece of paper and then pronounced it [liner], using two syllables, just as if he was reading the letters as a Romanized Japanese word. Similarly, he would fully pronounce the letter " $u$ " in the word restaurant. This technique is similar to an American child pronouncing the word "Wednesday" as [wednesdeI] or saying the $/ \mathrm{k} /$ in knee, as a mnemonic device. 
Beliefs. Yoshito believes in the power of repetition. This was most evident when it came to his study of vocabulary. Yoshito used the phrase "look many times" on several occasions. Most people would likely agree that whatever strategy you use, vocabulary memorization takes time and repetition. However, as opposed to repeatedly using a particular strategy, repetition itself was Yoshito's strategy. His description of his primary vocabulary study activity was that he simply looked at and thought about a word, repeatedly. Repetition was also Yoshito's response to a question of the best way to improve reading skills; he said "read many times."

Yoshito also professed a belief in the importance of developing oral communication skills, saying "I think speaking and listening is more important skill than reading and grammar." Further supporting this belief, he said that his favorite formal learning experience thus far had been his classes in the US “because it's practice speaking."

Lastly, Yoshito demonstrated a belief in the effectiveness of the formal English education system and the expertise of his teachers. From his reliance on a teacher for additional guided entrance examination preparation to taking noncompulsory English classes in preparation for studying abroad to his stated intention to continue taking university English classes to maintain his skills after returning from studying abroad, Yoshito demonstrates a strong trust in formal education.

\section{Connections between experience, beliefs, and informal study habits.}

Yoshito's experience with and trust in formal English education and his teachers 
seems to have had a very large impact. His study outside of class was influenced by his teachers and experiences in class, whether it was using practice tests the teachers provided, using materials from class for extra study, or techniques that he learned from them. When I asked Yoshito if he would take more English classes after returning to Japan he replied that he would do so "to keep my English skills." Another connection could be found in Yoshito's use of repetition as a tool. This was something he was exposed to in formal education, seemed to take to heart, and continued to use. To a certain extent Yoshito's belief in the importance of speaking and listening skills could be seen in his choices as well. One example of this was his choice to study abroad, where communicating in English would be a daily necessity. It also showed in his choice to take speaking and listening focused classes that were not required for his degree at his Japanese university.

Analysis. As demonstrated above, many of Yoshito's choices can be explained by experiences and beliefs, but not all of them. One of the more interesting ways that Yoshito's beliefs did not fully match up with his actions was with regards to his belief in the importance of developing speaking and listening skills. Yoshito was one of two participants that did fill out the study log, but he did not list any speaking and listening study. It is likely that he does participate in some activities that are helping to develop these skills. As an example, Yoshito skipped filling out a few days on the log because of being away on a university organized rock climbing trip. These types of club or group activities were mentioned by several participants as being a great opportunity to converse in English, and that may have been part of his 
motivation. On the other hand, Yoshito also disagreed with the other participants about how helpful activities like watching TV and movies in English can be. So it is difficult to say with certainty that he was putting much effort into improving his speaking and listening skills through some kind of informal study.

Also worthy of note, the impact Yoshito's belief in the effectiveness of formal English education and teacher's advice has had extended beyond how he studied informally to how much he studies informally. The study log that Yoshito filled out for me did not have any informal study documented on it; it had only study for class written down. I got the impression during our interview that Yoshito worked hard to study and prepare for his classes, probably above and beyond what is necessary. However, calling that extra time spent on class assignments and preparation informal study would not fit my operationalization of the term. Instead, I think it is plausible that this focus on formal English instruction may have been eating up time that would otherwise be devoted to informal study.

So the question becomes why these beliefs and experiences were not matching up with his actions in a few key ways. It may have been for reasons of personality. Perhaps the quietness I observed during our interview was an indication of general shyness. It is also possible that Yoshito was outgoing in the company of other native Japanese speakers, but had not yet developed enough confidence in his English skills to get over some initial communication anxiety. Both of these are definitely factors that could have inhibited him from actively putting himself in more situations where he was getting experience speaking English in authentic settings. An alternative 
possibility is that his faith in formal English education was simply prevailing over the alternative informal methods of study for the time being. After all, Yoshito has already developed the ability to speak English at a fluent enough level to live in the US by relying on formal English education.

\section{Summary}

The table below provides a summary of the experiences, beliefs, and informal study techniques of each participant. It is important to note that this list is not intended to be exhaustive. For example, in the "experience" column, I highlight each level of formal education or other setting that a participant received English instruction in and include the focus or importance of each experience, from the participant's perspective. If only grammar and vocabulary study are listed, this does not indicate that speaking and listening skills were never addressed, only that the participant did not feel they were a primary focus.

Table 2: Summary of participants' experiences, beliefs, and informal learning techniques

\begin{tabular}{|c|l|l|l|}
\hline Name & \multicolumn{1}{|c|}{ Experience } & \multicolumn{1}{c|}{ Beliefs } & \multicolumn{1}{c|}{ Informal Study } \\
\hline \multirow{5}{*}{ Honami } & Jr: grammar. & -Motivation: & -Authentic materials: \\
& Cram: grammar, vocab & extrinsic and & TV/movies/music/books \\
& HS: vocab. & intrinsic. & -TOEFL materials \\
& UCLA summer exchange & -Repetition. & -Vocab book from Japan \\
& Uni: authentic materials, & -Native instructors. & -Skype: typing -> talking \\
& participation. & -Order of study: & -Extensive social \\
& US: native instructors, participation, & grammar/vocab -> & interaction w/ friends \\
& discussion, pronunciation. & speaking/listening. & \\
\hline \multirow{5}{*}{ Ichigo } & Child: neighborhood instructor & -Effectiveness of & -TOEFL/EIKEN materials \\
& Jr: alphabet, grammar, ALT & formal education & -Textbooks \\
& Cram: grammar. & and instructional & -Flashcards \\
& HS: grammar, 2 ALTs, & materials. & -Breaking New English \\
& speaking/listening. & -Repetition. & web resource \\
& Uni: grammar, reading, ALT & -Native instructors. & -Conversation partner \\
& US: grammar, reading, & & \\
& speaking/listening. & & \\
\hline
\end{tabular}


Table 2 (continued)

\begin{tabular}{|c|c|c|c|}
\hline Name & Experience & Beliefs & Informal Study \\
\hline Norio & $\begin{array}{l}\text { Child: English club, vocab. } \\
\text { Jr: reading, grammar, } \\
\text { pronunciation, no ALT. } \\
\text { Cram: grammar, reading } \\
\text { HS: reading, grammar, no } \\
\text { ALT. } \\
\text { Uni: } 4: 1 \text { student to instructor } \\
\text { conversation, grammar, } \\
\text { reading. } \\
\text { US: American culture, } \\
\text { listening, pronunciation }\end{array}$ & $\begin{array}{l}\text {-Persistence, positive } \\
\text { attitude. } \\
\text {-Motivation } \\
\text {-Automaticity } \\
\text {-Acquisition over learning } \\
\text { for speaking/listening } \\
\text { skills }\end{array}$ & $\begin{array}{l}\text {-Flashcards (Jap-Eng and } \\
\text { Eng-Eng) } \\
\text {-Dictionaries (Jap-Eng } \\
\text { and Eng-Eng) } \\
\text {-TOEFL materials } \\
\text {-Non-compulsory classes } \\
\text {-Authentic materials: } \\
\text { TV/movies/Fifa.com }\end{array}$ \\
\hline Natsuo & $\begin{array}{l}\text { Child: Elementary school } \\
\text { lesson in Philippines, speaking. } \\
\text { Jr: alphabet, writing, grammar. } \\
\text { Cram: reading, writing, } \\
\text { grammar. } \\
\text { HS: reading, writing, grammar, } \\
\text { ALT taught speaking. } \\
\text { Uni: lecture, presentations. } \\
\text { US: group work, American } \\
\text { culture, less grammar. }\end{array}$ & $\begin{array}{l}\text {-Order of study: } \\
\text { grammar/vocab -> } \\
\text { speaking/listening. } \\
\text {-Acquisition over learning } \\
\text { for speaking/listening } \\
\text { skills. } \\
\text {-Effective study more } \\
\text { important than fun }\end{array}$ & $\begin{array}{l}\text {-Leafcup café } \\
\text {-Extensive social } \\
\text { interaction w/ native } \\
\text { speakers } \\
\text {-Authentic materials: } \\
\text { novels/TV/movies/music } \\
\text {-Flashcards (Jap-Eng and } \\
\text { Eng-Eng) } \\
\text {-Grammar textbook }\end{array}$ \\
\hline Hanako & $\begin{array}{l}\text { Jr: alphabet, grammar, } \\
\text { translation } \\
\text { Cram: practice examinations, } \\
\text { grammar } \\
\text { HS: grammar } \\
\text { Uni: conversation, writing, } \\
\text { reading (novels), audio lab for } \\
\text { listening practice } \\
\text { US: ESL course - writing, } \\
\text { pronunciation, grammar, } \\
\text { speaking; Non-ESL public } \\
\text { speaking course }\end{array}$ & $\begin{array}{l}\text { - Motivation/Demotivation. } \\
\text {-Language learning as a } \\
\text { social endeavor. } \\
\text {-Goal driven nature. }\end{array}$ & $\begin{array}{l}\text {-Use of friends for } \\
\text { grammar and speaking } \\
\text { correction } \\
\text {-Authentic materials: } \\
\text { books/movies/TV } \\
\text {-Repetitive writing } \\
\text { (spelling) } \\
\text {-Extensive social } \\
\text { interaction with friends }\end{array}$ \\
\hline Yoshito & $\begin{array}{l}\text { Jr: grammar, listening, ALT } \\
\text { led English games. } \\
\text { Cram: did not attend } \\
\text { HS: grammar, reading, some } \\
\text { listening. } \\
\text { Uni: reading, grammar } \\
\text { US: pronunciation, } \\
\text { conversation, reading }\end{array}$ & $\begin{array}{l}\text {-Repetition } \\
\text {-Effectiveness of formal } \\
\text { education and } \\
\text { instructional materials. } \\
\text {-Importance of speaking } \\
\text { skills }\end{array}$ & $\begin{array}{l}\text {-Repetitive writing } \\
\text {-Flashcards } \\
\text {-Non-compulsory classes } \\
\text {-TOEFL materials } \\
\text {-Grammar book }\end{array}$ \\
\hline
\end{tabular}


This table demonstrates many similarities between the participants, especially in the "experience" column. With the exception of Natsuo, who lived in the Philippines during elementary school, all the participants began formal English education in junior high. There was also only one exception to the attendance of cram schools, Yoshito. While there was a somewhat variable amount of exposure to ALTs and speaking/listening focused classes, participants largely reported a junior high and high school experience that consisted largely of teacher-fronted grammar and reading experience. For most participants, university classes began to have a greater focus on speaking/listening skills and authentic materials, as did the classes they took while in the United States.

Despite similarities in formal educational experiences, the differences in beliefs and informal study techniques were much more pronounced. The table above definitely shows some items that were used almost across the board, such as flashcards, TOEFL materials, and television. However, there were also some very stark contrasts between participants.

One of the strongest examples of this contrast was the amount of trust that participants placed on formal education and traditional study techniques. On the one hand, Ichigo and Yoshito displayed a strong trust in formal English education and traditional study techniques such as flashcards, textbooks, study guides, and heavy use of repition. Ichigo often repeated the beliefs of her instructors and sometimes studied by doing extra homework beyond what was assigned. She mentioned only one web resource, which she learned about from one of her instructors. Yoshito took 
non-compulsory classes, and stated an intention to continue to do so after returning to Japan. Like Ichigo, he also studied above and beyond what was necessary for classes, and rarely strayed from study materials that were from his classes.

In contrast, the other four participants spent much more time exposing themselves to authentic English materials and maximizing their interactions with native speakers of English. The most extreme example of this was Honami, who even specifically expressed that "school English is not actually helpful." For Honami, the study technique that she found to have the greatest impact on her English development was the use of Skype. She learned about this way of studying by doing her own research on the internet. Much of her remaining informal study consisted of spending as much time as possible using English with American friends or in other authentic settings.

The other three participants did not profess as strong of a distaste for formal English education as Honami did, but they still fell much closer to her practices than to Ichigo and Yoshito's. Each of these three had one defining practice that differentiated them from other participants. For Hanako, it was her extensive use of friends, not only for authentic practice but to help her prepare for tests and presentations or to correct her while she read a book aloud. For Norio, his integration of soccer into his study was unique. He motivated himself to read in English by using the FIFA.com website and credited English interactions on the soccer field for some of his improvement. For Natsuo, it was his use of a conversation café to prepare for 
studying abroad and subsequent recommendation to future hypothetical students of English that they do the same.

The individual analyses of interactions between student's experiences, beliefs, and informal learning practices help to explain many of the participant's choices. It is also interesting to consider how participants with such similar formal English education backgrounds developed very different informal study habits. For some participants, there was a singular experience that seemed to be a catalyst for a change in study, despite experiences that were on the whole similar to the rest of the group. For example, when Honami studied abroad for a month at UCLA, she was very upset to find herself unable to communicate with Americans despite years of English study in Japan. Upon her return, she began using Skype as a study tool and moving away from traditional study technqiues. Likewise, Natsuo's early English education in the Philippines exposed him to spoken English at an earlier age than the other participants. It may not be a coincidence that his English study was likely the second least dependent on traditional techniques.

For other participants, there may not have been a singular powerful experience of this nature. However, Norio and Hanako both acknowledge that they struggled upon first arriving in the US, which may have led to them rethink their study. Even Norio and Natsuo's discovery that their current English skills did not allow them to talk with American girls could have played a role in rethinking informal study habits.

In the individual analyses of Ichigo and Yoshito, I also posited that personality may have played a role in their informal learning habits. Looking at the 
group as whole lends extra support to this idea. Ichigo and Yoshito were the two participants that I perceived to be fairly shy, and it may not be a coincidence that they were also the two who had incorporated the least amount of authentic social interaction in English into their informal study.

Though this study was not intended to be a cross-case analysis, there are definitely things to be learned from comparing the experiences, beliefs, and informal learning choices of the participants. 


\section{Conclusion}

The main research question of this study was "what is the relationship between the learners' informal learning methods on the one hand and their past formal language learning experience and beliefs on the other?" In my small sample, there were a fair number of connections between participants' experiences, beliefs, and informal study habits. All of my participants continued to use techniques that they learned in a formal education setting, and two of them (Ichigo and Yoshito) seemed to rarely stray from those techniques. Likewise, all participants' decisions about informal learning seemed to be connected to their underlying beliefs. For some, this manifested itself in a predisposition towards rote learning techniques, and especially the use of repetition. For others, as in the cases of Norio, Honami, and Natsuo, there was a belief in the importance of authentic communication and a practice of placing a large emphasis on social interaction with native speakers of English. The results of the study definitely showed relationships between experiences, beliefs, and informal learning methods.

\section{Limitations}

There are some limitations to discuss that may have impacted the findings of this research. The first of these limitations was that not all participants filled out the study log. More stress was placed on the importance of the interview as the main source of data, but participants were still encouraged to fill out the study log as a secondary source of data. The first four participants were given the study log a week 
before the interview, as planned, but only two completed it. The fifth and sixth participants were unable to complete the study log due to time constraints. For the fifth participant, the constraint was that he was leaving the country within several days after agreeing to participate. Time constraints were again an issue with the sixth participant, but this time from my side. Due to the need to finish my research, this participant's process was expedited. Both of the latter two issues could have been avoided had I been working with a larger pool of volunteers, but as it happened getting six participants was a struggle.

Having study logs from all participants would have provided additional data that would have two distinct benefits: potentially revealing themes that did not surface in the interview and providing greater confidence in findings through triangulation. The first benefit, revealing new themes, is directly in line with the aim of an exploratory study such as this. Just as important is the benefit of triangulation, which is the use of multiple sources of data to strengthen confidence in findings. Dörnyei (2007) said "triangulation can help to reduce the inherent weaknesses of individual methods by offsetting them by the strength of another, maximizing both the internal and external validity of research" (pp. 42-43). For these two reasons, not having study logs for all participants is a limitation that must be acknowledged.

Another issue came as a result of setting a maximum length for the interviews. As discussed in the methodology section, it was decided that anything longer than an hour would be too much to ask of participants. One result of this was that I was not always able to ask completely open ended questions. As an example, if a participant 
mentioned using flashcards, I did not have sufficient time to spare to have them physically recreate the creation of these cards. If I wanted to know if the participant used flashcards that were English-Japanese, English-English (with definition), English-English (with synonym) or some combination of those, I found it necessary to ask more probing questions. Sometimes this meant asking directly, which could be seen as leading.

To help mitigate the risk of leading, I did my best to phrase the questions in a way where there were multiple options, none of which were made to sounds as the "right" answer. For example, I tried not to ask "Did you write English on one side and Japanese on the other?" Instead, I would offer multiple alternatives "Did you write English on one side and Japanese on the other, or did you write an English word on one side and an English definition or synonym on the other side?" This was not a perfect system, but it allowed me to get more information in the amount of time that was available to me.

Additionally, I made the choice not to have a long list of study techniques to ask each participant about. Working off a list may have provided a more thorough view of all the study techniques that a given participant uses or has used. However, I felt that letting participants freely talk about what came to their minds had two important benefits. Participants were able to talk about any techniques they have used, including ones that I would not have thought to ask about or put on a list. This proved to pay off on several occasions, when participants talked about techniques that were not on my radar. 
Secondly, I asked each participant how they study to develop a given language skill. Being unburdened by a prepared list of techniques, my hope was that the techniques that they thought to mention would be those they used most often or believed most strongly in. I believe that this was effective, as I did at times ask about other techniques after first giving participants the free reign to answer. On several occasions, the participants rated the techniques I asked about as less effective or not their style, when compared with what they had previously mentioned.

\section{Practical Implications}

Bearing the aforementioned limitations in mind, there are still some valuable practical implication of the connections that began to emerge between experience, beliefs, and informal learning practices. The main implication is that language educators can have a profound effect on their students' approaches to informal language learning, and therefore have the opportunity to expose students to a range of study techniques and resources that can later be used in informal study.

On several occasions a participant directly credited an English instructor for teaching them a study technique that they currently use. As an example of this, Yoshito credited his teacher for teaching him to improve his reading comprehension by starting with the topic sentence of each paragraph and then reading the remaining content. In addition, participants echoed their teachers' beliefs at times. There were several examples of this in Ichigo's interview. Of one teacher at her high school, Ichigo said "she thinks talking is more important." She made a similar statement 
about a teacher at in the US, saying "my teacher thinks that reading you need a lot of vocabulary if you want to read good." Statements similar to these could also be found in the interviews of several other participants.

If language educators make a point of using or demonstrating a large number of study techniques, they can expand students' repertoires. A student with an increased knowledge of study techniques and resources will have a better chance of finding something that motivates them or fits their particular learning style. In this way, language educators can positively impact students' learning beyond the classroom.

\section{Suggestions for Future Research}

This research was mostly aimed at discovering whether connections existed between experiences and beliefs on the one hand, and informal study techniques on the other. Based on the findings of this study, which are detailed above, it appears likely that these connections do exist. It would be interesting to see the results of a larger scale study, which might be able to not only confirm the existence of these connections with greater confidence, but also investigate the factors behind connections. Another interesting avenue for future research on this topic would be a longitudinal study. A long term study would be able to shed further light on when and why students begin using informal learning techniques, as well as tracking how beliefs develop and interact with informal learning choices over time.

My own research showed that participants at times strayed from familiar 
techniques when they had an experience that led them to believe the techniques were not effective. An example of this was Honami's experience abroad, in which she found herself unable to communicate in English and subsequently added Skype conversation partners to her study regimen. However, I don't think all the factors that go into students' informal study decisions are so cut and dry. It would be very interesting, and potentially useful for language educators, to know more about what goes into these decisions. By further understanding this subject, language educators could seek to positively influence students' study time outside of class parameters. 


\section{References}

Arnold, N. (2007). False beginners' transition to college level foreign language classes: Beliefs, expectations and cultures of learning. In J. Siskin (Ed.), From thought to action: Exploring beliefs and outcomes in the foreign language program (pp. 112-134). Boston: Thomson Heinle

Barcelos, A. (2000). Understanding teachers' and students' language learning beliefs in experience: A Deweyan approach (Doctoral dissertation). University of Alabama, Tuscaloosa, AL.

Bernat, E., \& Gvozdenko, I. (2005). Beliefs about language learning: Current knowledge, pedagogical implications, and new research directions. TESL-EJ: Teaching English as a Second or Foreign Language, 9 (1), [np]

Candy, P. (1991). Self-direction for lifelong learning. San Francisco, CA: JosseyBass.

Comas-Quinn, A., Mardomingo, R., \& Valentine, C. (2009). Mobile blogs in language learning: Making the most of informal and situated learning opportunities. ReCALL, 21(1), 96-112.

Cotterall, S. (1995). Readiness for autonomy: Investigating learner beliefs. System, 23 (2), 195-205.

Cotterall, S. (1999). Key variables in language learning: What do learners believe about them? System, 27, 493-513. 
Creswell, J. (2007). Qualitative inquiry and research design: Choosing among the five approaches. London: Sage Publications.

Dörnyei, Z. (2007). Research methods in applied linguistics. New York, NY: Oxford University Press.

Egert, C. (2000). Language learning across campuses. Computer Assisted Language Learning, 13 (3), pp. 271-280.

Ellis, R. (1980). Classroom interaction and its relation to second language learning. RELC Journal, 11, 29-48.

Fernandez, C. (2007). Persistence in foreign language study: An investigation of learners' beliefs. Issues in Language Program Direction, 135-154

Garrick, J. (1996). Informal learning: Some underlying philosophies. Canadian Journal for the Study of Adult Education, 10(1), 21-46.

Garrick, J. (1998). Informal learning in the workplace: Unmasking human resource development. London: Routledge.

Golafshani, N. (2003). Understanding reliability and validity in qualitative research. The Qualitative Report, 8(4), 597-607. Retrieved from http://www.nova.edu/ssss/QR/QR8-4/golafshani.pdf

Guo, Y. (2005). Asia's educational edge: Current achievements in Japan, Korea, Taiwan, China, and India. Lanham, MD: Lexington Books.

Hatch, J. (2002). Doing qualitative research in educational settings. Albany, NY: State University of New York Press. 
Horwitz, E. (2008). Becoming a language teacher: A practical guide to second language learning and teaching. Boston, MA: Pearson.

Horwitz, E.K. (1988). The beliefs about language learning of beginning university foreign language students. In The Modern Language Journal, 72/3, 283-294

Horwitz, E.K. (1983). Beliefs about language learning inventory. Austin, TX: University of Texas. [instrument]

Krashen, S. (1981). Second language acquisition and second language learning. Oxford: Pergamon.

Kukulska-Hulme, A. (2006) Learning activities on the move. Handheldlearning, 1213 October 2006, London. Retrieved from http://www.handheldlearning.co.uk/hl2006/present/AKukulskaHulme.pdf

Kukulska-Hulme, A. (2009). Will mobile learning change language learning. $\operatorname{ReCALL,~21(2),~157-165.~}$

Livingstone, D.W. (1999). Exploring the icebergs of adult learning: Findings of the first Canadian survey of informal learning practices. Canadian Journal for the Study of Adult Education, 13(2), 49-72.

Livingstone, D.W. (2001). Adults' informal learning: Definitions, findings, gaps and future research. Toronto: NALL Working Paper. Retrieved from http://www.oise.utoronto.ca/depts/sese/csew/nall/res/21adultsifnormallearning.ht m.

Mantle-Bromley, C. (1995). Positive attitudes and realistic beliefs: Links to proficiency. The Modern Language Journal, 79 (3), 372-386. 
Mocker, D., \& Spear, G. (1982). Lifelong learning: Formal, nonformal, informal, and self-directed. Columbus, OH: ERIC Clearinghouse on Adult, Career, and Vocational Education, National Center for Research in Vocational Education.

Pajares, M. (1992). Teachers' beliefs and educational research: Cleaning up a messy construct. Review of Educational Research, 62(3), 307-332.

Peacock, M (1998). Exploring the gap between teachers' and learners' beliefs about 'useful' activities for EFL. International Journal of Applied Linguistics, 8 (2), $233-250$.

Pemberton, L., Fallahkhair, S., \& Masthoff, J. (2004). Towards a theoretical framework for informal language learning via interactive television. In Kinshuk, Sampson, D.G. and Isaias, P. (Eds.) Proceedings of IADIS International Conference of Cognition and Exploratory Learning in Digital Age (CELDA), 27-34.

Peng, J. \& Woodrow, L. (2010). Willingness to communicate in English: A model in the Chinese EFL classroom context. Language Learning, 60 (4), 834-76.

Perry, F. (2005). Research in applied linguistics: Becoming a discerning consumer. New York, NY: Routledge.

Roesgard, M. (2006). Japanese education and the cram school business: Functions, challenges, and perspectives of the juku. Copenhagen: Nordic Institute of Asian Studies.

Rogers, A. (2004). Looking again at non-formal and informal education: Towards a new paradigm. The encyclopaedia of informal education. Retrieved from 
http://www.infed.org/biblio/non_formal_paradigm.htm. Last updated: June $04,2004$.

Ryan, R. \& Deci, E. (2000). Intrinsic and extrinsic motivations: Classic definitions and new directions. Contemporary Educational Psychology, 25, 54-67.

Sawchuck, P. (2003). Informal learning as a speech-exchange system: Implications for knowledge production, power and social transformation. Discourse Society, 14, 291-306.

Segalowitz, N. (2003). Automaticity and second languages. In C.J. Doughty \& M.H. Long (Eds.), The handbook of second language acquisition (pp. 382-408). Oxford: Blackwell

Tough, A. (1971). The adult's learning projects. Toronto: Ontario Institute for Studies in Education.

Vygotsky, L.S., 1978. Mind in society. Cambridge, MA: Harvard University Press.

White, C. (1999). Expectations and emergent beliefs of self-instructed language learners. System, 27, p. 443-457. 


\section{Appendix A: Core Interview Questions}

1. When did you begin studying English?

2. Can you describe those classes?

3. What do you feel you learned in those classes?

4. What skills were focused on? (grammar, reading/writing, speaking/listening)

5. What was your textbook like?

6. What role did your teachers play?

7. What sorts of exercises/techniques did you use to learn?

8. What did you like or dislike about those classes?

9. (If the initial classes discussed are elementary school or earlier, ask similar series of questions about high school language learning experience)

10. Did you study at home? If so, what materials did you use? (textbook from class, flashcards, etc.)

11. Did you study English (or another language) at a juku (cram school)?

12. Was that experience similar or different than your language classes at school? In what way?

13. Did you study English at University in Japan? (If so, ask similar questions)

14. Why did you decide to continue your study of English?

15. With regards to English, did you do anything special to prepare for your time in the US?

16. Can you describe your experience studying English in the United States?

How is it similar or different from studying in your home country? 
17. Are your English classes in the US taught in the same way as the classes you took at home? Is the emphasis the same (i.e. grammar, speaking/listening, etc.)

18. In all of your experience studying English, what have you found to be the most effective? Ineffective? Fun? Boring?

19. Do you currently study English in your free time? If so, what materials do you use?

20. Why do you choose to study this way?

21. If you decided you wanted to work on your vocab/speaking/listening/grammar/reading/writing skills, what do you think would be the best way to do that? (This will be a series of questions, with each skill asked about individually)

22. How does that type of learning (from Ss answers to 21) compare with the type of learning that happens in your ESL classrooms? Happened in your home country EFL classes? 
*These questions represented a starting point. Follow up questions were asked as the conversation progressed. 


\section{Appendix B: English Study Log}

\begin{tabular}{|c|c|c|c|}
\hline \multirow{2}{*}{\begin{tabular}{|l|} 
Length of study \\
Ex: $30 \mathrm{~min}, 5 \mathrm{pm}-$ \\
$6 \mathrm{pm}$
\end{tabular}} & Day 1 & Day 2 & Day 3 \\
\hline & & & \\
\hline $\begin{array}{l}\text { Location } \\
\text { Ex: Library, at } \\
\text { home, friend's } \\
\text { apartment }\end{array}$ & & & \\
\hline $\begin{array}{l}\text { Grouping } \\
\text { Ex: Alone, with a } \\
\text { friend, study group }\end{array}$ & & & \\
\hline $\begin{array}{l}\text { Materials Used } \\
\text { Ex: Study guide } \\
\text { from Japan or the } \\
\text { US, flashcards, } \\
\text { English TV shows, } \\
\text { etc. }\end{array}$ & & & \\
\hline $\begin{array}{l}\text { Focus of Study } \\
\text { Ex: Reading, } \\
\text { pronunciation, } \\
\text { grammar, etc. }\end{array}$ & & & \\
\hline $\begin{array}{l}\text { Why did you } \\
\text { choose to study this } \\
\text { way? }\end{array}$ & & & \\
\hline $\begin{array}{l}\text { Do you think your } \\
\text { study was } \\
\text { successful? }\end{array}$ & & & \\
\hline
\end{tabular}

Please give as much information as possible

* The reverse side of the $\log$ contained identical entries for days 4 through 7 
INFORMAL LEARNING CHOICES OF JAPANESE ESL STUDENTS

\section{Appendix C: Interview Transcriptions \& Follow up Communication}

\section{Honami}

Interview transcription

M: Alright, I'm just going to look at this thing real fast \{examines study log\}.

$\mathrm{H}$ : I usually do the same thing for, like almost everyday. I watch TV shows on computer.

M: What TV shows?

H: (Uh) Glee or Gossip Girls, because like, I think the Gossip Girls story is kinda like (uh), it's kinda like you know, easy for me to understand.

M: I see. Did you start doing that specifically to learn English or did you just because you like it?

H: (Uh) It's both. I like Blake Lively, the main character, and I watch it. And also it's going to be my studying, so.

M: So you feel like it helps?

H: Yeah.

M: And what about vocabulary? Friday it says you studied vocab.

H: I have like some word work book, and I usually like write it many times, until I remember. And I memorize about thirty word per day, when I have time.

M: Ok.

H: Yeah, but last (I had like) I just finished midterms, so I didn't feel like study very much, and I watched TV show a lot. 
M: So, (what were there) what words were you studying?

H: (um) It's kinda like random words, but do you know the test, TOEFL?

M: Yeah.

H: Yeah, and then I wanna take like very good score on TOEFL, so it's the words based on TOEFL test.

M: Ok.

H: Yeah, it's Japanese companies book. If you wanna know the name of the book, I can just write it down.

M: Yeah, sure, do you know the name?

$=\mathrm{H}$ writes down the book's information.

$\mathrm{H}$ : The company's name is Obunsha. In kanji, or?

M: My kanji is ok. I can read some. If you tell me what it says, that might help.

H: Eitango.

M: Yeah, some of those I don't know. I know this first one, that's for like eigo, like English. That one right?

H: Yeah.

M: The other two I don't know I think. Oh, that's go, like language, right?

H: Yeah.

M: (What is) what is tan mean?

H: Tan is the words, like words.

M: Ok. Like vocabulary?

H: Yeah. 
M: Is this how many words are in the book?

H: Yeah.

M: 3,800 words are in the book.

$\mathrm{H}$ : Yeah. And it looks kinda orange and white.

M: Ok. Cool. And you got that in Japan?

H: Yeah, I got that in Japan. And I'm pretty sure you can find, like Amazon Japan.

M: So you just picked some words out of there that you didn't know yet, and you just write them?

H: Yeah I just write them. (And) for example, if I am just learning the word apple. And I'm going to write, until I (like) remember $\{\mathrm{H}$ pantomimes writing the word Apple over and over $\}$.

M: So you think about the meaning while you're righting it too?

H: Yeah.

M: I see. Let's see $\{\mathrm{M}$ looks at study log again $\}$. Oh, (you read, you do) you read English books too?

H: Yeah, I usually don't like to read books because I don't like reading in English. But (I think) I feel like I need to read something so I started reading Harry Potter series because that's for like children, right?

M: Yeah, kind of.

H: yeah, kind of.

M: So, you started reading English books (to) mostly to improve your reading skills?

H: Yeah. 
M: So if you were reading for fun, would you probably do that in Japanese or in English.

H: (Um). I think reading in English is better for me, so I wanna read in English. And actually this book is number two and I already finished reading number one last week.

M: Let's see. On Monday you watched a Harry Potter movie, but you didn't think that was helpful because it's British English.

H: Yeah. British English is hard for me to understand.

M: I see. And then Tuesday this looks like (kinda) maybe homework stuff.

H: Yeah.

M: Textbook for ESL. And you're taking an Economics class right now?

$\mathrm{H}$ : Yeah, so this is just for my study. This is homework.

M: Besides what you put here. I think this book is interesting to me \{pointing to reference of Eitango book\}. And I think it's interesting that you use TV shows to study. (Um) and that you read in English. Are there any other books that you brought from Japan? Study books or anything like that you use sometimes? H: (Um) I don't really use books. I don't bring any books from Japan. M: Ok.

H: When I was in Japan, I studied with Skype (like on Skype). I found (like) Japanese and English exchange website and then I kinda put (like) my nickname and email address and (like) skype account. And then I found some friends overseas and I talked to them in English. 
M: Did you do typing or speaking chat?

$\mathrm{H}$ : I started from typing and then a girl, like my friend, suggested me get webcam and mic. So, I got it. And then I started to seeing the faces and talking. I first start from typing and then move on to speaking.

M: That's good. How did you come up with that idea?

H: (Um) I thought I really (should like) I need someone to speak. (For like) I was thinking about studying abroad for a while. And then I felt like I need to (like) actually speak. So I went on research and then some people said that skype studying is really helpful.

M: Ok. So you were just searching on the internet about how to study. H: Uh huh.

M: And what about this book, the TOEFL book from Japan. Where did you get that? Or who told you to buy that? Or

H: (Um) I think this book is actually pretty common.

$\mathrm{M}: \mathrm{Oh}$, is it?

$\mathrm{H}$ : And this is a best seller for TOEFL test.

M: So, you don't know how you heard about the book? You don't remember?

$\mathrm{H}$ : I saw the ranking on the internet, and then it ranked as number one for TOEFL section.

M: Cool. Good stuff. 
M: Ok, that's good for that. Then I'm just going to ask some general questions about your experience studying English. And let's get started with that, so we can get you to the gym.

$\mathrm{H}: \mathrm{Ok}\{\mathrm{H}$ laughs $\}$.

M: So, do you remember when you first started studying English?

H: Uh, for Japanese people, we have to learn, like start learning English as a second language from middle school. Yeah, so I think everybody in Japan started around that time.

M: What were those classes like? Do you remember them at all?

H: I do, but they were not really helpful at all. I didn't like English at the time. M: So, can you give me an example of some of things that you did in that class? H: I learned how to write cursive and I learned some easy words. But the teachers were not native, of course. And then, they didn't speak very good English at all. M: Ok. And usually when we talk about language you talk about different skills like reading, writing, speaking, listening, grammar, things like that. What were those classes focused on, do you think?

H: Basically grammar.

M: Grammar?

H: Yeah.

M: And you said you practiced cursive.

H: Uh huh. And then reading. Easy books. 
M: Do you feel like after those classes you had learned anything? You said you learned some easy words.

$\mathrm{H}$ : Yeah, like apple, orange, those kind of easy words. And especially for me, I was like really bad at English. So I didn't really focus on that class.

M: What about the teachers in that class. You said they weren't native speakers, so they were Japanese. And you already said that you didn't think their English was that good. But I'm wondering about the role that the teacher played in the class. Did the teacher just lecture to you the whole time, or did the teacher get you involved? And students did a lot of talking too?

H: They made us like read textbooks out loud, but that wasn't really helpful.

M: I see. Um, what about high school? Was that experience similar to middle school, or was it different?

H: Um, high school. We mainly learned new words, and we didn't really focus on grammar. So we had like words test every week. And then we had to memorize like 100 words per week. It was really hard.

M: Was that teacher Japanese as well?

H: Uh huh.

M: Did he also just mainly lecture or did you work in small groups with other students, or?

H: He mainly lectured. Yeah.

M: Did you think you learned very much in that class?

$\mathrm{H}$ : Not really, but I memorize a lot of words, so that was really helpful. 
M: Ok, so you improved your vocabulary? Did you enjoy (that) English classes at all?

H: Not really, until my high school 2nd year, I went study abroad kind of like short term. Only a month during summer vacation. And then after that, I kinda realized that English is fun, and I need to learn.

M: Where did you study abroad?

H: America. California. UCLA summer program kind of thing.

M: That sounds like fun.

H: Yeah.

M: Um, in junior high or high school did you ever go to (like a) I think you call them juku, a cram school?

H: Uh huh, yeah, yeah. During junior high school I went to cram school to get into high school.

M: Did you study English there or just other subjects?

H: I studied English, mathematics and Japanese.

M: And what was studying English like at the juku?

H: Juku was mainly focused on grammar and reading and listening. Cause we had like listening test on the exam, the entrance exam.

M: Did you find those classes to be helpful?

$\mathrm{H}$ : Yeah, those classes were really helpful, but really intense. And we had to study 5 hours English per day during summer vacation.

M: So can you sort of describe a normal day in cram school? 
$\mathrm{H}$ : So, if that day is English, I need to sit in the classroom for like 2 hours and listen to lecture. And then he first, maybe like 20 minutes, he has vocabulary test. We had English class twice a week. So first starting from the exam (like) the word test, and then next he moves onto the grammar check, and then we kind read some articles and answer the questions and stuff. But he was not native speaker either.

M: Was he a good teacher?

H: He was really scary, but I don't think he spoke good English at all. He just knows how to get us into high school.

M: So he was strict?

H: Uh huh. Really strict.

M: It sounds like, but you can correct me if I'm wrong (it sounds like) it wasn't very fun?

H: Yeah it wasn't really fun. And then, I had to study and take good score on the word exam because he like gets really mad if I don't memorize 100 words for a week.

M: So maybe that was some motivation then.

H: Uh huh.

M: Don't make the teacher mad. Motivation.

H: Yeah.

M: Um, and then. At Waseda did you take English classes?

H: Yeah, it's mandatory. You have to take.

M: So you have to take like two years of English classes then? Or how much? 
H: Yeah, two years of English. But I'm actually a sophomore now, and so I only went to Waseda for first one year. And then came to PSU from this March.

M: Ok, what were the classes like at Waseda? The English classes.

H: Actually, my professor studied abroad in the US. He's Japanese but he's writing some New York Times articles and he's pretty fluent in English. Yeah, so, I was really lucky and I learned a lot from him.

M: Can you sort of describe what those classes are like?

H: Uh huh. So, he made us read some article from like New York Times or he showed us some youtube videos in English, and we listened to some famous music in English. And then we guessed what the lyrics mean. So, it was pretty interesting. Yeah, and then he made us do some presentations in English. And it was more like American style lecture.

M: (Ok, so) when you say American style, how is that different than Japanese style?

$\mathrm{H}$ : Japanese style is mainly like teachers talking and students are really passive. But in American style we get up and actually talk in class and students are really active in class.

M: And then, at what point did you start practicing English on Skype? When did that happen?

H: Uh, the last year of high school. Until then I couldn't speak at all. Yeah, like when I went to UCLA, the second year of high school, I could say like: "Oh, hi." And I got really nervous. And I didn't make any friends at all and I felt really sad because I spent so much time studying English at cram school and junior high school. 
Even though it wasn't very fun, I thought I learned a lot, because I know a lot of vocabulary and I know how to write. And listening. But the actual native speakers speak really fast, and their pronunciation is different from Japanese speaker's English.

M: And then you decided to come to the US, obviously, you're here in Portland. What made you choose that? Why did you decide to come to Portland?

H: Because Portland has starting from March program, and I have boyfriend, but it's related to why I came here. Because I wanted to ask him like "how's Portland?" because I really wanted to come here. And then so we could kinda get close to each other. (Just because university program had, like) PSU started from March, I mean at Waseda's program. Other than PSU it has only like Oregon Univeristy, University of Oregon starting from March program.

M: So that's why the timing worked, but I'm wondering why you thought it would be fun to come here or why you chose to study abroad at all.

H: Because I actually studied some English on skype and I was kinda able to speak in English and communicate with people. So I felt like maybe I want to study abroad and see how well I can do in the US.

M: Good. And what do you think so far?

H: After I came to the US I kinda realized I don't have enough English ability to live in the US. I mean, I can do like everyday conversations and stuff, but I can't really talk in group. I can do like 1 on 1, but I can't really be in the group discussion or group conversation and stuff. It's really hard. 
M: So, did you do anything special before you came to the US to get ready to be here, speaking English all the time? Did you study extra before (like the months before) you came to Portland.

H: A month before? (Maybe, I was) at the time I started to watch Gossip Girls. And then I was like learning a lot of everyday conversation, slang, and...

M: So you thought that might be helpful.

H: Uh huh.

M: And then you're taking English classes here. What do you think of those so far? H: English classes? You mean ESL?

M: Yeah, ESL classes.

H: ESL classes are not really helpful unfortunately.

$\mathrm{M}:$ Oh, really?

H: Yeah, cause they just make me speak in English, and then we have some discussion between Japanese people but they are not really active in the class, of course, because they are Japanese. So, we end up like being silent and saying nothing. And teachers are like "Talk, talk! Say something!" \{claps her hands \}. Teachers is native. And students are Japanese so we kept like really silent and say nothing.

M: So there's a lot of group discussions then, it sounds like.

$\mathrm{H}$ : Yeah, and then, maybe like pronunciation work. And then like, for example, so read the first sentence from that person to that person. Yeah, so and teacher will ask 
like "how do you pronounce this word?" And the a student will pronounce that word and the teacher will correct.

M: How do you feel about your English ability compared to the other students in those classes?

H: Um. Maybe other students say that my speaking is better than most of the people in the class, but I personally think that my grammar is not as good as them.

M: Are the ESL classes here, as far as difficulty goes, are they too easy or too hard? H: They don't really do exams and stuff, they just grade us based on our attendance and writing paper and presentation. So I would say it's kind of easy. Because I can choose any topic.

M: (Does this) you said at Waseda you have to take two years of English, right?

Does this count?

H: Yeah, this counts.

M: So you took one year already, and after you return to Waseda you're not required to take any more?

H: No.

M: Do you think you will? Or do you think you're going to be done?

H: I'm going to be done.

M: Why's that?

H: Because school English is not actually helpful.

M: So will you continue to study in a different way, then? 
H: Uh huh. By myself or maybe I'm going to find some other people to skype on the internet, or maybe I'm just gonna keep in touch with my friends that I meet here on skype.

M: That's good. Um. So that's basically all the questions about describing your experience that I want to ask. Now I just want your opinion on some things. So you can just tell me whatever you think.

H: Ok.

M: (This one is) The first one's just, in all your experience studying English, so you know, junior high, high school, cram school, college, being in the US...what have you found to be the most effective things? Best ways to study?

H: Skype.

M: And what's been the most fun?

H: Maybe studying abroad, and like actually talking to people in person.

M: And what do you think was not effective?

H: My junior high school. We really didn't learn anything.

M: Has there been anything recently that you felt you had to do for class, maybe in the last couple years that you thought was just not very effective?

H: Maybe like ESL class discussions.

M: The one here? Because the people don't talk?

H: Yeah, people don't talk, so we just kind of wasting time.

M: Ok, how about. (I'm going to ask you some questions about) let's pretend next week you have a test. And it's not for school, it's not homework or anything like 
that. Just, you're going to have a vocabulary test next week. And you can study however you want to for it. There's not teachers to tell you how to study. There's not teachers to tell you how to study. You pick. How would you study for that test? H: Vocabulary. I usually like to write the same words until I remember. So I would do the same thing. M: Do you remember where you learned to do that?

H: Um. It's just my way of studying. I did it when I was in cram school, so the teacher doesn't get made. I had to memorize and I had to be able to write, to spell it. M: But the teacher didn't tell you to do that? You just...

H: Some students are really smart, so they can just seeing the word and memorize at the same time.

M: Did you ever use flashcards?

H: No, I don't like flash cards.

M: You don't think they're effective or just too boring?

H: I need something active, like to write and spell every single (word) letters so that I can actually memorize like "r" and "l""s difference. Or maybe like two "t"s.

M: What if you were studying for a speaking or listening test?

H: Maybe I'm going to keep watching some movies that I like in English.

M: Yeah, you said you used TV and movies. That's good. Um what about to practice reading? 
H: Um. I'm just gonna find like some easy book to read. And then I'm going to make myself like used to reading something in English. Or if it's kind of like a particular test, then I can just buy the book for that studying book, based on the test.

M: What about for writing? Especially like spelling, because English spelling can be difficult. It sounds like maybe when you're doing vocab, you practice writing and you're kind of focusing on spelling while you're doing it.

H: Yeah.

M: Do you ever use textbooks from your classes to study outside of class?

H: Um.

M: Not for homework. But it seems like sometimes you're studying English just to improve your skills. Do you ever use textbooks for that or do you mostly just use textbooks to study for your classes?

H: Yeah, actually I don't really use for myself, like self-studying.

M: Ok, and why not?

H: Um. Because I'm not really interested in them, so that makes me not feel like studying.

M: So not as much motivation?

H: Yeah.

M: (I'm wondering) for my thesis, my research, I'm especially interested in things like using TV shows or (you know). I'm not as interested in when people use textbooks to study outside. So you have a lot of stuff that's interesting for my 
research, so I'm wondering if there's anything else you can think of that you've done in the past that we haven't talked about yet.

H: TV shows?

M: TV shows, or the way you practice by writing words over and over again. Are there any things that you do for studying English that we haven't talked about yet that maybe you think are interesting?

H: Actually, (like these books) these Japanese company's English (like) vocab book usually have some CD. And then for example it's apple, and then ringo \{Japanese word for apple\}. It's like the music MP3, and so that I can put in iPod. And then just listening them like over and over and over.

M: Ok.

H: While I'm commuting or maybe I'm doing nothing. I can just play it over and over, so that I can like remember how it's pronounced, and (like) Japanese meaning. M: Ok.

H: Yeah, so I think it's really helpful. And also I really like to listen to music in English. (Like) I listen to Michael Jackson because of my parents. And I listen to Lady Gaga lately. And then I like to go onto youtube. And youtube has (like) some lyrics and the song at the same time, so I can just watch it and listen and (like) understand what she's actually singing in the song.

M: I see.

H: Yeah.

M: That's good. 
$\mathrm{H}$ : Yeah, that really helped me to like speak, because I know like how the word is pronounced in (like kinda fast) fast paced. She speaks like really fast in the song. M: Ok. So you think that helps your listening skills. That's good. So let's see. We've got TV shows, music, and you've got (like) CDs that come with these books. H: Uh huh.

M: So you would listen to those on your MP3 player (like) when you're going on the subway somewhere.

H: Yeah, in Japan.

M: Um. (So a lot) it seems like a lot of your study is about listening and speaking. H: Yeah, especially after cram school. Until I get in high school and especially until the study abroad, like kinda short term at UCLA, I was doing just like on paper kind of study. Like Japanese kind of study.

M: Do you ever just specifically study grammar these days?

H: Not anymore. So my grammar is getting lower and lower.

M: Really?

H: Yeah, I feel that.

M: If you were to study grammar. How do you think you would do that? H: From now? I don't really feel like to go back to the old books that I used. So maybe I'm just going to try to listen to people, native speakers, and what they are actually talking. Cause I feel like sometimes native speakers don't use the grammar that we have in the book. 
M: Sometimes books can be a little more formal. We speak different casually. I think that's true.

H: Uh huh.

M: Well, I think that's pretty much all the questions I have. Before we finish, is there anything else you can think of? Take a minute or so. If you come up with something, good. If not, that's ok.

H: Um, maybe it's not supposed to be on thesis, but I think it's very interesting. But some people say that my English is good (like) Japanese people always say that "oh, Marina's English is the best" and stuff like that. I don't really personally think that, but (uh) because the other Japanese people think my English is good because I have boyfriend. American. Yeah, but actually personally I think with my boyfriend I don't really like talk that much. Like we text each other a lot, but we say only like simple things like "oh ok, let's meet at 3:30" or something.

M: Ok.

H: So we don't really talk that much. But like with friends, we come up with new topics every time and we actually have long conversations. So I don't think have an American boyfriend doesn't help that much, personally.

M: Yeah.

H: Cause, as long time we been together like the less topic we come up with. So I don't feel like boyfriend is actually that helpful.

M: Do you think at the beginning you guys talked more and that was helpful though? 
H: Yeah. That was really helpful at the beginning, but not very much anymore.

Cause I kind of realized that the same person use the same kind of like (you know) words and same kind of like expressions every time.

M: Yeah.

H: So first I learned a lot of like (his) his kind of talking style.

M: I see.

H: Yeah, but when I was on Skype, I learned like one particular person's talking style, you know? Like some people speak a little bit faster than other people or maybe like some people use like "oh my gosh" a lot. Or maybe some people use something like "like, like, like" and then I learned oh this person use like a lot. Or (like yeah) the longer I talk to the same person, the fewer things that I learn. M: Ok.

H: Yeah. So of course I enjoy hanging out with the same person, but yeah. I think the talking to many people and making new friends and hanging out with groups improve my English.

M: Ok. Um. With most of your friends, and with your boyfriend, do you usually speak English? Or are there some people you speak Japanese with a lot, while you are here in the US?

H: Um. Maybe some people are trying to make me speak in Japanese. But those people are not really close to me. Like he just wants to learn Japanese, so that is why he is talking to me in Japanese. So we don't really hang out each other. But actual 
friends, he or she can speak (English, uh) Japanese. They are trying not to use Japanese because I am here studying English.

M: Ok. Cool.

\section{Follow up communication}

M: First of all, I wanted to say thank you again so much for your help with my thesis research. I have one more question I wanted to ask: If you were giving advice to someone who is just starting to study English, what would you say? Can you think of 3-5 pieces of advice? Thanks again.

$\mathrm{H}$ : Memorizing words and grammar are the most important thing, in my opinion. (you should use some books and learn the basics)

then, you wanna improve your speaking skills.

however, speaking skills always comes after listening skills.

because, if you can't hear and understand what the person is talking about, you can't respond.

also, if you dont know the sound, you dont know how to pronounce it.

therefore, watching movies in English with subtitles, or watching news online with subtitles are efficient.

then you are familiar with the sound of english, so it will be easier for you to read and write in english! 
1st, memorizing words and grammar (visual)

2nd listening and speaking(hearing)

3 rd reading\&writing

in this way, you are not stuck with Japanese sound like English, (maybe far from the perfect english sound,) but you can at least prevent yourself from speaking with heavy accents.

\section{Ichigo}

\section{Interview transcription}

M: Ok, so first I want to talk just a little bit about your experience in Japan studying English. So, do you remember when you first began studying English?

I: Yeah, I think when I was like 6 or 7 when I started going to elementary school. I went to learn (um) a native speaker who married with Japanese man and she lives near my house. So I studied a class with some my friends. That's when I first studied English, but not grammar or something like that, just speaking.

M: That was like after school?

I: Yeah, after school. I think after 3.

M: After 3? How many days a week did you do that? 
I: Once a week.

M: Just once a week? And so, you were pretty young. (So was that) you're parents wanted you to do this, or?

I: Well, yeah. One of my friends went to that school, so she invited me or something like that. I went to there, and it sounds fun, so.

M: It was fun?

I: Yeah, it was fun.

M: How long did you do that for?

I: I did that for like (um) before I went to junior school so maybe like 5 years. Until I was $5^{\text {th }}$ grade or maybe before $6^{\text {th }}$ grade, I don't remember.

M: So, I know that was a long time ago, but can you describe how class usually was?

I: It's just easy because we don't know English that much. We started from like $\mathrm{ABC}$ and A, apple; B, bear. Like simple things like that. And we sometime do games and if that game (like) there's like some cards. We have a game called card time in Japan, there's a lot of pictures and word like apple, bear or something. And we take it. And the most who take it, we had like candies or something like that. M: How do you take it?

I: Oh no, (it's just like) it's all on the floor, and like teacher reads it. But sometimes she say like "a" but there's not only like one word for "A", so the fast one. And if you (like) hit the wrong one you can't do it the next time.

M: So she'll say like “a...apple” or something.

I: But there's like "airplane" too. 
M: Ok, so you have to grab apple first. If that's what she says.

I: Yeah, it's like a game like that. And the most one who can get like a lot of candies.

M: That sounds like fun. It's good motivation for kids, cause kids love candy.

I: Yeah.

M: So, that was fun. You liked doing it because it was fun?

I: Yeah.

M: At that time were you studying English in school or not yet?

I: Not yet.

M: When did that studying start?

I: At school?

M: Yeah.

I: Junior high school.

M: What were those classes like? Do you remember?

I: It's same. We started from like ABC, but we only did that one week. And (um) then we studied like "I am" and "are you?" and like the easy sentence. Then after that we study like happen and those things. And "ing" and stuff like that.

M: (So thinking) when we think about language we talk about different skills. Like reading, writing, speaking, listening, that type of thing. Which ones were those classes focused on?

I: Grammar. Just grammar.

M: Ok. 
I: It depends on junior high school, but my junior high school had ALT teacher (and he comes) but he only comes like one or twice a week. It depends on his schedule. So we don't do listening/speaking that much, and he's the only teacher. So it's a little difficult to do speaking. And we don't do that much because it's a Japanese teacher, so we focus on grammar.

M: So the ALT was American or British or Australian or something?

I: Yeah. Mine was American.

M: In high school did you also study English.

I: Yeah, cause I choose English course. So I study English a lot. But it's the same, a little bit as the junior high school. We focused on grammar a lot and (like um), well sometime reading, but almost grammar. And we (like) ALT teacher, because we had American English course, but there was only like two or three teachers. And one is from and America and one is from Canada. But, we have that class like three times a week, because it's English course, but most of the class was focused on grammar. M: Ok. (Did you) during junior high and high school did you study English outside of class at all? Or only at school?

I: (Um) Only at school. But when I was in high school I home stay one month in America, at Michigan. So that's the only one. But except that, only at school. M: (That was) what were you doing when you were in Michigan? Did you go to any school? 
I: Oh no, just homestay. So I went there for like one month. (Um) on summer vacation in Japan and here was summer vacation too. So I just stayed with a host family, and I spent time with them too.

M: Did you study English while you were in Michigan? I mean did you kind of practice a little bit?

I: No, just speaking.

M: Just speaking. Ok. And then (let's see) your university in Japan is in Chiba area?

I: Yeah, in Chiba area. But near Tokyo.

M: Near Tokyo?

I: Yeah, very close.

M: And what year are you there?

I: I am second now.

M: Second year? Have you taken English classes at University there as well.

I: Yeah.

M: And what was that like?

I: (Um) about the same. Like most of the teachers are mostly Japanese, so we focus on grammar. But we have ALT teacher and he's from Canada too. And I have the class two times a week. And on that class we focus on speaking very much. Oh no, I forgot, three times a week.

M: Three times a week with the ALT? 
I: No, he has two class, but we have twice a week. That means (four) four days a week. (Because he has) I take his class, two classes and they both have two times a week.

M: So you took some classes with Japanese teachers that are mostly grammar, and some with the ALT.

I: Yeah, and one class is focused on reading. And the teacher is the ALT teacher, native speaker. But the grammar focus is all Japanese teacher, and we have a lot of that. But we have to take it.

M: Yeah, it's required?

I: Yeah, it's required.

M: What kinds of things do you do in those classes? The grammar ones?

I: We have a textbook, and there's a paragraph and we have to read it. And we have to learn the vocabularies, and there's some questions like true and false. And we have to do it as homework. And in the class the teacher tells the story about us and tells how the grammar works in that sentence. And after that we have to do the true or false questions or like what's the topic. If it's like a story or something, what did the main character think when he felt something. Or something like that.

M: So it's usually content questions? The questions aren't about grammar, it's about the story.

I: Yeah, about story. One class I did was like that. It depends on the teacher what we do. One teacher we have textbook so she just use textbook. So that textbook was like that. 
M: What about the classes with the ALT? The speaking/listening ones, what do you do in those classes?

I: (Um) Also we have a textbook, and there's some words in it. And we have to learn those words. And we test them sometimes. And (um) we have three books in that class. And one book is for reading. And there's a short story. First we listen to the story, and then we do the questions. And (um) then we check the answer. And after that we learn the vocabulary. And without looking we separate into little groups. And there's definition about the vocabulary so we read the definition and the others answer. And we do that every week. There's a lot of vocabularies on different pages, so we do that every week.

M: Do you work in small groups a lot in those classes?

I: Yeah.

M: And sometimes you're asking each other questions? Like you said somebody reads the definition and somebody says the vocabulary word.

I: And sometimes you can do hint. Yeah, and we can't choose like friends. The ALT teacher says $1,2,3$ and 1,2,3. Yeah, and like that.

M: Yeah. I know that. Is there ever times when you break up in small groups and just talk to each other in English? Or is it usually, you're doing some kind of activity. I: Well, I think it's kind of activity. And we make flashcards in that class, and we test each other. The flashcards, you make it yourself and you write the words in the textbook or the reading that you don't understand. And you can write the meaning and after that we do like flashcard test and how many you can remember. And you 
have your own one, and you switch each other. The other people read Japanese, you have to say English, or if it's the opposite. They will say it in English and you have to answer it in Japanese. We took that little quiz.

M: With vocabulary mostly?

I: Yeah. But (well) everybody has different levels. So you don't have to write everything. You write it yourself, the teacher trusts you. Just write the word you don't know. But every day we have to write at least 10 and the maximum is 20 if you don't know a lot of words. But that's all homework.

M: Ok. What about the class for reading?

I: Oh yeah. Reading is like same. We read and there's a textbook and there's like a small paragraph in each page and we read that. First we listen to that and then we take the quiz. And after that, after we listen, we check the answers. The teacher writes the answers on the board or something, and we check the answers. And that class we have a homework and we have to read English books. There are some in our university's library. It's not that hard (there's some) I forgot the publisher, or the company. Thomason, or something. It's like a easy one. And there's some levels and you can choose the stories you want to read. There's like fantasy or fake stories, or about a person who really is like Beckham. It's just a short book, and you can choose from the library, and that's a homework. And you have to read at least two, but I like reading so I read four a week.

M: You have to read two per week?

I: Two per week. 
M: How long are the stories, usually?

I: Well, it depends on what you choose. Cause there's like level 1 from level 5. Level 1 is like only twenty pages or something, but level 5 is like 100 pages or something, so it's really long.

M: I see.

I: People who don't like reading choose two. But I mostly choose like three and four, because I like reading.

M: (So these classes) Let's start first with the classes that the Japanese teachers taught. Do they do a lot of talking during the class or do they talk a little bit and then the students talk a little bit?

I: No. Actually, when I was in junior high school they didn't talk that much at all in English. They just teach grammar and do the questions in the textbook. And if you don't know, you can ask. And we go along together. We don't do talking that much. M: So usually the teacher is just teaching you?

I: Teaching, and then we listening. Listening or writing.

M: So that is true of junior high, high school, and university? Or were some of those different?

I: (Well, I) because normally, most of the Japanese teachers are like that, but one teacher in my high school, I had language course and she was really good at English. And she liked talking so much (so, and how she thinks) she thinks talking is more important too. She did a little bit of talking. If some students tried to speak in Japanese, she said "No Japanese." So, that class was interesting to me, because other 
Japanese teacher doesn't do a thing like that. (But she tries) if you have a question you have to ask in English. And when she teaches, she teaches in English too. I don't know why.

M: So did students to speak in that class?

I: A little bit than other class, I think.

M: A little bit more. So it wasn’t always just her teaching you? Sometimes you got to participate.

I: Yeah.

M: And what about the classes with the ALT? It sounds like you did small groups. So that's a little different. And sometimes the ALT also just teaches? Or?

I: No. He always (like, um) is talking more than grammar. We don't do grammar that much. But one class, actually it's the same teacher but it's a different class. It's a speaking/listening class, so every week we worked in a little group, four or five people. Also, he hands out like a paper and it's about a variety of topics. But once we did like about taking a trip abroad. And we asked our other group members "have you ever been to another country or where do you want to go or what airplane company do you want to use?"

M: That's funny.

I: Yeah. We do it first in a group, and then we have to ask another person not in your group. And you have to like ask at least 5 people or something like that. We do that kind of talking work and we try to talk to everyone in the classroom like that. So it was really interesting. It's not like just sitting and just writing. 
M: Ok. So you thought those classes were more interesting?

I: Yeah.

M: What about the ones the Japanese teachers taught? Did you still think those were interesting? Or did you not like them? Or?

I: Which ones?

M: The ones that were taught by a Japanese teacher. The ones that were more like grammar. Was that still interesting? Or not really?

I: Well not really. The first junior high school like "I am Rachel," or "I am Lucy," or "Are you ok," and "I am fine." It's too easy, and I don't know why we're doing it at school. So it was kind of boring and...but maybe we have to teach it, and Japanese teacher has to teach it, so. But it was not that fun.

M: Did you ever study at a juku? At a cram school?

I: Oh yeah.

M: When did you do that?

I: I did that when I was in junior high school before when I was in second grade. Most friends went there so. It costs money, so I didn't want to. And because I don't like studying. But there was a nice juku a little near my house. So I went there almost two years before I go to high school, because I have to have a test, and exam. M: Did you study English at the juku at all?

I: Yeah, I did.

M: And how was that? 
I: It's quite the same, like the grammar. We focus on grammar, and there's a textbook so we do that for homework. Well, it's (I think) more quiet because it's a juku. Well, it was a class but we do it by ourselves. Like if we do the homework, we'll check it together. But after that the teacher will say "do this and this and this," and we do that. And if you have a question you can ask. But we don't do it like a class sometime.

M: So, besides the juku and the normal high school, junior classes, did you study English outside of school at all during that time? Or only homework and school? I: Well, only homework and school. And sometimes (I watched) I listened to CDs. You know the Eiken test, or something like that? The TOEFL test? Sometimes I wanted to take the test, so I listened to them. But only sometimes. Not every week, only the time when I have the test.

M: (Did you) How did you find out about those? Did someone recommend them? Or?

I: No. When I was in high school I was in English course. So every (not every, but) my teachers tried to say good for taking it. And some of my friends took it, so I tried to too. It's like everybody takes it, a lot.

M: So you went out and you bought those CDs by yourself?

I: Yeah. And I listened to it and I took the test. And if it's like TOEFL we have a score, and I wanted to get a high score so I studied.

M: So, those one's were CDs. So mostly listening practice?

I: Yeah, I think. 
M: (Um) And then how long have you been in Portland now?

I: One month.

M: So you've had some classes. Some English classes.

I: Yeah. Yeah.

M: What do you think of those so far?

I: (Um) Grammar and Writing, I'm in level 2, but I think it's a little difficult. The thing we're doing is not difficult, but the word like "process paragraph" or "simple past," those words are difficult for me. (And um) I know it in Japanese, and I know the meaning, but I can't match it in Japanese and English. So it's a little bit hard. And the teacher asks us "write it in past sentence" or something like that. And I don't know the meaning, so it's difficult.

M: I see. (So you've taken) which classes are you taking so far? You took a grammar course.

I: And reading, level 2. And speaking/listening, level 3. And reading level 2 (is I think it's) we do like a textbook, like a little paragraph. (And we read that and we, well he) My teacher thinks that reading you need a lot of vocabulary if you want to read good. So we focus on vocabulary very much, but I think some of the words I know and I studied already. So it's kind of a little easy for me. And reading is not as hard for me as grammar. And speaking and listening is level 3. And we do speech like I talked about. And we have to interview people who has a work. We have make up speech, but we can't write like everything we want to say. We have to write only like key words or something like that. So I think it's the write level for me, cause it's 
not that hard and it's not too easy too. Talking in front of people without preparing, like without writing everything, I think it's good for practicing English. In that class we do another interesting thing. We listen to a CD and it's like (um) about really a difficult. One day the topic was about shyness. And that writer thinks that shyness comes from genetic. It's about shyness and we have to listen to it and write down keywords. And if you write everything you can't write the main idea. So we have to write it in marks or something. You know we have to write down topics, important thing. And after that we take a quiz and we can see the paper that you wrote. But you can't listen to it again and you can't ask your neighbors. So I think that's a good practice.

M: I see. So you take a quiz, but you get to look at what you wrote down.

I: Yeah, so you have to write down fastly. And you can understand that key sentence or key word. And we have to the quiz and they are graded, so.

M: So it kind of helps you look for the important things?

I: Yeah, and it's a practice to take a note fast in English.

M: And do you like that class?

I: Yeah, I like it. I don't like the speech, but I think what we are doing is important. M: And have you been studying much outside of class since you've been here?

I: No, just (I have) I will take the IELP TOEFL on the $19^{\text {th }}$ so I got a free CD from the learning center in UCB, so I just did only that.

M: Just studying for the TOEFL?

I: Yeah, studying for the TOEFL. 
M: I see. (Let's see). So you told me the reason you want to study English is that you want to get a job at the airport, right?

I: Yeah.

M: Because it's close to home?

I: Yeah.

M: Did you anything to prepare before you came to the US? Probably before you came, a couple months before you came to Portland, you know you were going to come, right?

I: Yeah.

M: So did you study extra English before you came to get ready?

I: No, I don't think so. I just studied a little bit grammar. Well, sometimes there's a TV program in Japan, you can learn English. There's a channel in Japan that we can learn a lot of other countries language. I tried to watch those a little.

M: What channel is that?

I: It's 3 where I live, but it's a little different where my grandma lives. It's three, it's NHK.

M: Oh yeah. I know NHK.

I: They do a lot of language radio and TV. So I listened to a little bit of that.

M: So I think we've talked about a lot of what you've done. We talked about the class that you had with the woman (who was). Was she American? The woman when you were young.

I: Yeah, she's American. 
M: So we talked about that, junior high, high school classes, university classes, cram school.

I: She's American and she just live in Japan. So she speaks English.

M: Out of all of those classes, what have you thought was the most fun?

I: Well, actually what I took when I was young. It was not like learning, so it was fun. But after that I studied with her again when I was high school. Not long, but when I had the big TOEIC test, I studied with her again. So (well) I don't know. Everything has good thing and bad thing, I think. Well the study I did at university class and the ALT teacher, the class that we separate in group and talk to other people, I think that was interesting. Because we can speak a lot. Every week we change people. So I think it's a chance to make new friends and talk to everyone in the classroom. Because I only had like two friend for the first time. It was really fun to talk to other people.

M: What do you think was the most effective, the best English study? Where do you feel like you learned the most?

I: Well, I have two place. Here, now is very good. Well reading is a little easy, but grammar and listening speaking, studying here is really good. Because teacher is native and most of the students are from different country, and I don't speak their language. So we only can speak in English. So it's really good because I only speak in English. The other one is studying with the American teacher that taught me when I was little. I studied with her a little bit before the TOEIC test and I think that was good too, because she is American and she speaks English well. Actually, I got a 
little high score after I learned with her. And also her husband is Japanese but he's really good at English. And what she can't teach, because she doesn't know every Japanese. The test is like EIKEN, and it's English test but it's made for Japanese. Because the directions are in (like) Japanese. And he did it for me too. And did it too and he has (like) really good grade on that, so it was really good for me. She said that her husband studied English when he was young. And how he studied it was he tried to learn American dictionary, and after he remembers the page he rips it. He studied like that. And he's really good at it.

M: Was there any kind of activity or exercises that you did with the American woman that you thought were really effective?

I: No. She just teach me English. We didn't do like such a activities or anything like that?

M: Did she teach you how to study by yourself at all? Like "practice like this" or something like that?

I: Oh yeah. Well, actually not she, but her husband did. And yeah, if you want to study English you have to like listen and (like) if you don't want speaking in Japanese make your English worse. Try to speak in English. You don't have to speak everday, but try to speak like one day, one hour or one day two or three hours or something like that. Even with your family. M: Even if they don't understand? 
I: Well, my mother understand a little bit, but my sister doesn't. But my mother can speak a little bit, because she studied abroad a little bit when she was in university, when she was younger. So she can speak a little bit.

M: Alright, I have just a couple more questions for you. I just want you to give your opinion on the best way to study for certain things. So let's say that in two weeks you are going to have a quiz on vocabulary. It's not for school and your teacher doesn't tell you how to study or anything like that. It's your choice. What do you think the best way to study for vocabulary is?

I: Well, it depends on how it's difficult. If it's not too difficult for you and you know the words you can just write a lot and remember it. Because if you know the word and meaning already you don't have to study very much. I think it's a lose time. If you know the word, write it and write it a lot. But if it's too difficult for you and you've never seen that word before you should write it and if possible make a flashcard or something and check it every day before bed or something like that. M: So sometimes you do flashcards?

I: Yeah, I do flashcards a lot.

M: Where did you learn to do that?

I: Well, in Japan many students do that. I don't remember how. There are a lot of flashcards and they're not very expensive. They like one dollar, so I think that's a good way. And you have to see it every day. I think that's important. So I made a lot of flashcards, but sometimes I made too much flashcards and I don't know which one is which. 
M: Do you think that's something you learned from a teacher or other students?

I: I think maybe teacher first. My junior high school teacher, she was a woman, but she only did one year. And she was a nice teacher too, and it's really easy to know her teaching stuff. And she taught me, I think.

M: What if it was for a speaking and listening exam. And you get to choose how you're going to study for that. What do you think the best way to practice is?

I: Well, I think it's difficult but listen to some CD or in textbook. Because I have some, and some textbook I think has CDs. So try to listen and figure out. Nowadays you can search websites or something like that. And this website my teacher told me, and it's really useful, it's "Breaking News English." I think I told you. But it's really useful. You listen and you write some words in it and do questions and the answers are at the bottom. And you can check after you do it.

M: It's called breaking news English?

I: Yeah, and if you type it and google it, I think it will come number one or number two.

M: Have you used that before?

I: Yeah, actually it's extra point in reading class. They're not quite difficult, they're quite short and while listening you have to do some questions. And I think it might be helpful for people who don't speak English as their language. If they speak good English it might be too easy.

M: Have you ever done anything like watch English TV shows to practice English, or anything like that? 
I: Yeah, actually I like watching TV and movies. You know in Japan, there's a lot of American famous movies like Harry Potter and Lord of the Rings or Pirates of the Caribbean or something like that. And they play it in English but the words come down in Japanese, because they don't understand it. But I try not to look at the Japanese and try to listen to it. And now at my homestay they like to watch movies very much. And I watch it, and of course it's American DVD, so they don't have Japanese under it. So I watch like 3 or 4 movies and I watch TV every Friday. There's a show I like, and I don't know every meaning but I try to learn English. The show is fun, so I'm watching.

M: What show is it?

I: Do you watch Disney channel? It's Jesse. It's on every Friday.

M: Oh no. I don't know it.

I: Ok. It's so fun.

M: Do you think that helps you with your English?

I: I don't know. Maybe. But I watch because it's fun.

M: Yeah, yeah. I see. What about for studying grammar? What do you think the best way to do that is?

I: Grammar. Well, I think like looking at your textbook and try to learn it. And if you don't understand it you have to ask someone. But if you understand it, just look every day. Grammar is kind of like a little bit of vocabulary, so try to learn vocabulary. Well, I think the best way is if you know what is your weak point, try to 
do that grammar point a lot. And do the textbook or something. And if you have a question, go to the learning center or ask your teacher or something like that.

M: And for improving reading skills?

I: I think vocabulary is important. So, work on vocabulary and try to read English a lot. Yeah because we have a reading room in UCB. So try to go there or try to go the library and borrow some books. And try to read. Maybe if you don't know some words you can check the dictionary or if you don't know the sentence you can ask your teacher or go to the learning center or something?

M: What about writing? Especially spelling. Do you ever have trouble spelling in English?

I: Ah, a little bit.

M: Because sometimes we spell things kind of funny, I think, in English. Have you developed a way to spell words or remembering how to spell them?

I: Yeah, I just try to write them a lot.

M: Just write it over and over?

I: Over and over. But my class teacher, that teacher is not an English teacher, she's a Japanese teacher. She said how to study is like write, write, write, write. She thinks that if you don't write, you can't learn. She taught me that way. After I went to high school, I tried to study that way a lot. So I write try to write a lot.

M: And I asked a little bit about speaking and listening, but I think we talked mostly about listening. You know, we talked about using CDs or watching movies or TV. 
So what about specifically improving your ability to speak. What do you think is the best way to do that?

I: Well, if it's possible, I think come study abroad is the best. But if it's not possible for some people, or they might be scared. If you don't want to do that and you live in Japan or your home country, you might try to (like) talk there. I think if it's in Japan, there's a lot of native speakers. So, go to talk with them a lot. Like one boy, he's Japanese and he wanted to improve his English skills. So even when he doesn't have class he goes to the ALT's room and try to talk to him a lot. And I think that's the way to improve English. (Um) some parents speak English, but most of the parents don't speak English. So we can't study speaking at your house, so there's only school and some places like that. If you have ALT teacher, try to speak with them a lot. If you can, try to make American if friends. They might be really good in Japanese, so you might talk in Japanese. But try to be friends with them.

M: What about here in the US? Do you try to talk to lots of people every day?

I: No, I only talk to my host family. Well, I want to get my speaking skills, so I might go to conversation partner room. And we can sign up one week, thirty minutes. I sign up every week, one time. And there's a conversation partner and you can have a conversation partner if you want. And you can meet them twice a week or something, but it depends on you and your conversation partner. Yeah, I have a conversation partner and I met her and talk to like one hour, two times a week. M: Oh, that's good. 
I: Yeah, she's twenty one and she's a student at PSU. She's quite close age, so it's fun talking with her.

M: Do you ever (go like) try to go to the store or something like and try to talk more than just ordering food or something? Do you ever try to make conversation with someone who works at a store or restaurant or something?

I: (Um) well, not for me. But sometimes the people who work there are friendly and they try to talk to me. And I try to answer. I go to Safeway a lot, and the people who works there are really friendly.

M: Ok, I think that's all the questions I have. But before we finish I wanted to ask if there is anything you think I missed. Like is there anything you have ever done that is interesting, to study, that maybe I wouldn't think of.

I: No. I think. Yeah, watching DVDs or CDs sometimes works too, I think. I watch it, but it's a little hard to understand because they talk normally. I think it's a good way, but it's a little hard for me now.

M: Is there anything else besides using textbooks or flashcards or writing things a lot. Is there anything else you've done that you think is interesting or is a really good way to study?

I: Well, I think (um) try to speak a lot is the most way to study English? But I'm trying to speak a lot, but it's a little difficult for me to go to a person I don't know and speak "how are you?"

M: Yeah.

I: In Japan we don't do that many times. 
M: So you look for opportunities where you can...

I: Yeah, (I'm looking for) I wanted to go in a club. Because speaking English is the way to learn English fast. Like talking with American people, so I wanted to take part in a club. I looked at BEBC? Bible, English, basic...yeah. Tomorrow, I'm going to go. So they have a meeting so I will be there. Yeah, I think speaking and talking to native speakers is the best way to encourage your English, so I try to do that a lot. M: So kind of like this too. Like you had this opportunity and you volunteered to do this interview and it's good practice...

I: To speak English. And of course grammar and those things, I think are important too because you need some, you can't just be the first class like elementary school level. If you can speak that language you can live there.

M: Good. Ok. That's all. So thank you very much for your help. I really appreciate it.

I: Ok.

Follow up communication

M: First of all, I wanted to say thank you again so much for your help with my thesis research. I have one more question I wanted to ask: If you were giving advice to someone who is just starting to study English, what would you say? Can you think of 3-5 pieces of advice? Thanks again. 
I: Here's some advice I will give

Don't hesitate when you make a mistake.

Don't hesitate to ask someone a question when you don't understand.

Try to listen many times as possible.

(anything is ok, recording, TV, radio)

\section{Norio}

Interview transcription

M: Ok, so the first thing I want to ask is do you remember when you first started studying English? How old you were.

N: I think junior high school. Oh, but actually maybe six years old. But just "apple" or "banana," or something?

M: Was that at school?

N: Not school. I went to kindergarten and that was kind of club or something.

M: Ok, and after that just junior high?

N: Yeah. And after that I didn't do anything until junior high school.

M: (So that was) you just had English class in junior high school?

$\mathrm{N}$ : Yeah.

M: And what was that class like? Do you remember what you did at all?

$\mathrm{N}$ : I just read the textbook and then I did like pronunciation. The teacher read something "I have a band." And then students say "I have a band." Try to remember the textbook sentences and then we had a test. Does that make sense? 
M: Yeah, that makes sense.

$\mathrm{N}$ : Yeah, pronunciation and textbook. So reading and grammar.

M: Ok. And did you like that? Did you enjoy the classes?

$\mathrm{N}$ : Uh yeah. At the beginning I liked studying English because that was really (first time) first experience for me to study English. But gradual it was like boring, because always reading and then pronunciation. But pronunciation is not conversation. And also I have to memorize a lot about grammar or something, and that was not so fun.

M: So you said no conversation?

$\mathrm{N}$ : No conversation?

M: So did you ever work in groups with other students? Or was it just the teacher... N: Teacher and us. Yeah and then sometimes the teach asked me. But just answer and no conversation.

M: So the teacher would call on you?

N: Yeah.

M: Do you think learned English in those classes?

$\mathrm{N}$ : Yeah, I learned grammar and reading stuff. A little bit listening. But I think I just learned grammar and reading. Listening is not so helpful for me, because I can hear and listen English but it's not working. So I think I learning only grammar and reading.

M: Ok. Did you also have English classes in high school?

N: Yeah. 
M: Were those similar or different?

N: I think similar. My junior high and high school were kind of connecting school.

Private school. So our schools purpose is to enter the good university. It's like steps. Junior high school and then step. Study hard and then gradually. The purpose is to enter the good school. So kind of similar.

M: What were the teachers like? Do you remember the teachers?

N: Yeah. Junior high school is more strict. They were really anger person. Like they can hit us. So if we can not pass test, we have to go in the morning like 6:30. And we have to do something for English. And if we sleep, the teacher was really angry and then they use the time to get mad. Like 10 minutes or something. We have only 50 minutes, but 10 minutes they angry to someone. So junior high school is more, they want to teach English and they want to teach manner. But in high school the teacher changed. Different person. They tend to pay attention, to make us study more for university.

M: Did you ever have an ALT? Like somebody from a western country? N: Yeah, I think. In high school there's no other countries teacher. But junior high school, maybe one teacher is from America.

M: And that person taught English class like once a week or something?

N: Once a week... actually I don’t remember very much.

M: Did you ever go to a juku, a cram school?

$\mathrm{N}$ : Yeah, yeah.

M: And did you study English there? 
N: Yeah.

M: What was that like?

N: After high school I went to cram school. That was only studying for university. So like grammar, reading, little bit listening?

M: So that was just to prepare you for entrance exams for college?

$\mathrm{N}$ : Yeah. I think in my experience, almost all the time it was preparing for university. To pass the university.

M: Were those classes similar to high school English classes? Or was it different? $\mathrm{N}$ : Almost the same. The content is almost the same. But the difference is like long. So in high school our class is like 50 minutes, but in cram school it's like 2 hours per one class. So more harder to concentrate and learn. And I think in cram school is only teacher talk to us. We can have a question, but almost all the time they teach us. M: So you said you're a senior now? At Waseda?

$\mathrm{N}$ : Yeah.

M: So I think they require English at Waseda too? Like two years of English or something?

$\mathrm{N}$ : Yeah.

M: So you took English classes there too, and how were those?

$\mathrm{N}$ : Uh, that was really good, because that's more attention to conversation. So I was really happy to talk. The one class is like four Japanese people and one other countries teacher. And we talk. I feel like I could learn practical English. Like conversation. So that was really good for me. In university, I took this one English 
class, tutorial English class. That was kind of I have to take that class. The next year also, I took the same class for me.

M: So one of the classes was like four students and one teacher?

N: Yeah.

M: That sounds good.

$\mathrm{N}$ : Yeah, that was very helpful. Every class in junior high and high school was like 50 students and one teacher. And also in cram school, was I think 200 students and one teacher. And everything was just to pass the university test. So that was really boring. But I wanted to learn English more practical. So that's why that class in Waseda was really good.

M: That one was a required class or not?

$\mathrm{N}$ : It depends on department. My department is sports business, and then its required. In Freshman we have to take that class like twice a week.

M: Ok. So you had some other English classes too though. Like more traditional grammar/reading class, or?

N: In university I took tutorial English, and one is sports business English. That was kind of traditional, like same as high school or junior high school. But it was more fun because the reading stuff was like real English newspaper. And then the teacher tend to grammar also, but more fun.

M: So you were at Waseda for three years before you came to Portland?

$\mathrm{N}$ : Oh no, four years.

M: Four years. And did you take English every year? 
N: Freshman and Sophomore. And Junior is, I think no English. Senior is also no class. I tried to get the teacher license, physical teacher license, so I didn't have time to take the TOEFL tutorial class. So if I did, of course, I took.

M: And then you decided to come study abroad? Why did you choose to do that? N: So, I belonged to the Waseda University soccer team. So I have to spend four years for soccer. But I also, always have want to talk with another countries' people. Because if I can talk with them more, I can be happy and I can have wide thinking. Yeah. And also, I heard from my senior friend who also belongs to my soccer team, and he told me he played for PSU team. And he told me if you go to PSU you can play with 15 countries' people. So that was also good for me. Makes sense?

M: Yeah, that makes sense. So you just wanted to come and meet people. Kind of open your mind a bit.

$\mathrm{N}$ : Yeah, and of course to improve English skill. But everything is for my open mind. M: So how did you feel about your English when you first arrived in Portland? Did you feel like you could communicate well?

N: No I could not. So that was really hard. So first of all, I had a class. Teacher and others are waseda students. That was not so hard, but even though it was not so hard, it was really hard for me. I could not hear anything. So I thought "I don't know, I can't catch this class and this life in America."

M: But it got easier?

N: Yeah, it got easier. Absolutely.

M: And now you feel good? Feel like you can communicate. 
N: Yeah. Still sometimes, not sometimes, many times I have trouble to communicate. Sometimes store or sometimes class. But lots easier than before.

M: So you had English classes with Waseda students here in Portland right? N: Yeah.

M: And what were those classes like? Can you kind of describe those classes?

$\mathrm{N}$ : That class is like one teacher and 20 Japanese people. And he tries to teach us like listening. One is listening, they use NPR radio and we try to listen. And then they want to make us understand. So we had it three times: Summer, Fall, Winter. Summer is more fun. Watch movie and we use American Way textbook to introduce American culture and politics or something. And they taught us culture.

M: So the textbook had, while you learn English you're learning culture. And what did you think about listening to NPR, did that help?

N: NPR is in Winter, so yeah that was ok. But still difficult. But I think that's good for me. Because I really tried to "oh, I want to understand." But I think the beginning of this American life if I tried to use NPR, maybe I could not understand everything. At the beginning of this class I should learn more easy stuff.

M: So you came to Portland in March, right?

N: Yeah.

M: When did you decided you were coming to Portland? Like three months before that, or?

$\mathrm{N}$ : I think one year ago. I was junior and I tried to get a job. I hunted a job, I did job hunting. But also, I felt like I should learn more other countries opportunity or stuff. 
Because I thought if I try to get a job at the moment, my thinking is too narrow. I decided this one year ago.

M: Did you do anything to prepare for coming to Portland? Did you study English extra or anything like that?

N: I did studying for TOEFL. So vocabulary and grammar stuff.

M: What did you use to study? Did you use a textbook to study?

$\mathrm{N}$ : Textbook, yeah. Only grammar and vocabulary stuff.

M: Since you've been here, besides English classes, have you been studying English a lot on your own time.

$\mathrm{N}$ : I think yes. But I spend time with my friends more than studying. I think I always hang out with my friends, and play soccer.

M: (Do you think like) hanging out with American friends or Japanese friends?

N: I think American friends. Because I didn't want to hang out with Japanese friends, because maybe I knew I will use Japanese. So I try to spend it with my American friends: soccer mates, or host family.

M: Oh so you have a host family?

N: Yeah. They are Kenyan.

M: Oh cool. So kind of you were practicing English by hanging out with people and talking?

N: Yeah.

M: Do you think that was helpful?

$\mathrm{N}$ : Yeah, I think so. 
M: Compared with classes, what do you think is more helpful?

$\mathrm{N}$ : Both are really good. I don't know which is better, but hanging out with my American friends is more difficult. Their English is natural speed. So at the beginning it's like "Oh....ehh...oh yeah....uh huh yeah.." It was really hard, but because of that I think I could get used to natural speed or faster speed. So I think that was really good. But also I think class is really important, because I can ask question all the time to the teacher. So which is helpful?

M: You don't have to choose one. I just wanted to know what you thought about what is beneficial about each one. So talking with friends helped you listen like full speed English. And class is helpful because you can ask questions and maybe learn grammar and things?

$\mathrm{N}$ : Yeah.

M: So thinking about all these experiences: junior high, high school, cram school, Waseda classes, hanging out with friends. What are some of the things that you think helped you learn the most.

$\mathrm{N}$ : I think here. I learned here is the most helpful for me. Because I am here, so almost 24 hours I hear English, and I watch TV only English, and read English. I can read (of course) some Japanese stuff on the internet, but when I go to store I have to conversation with English. Even play soccer I have to explain the situation or something I need to speak English. So living here is most good for me. Plus, I think class is also helpful. But it could be learning in Japan, like Waseda. So living here is the most. 
M: So what about your classes? Are there things in your classes that you thought were really helpful? Like you said listening to NPR. You know thinking about inside class, what's helpful in the classes you took?

N: Helpful for English skill?

M: Yeah.

$\mathrm{N}$ : Uh. I think one is presentation. I have to use English sentences all the time in presentation. So I have to use my brain and then I have to do presentation. (That was) and then pronunciation is helpful for me. Sometimes they distribute to us pronunciation paper. They try to understand the difference between "set" and "sit." M: For pronunciation did they ever use IPA? Do you know what that is? $\mathrm{N}$ : No. I think it looks original one.

M: Ok. It doesn't matter, I was just wondering if you used that at all. Was there anything else? You said pronunciation helped, giving presentations helped.

N: Yeah. Reading stuff is also helpful for me. I think reading stuff I can increase my vocabulary.

M: Ok, so now for the last part I just want to ask your opinion about the best ways to study for things. So let's start with vocabulary. So let's say on your own time, by yourself you want to increase your vocabulary. What do you think the best way to do that is?

$\mathrm{N}$ : I think (vocabulary is like) I always just try to remember. I always use a vocabulary book, like English and Japanese. But also I think maybe it is helpful to only use English - English dictionary. So English - Japanese vocabulary book is like 
English and Japanese. And English - English vocabulary book is only English. And also like the one is like have more same words. Like... they have same word and same meaning word?

M: Like a thesaurus? We call it a thesaurus. So like fast and the quick. Like that? N: Yes. Yes. Yes. That's more helpful. If I use just English and Japanese, I think I have to change the word in my brain. So chair into Japanese: "Oh chair in Japanese is..." and then understand. But if I use fast: "Oh fast is like quick" and I can use more smoothly.

M: Ok. So you said you use all of those? Do you use all of those?

N: Oh yeah.

M: So sometimes you might use English - Japanese, and sometimes English English, and sometimes thesaurus.

N: Yeah.

M: What about using something like flashcards? Do you use those, or do you not like them?

$\mathrm{N}$ : Oh yeah. I also use flashcards. Like if I read something and I cannot understand this. I try to get the meaning in the dictionary and then write English and different way. Sometime English same meaning different words and sometimes Japanese. So I also use flashcards.

M: Ok. A couple people that I have talked to said sometimes to remember a word they'll just write it over and over again until they remember it. Have you ever done that? 
N: Oh. I don't like to [makes writing noise].

M: You don't like to, yeah. What about if you just want to improve your listening skills.

$\mathrm{N}$ : I think hang out with friends.

M: Hang out with friends?

$\mathrm{N}$ : Yeah, because the situation is important I think. If I cannot understand the situation, I cannot talk with them. So I have to catch the conversation. So I really concentrate. Also, I think the movie or radio is helpful, but I think conversation is more I have to concentrate. Conversation is only one time. TV and radio is, I can repeat them. So yeah, conversation is important for listening I think.

M: But TV and radio might help a little bit?

N: Yeah. And also sometimes I watch movie in English all day. That was also maybe helpful.

M: Yeah. I've talked to a lot of people who watch TV in English. But some people say it's helpful and some say it's just fun. But you think it really does help?

$\mathrm{N}$ : Yeah. But I have to watch maybe long time.

M: Um. And what about for speaking?

$\mathrm{N}$ : Speaking is conversation?

M: Yeah, just talking to people.

$\mathrm{N}$ : I didn't train to speak in English, I just spent the time with friends. And then maybe naturally more I could talk with my friends.

M: What about for reading skill? 
N: (Reading skill is like I think the) I did reading stuff in class. And also, I read the internet stuff. I used FIFA.com. I like soccer, so it's easier to understand. I tried to do the Time magazine, but that was kind of difficult and kind of boring. I think for me, the fun thing is helpful.

M: Ok so if you're enjoying what you're reading, you are going to read more. And then more practice. Ok, that's good.

$\mathrm{N}$ : Yeah.

M: (Do you ever have trouble) do you ever practice spelling? Because sometimes English spelling can be difficult.

N: Sometimes. Really sometimes. But actually I didn't write very much, because I always use internet or...

M: Is there anything else that we haven't talked about today, that you thought was helpful, that we haven't talked about or that I didn't ask about?

$\mathrm{N}$ : Maybe the important thing is attitude for English? So at the beginning I really don't understand anything in English. But I always try to understand English. Also, I tried to talk with woman. I tried to talk with woman a lot. That was really helpful for me?

M: Yeah? Why?

$\mathrm{N}$ : Because I thought “Oh, she is pretty." I should talk with her, but I need to talk with her naturally. So I should study (laughing). M: So it's good motivation. 
$\mathrm{N}$ : Yeah. And then when she talks to me I have to understand her conversation. If not, I could not talk with her, so I really concentrate.

M: That makes sense. Let me think...So if you were studying English. Let's say you were in your dorm room and you just wanted to study English, have you ever used textbooks in your own time? Or mostly you do things like watching TV or talking with friends.

N: I use the vocabulary book. And TOEFL. So I have to take TOEFL for class. I use vocabulary and TOEFL stuff. TOEFL is really helpful. TOEFL has many vocabulary, so I can learn.

M: Ok I think that is all the questions I have...unless there is anything else you think is important that I should know.

$\mathrm{N}$ : I think attitude is important.

M: That's good.

N: So like, always use English.

M: So like you were saying you like hanging out with American students here, because if you hang out with Japanese students you know you're going to use Japanese? Like that?

N: Yeah. And then I can do those things in Japan. So I feel like, why I hang out with Japanese friends in America.

M: Good. Ok.

\section{Natsuo}


Interview transcription

M: Ok. So the first question is do you remember when you first started studying English?

$\mathrm{N}$ : Yeah. My experience is kind of strange, because I lived in Philippines for four years because of my father's business. So I started English in Elementary school. In first grade.

M: In first grade? And do you remember anything about those classes? What you did, or?

N: (That class was like um just speaking) professor started to teach greetings first. And then next is like basic conversation. Like "hello" or something like "hey how are you" or "what is this? This is a pen?"

M: Or "my name is"

$\mathrm{N}$ : Yeah, something like that.

M: Ok. So pretty basic stuff.

N: Yeah. Pretty basic stuff. Yeah.

M: What kind of skills did you work on? Reading, writing, grammar, speaking, listening?

$\mathrm{N}$ : Um. I think in American school it is just speaking. The professor didn't taught me like grammar or reading skill. Just speaking.

M: What was the school like? 
$\mathrm{N}$ : It is a Japanese school.

M: In the Philippines?

$\mathrm{N}$ : Japanese school in the Philippines.

M: Was it a big school?

$\mathrm{N}$ : [misunderstands the question] We call it Manila Japanese school. MJS. There is maybe the one school in Japanese school in Manila?

M: Ok. Were there many students? Or not very many?

N: I think 700 people. 700 Japanese people.

M: Wow. That's a lot. Ok. When did you return back to Japan.

$\mathrm{N}$ : When I was in $5^{\text {th }}$ grade. In elementary school.

M: And English education in Japan starts in junior I think, right?

N: Yeah. Junior high.

M: So you took junior high English.

$\mathrm{N}$ : Yeah.

M: What were those classes like?

N: Um. That's pretty easy. The professor taught us like how to write alphabet. Like a,b,c. There's a capital one and also a little one. And after that (um) there was maybe easy textbook. Professor used that and at first we learned grammar. Like "is" "are" or something like that. And "have" "had" "have been" "had been." And also we use grammar book. And professor asked us to use that. That is the homework. Like write down. 
M: Did you ever have an ALT? An assistant language teacher from some other country?

N: No. No.

M: Just Japanese teachers?

$\mathrm{N}$ : Just Japanese teacher.

M: What about in high school. Was that similar to junior high or different?

N: Similar to junior high, but the content is more difficult.

M: Ok. Still learning mostly grammar? Or did you focus...

N: (Not anymore) Almost reading and writing. So, I think Japanese people can't speak or (hearing) hear English. Just focus on reading and writing. Sometimes listening.

M: No ALT's in high school either?

N: Um high school. Sometimes we have one speaking class, the professor is native American. And we practice our English speaking skill but that was pretty easy. And kinda boring?

M: Kind of boring?

$\mathrm{N}$ : Yeah, and not beneficial.

M: So did the teacher just get you to repeat things? Or you didn't get to have a conversation?

N: Yeah, that's right. Sometimes we had a conversation, but not really. M: Ok. Did you learn more in the school in the Philippines? (Did you think that was like) did you feel you learned English at any of these schools? 
$\mathrm{N}$ : In the Philippines?

M: In the Philippines or Japan. Junior high and high school. Do you feel like you really learned very much.

N: Hmm. Yeah I learned) As I said before I just learned reading and writing skill. Sometimes hearing. Because we need hearing skill to take the entrance exam for college. So sometimes we need a listening skill.

M: Ok. And did you go to a cram school at all?

N: Yeah. Two years.

M: Two years? During high school or junior high?

$\mathrm{N}$ : (After I graduate) No, I started to go there from high school second grade. When I was 17 years old?

M: And did you study English there?

N: Yeah.

M: And what was that like?

N: More focused on English that is used to entrance exam.

M: Ok. What is the English like on the entrance exam? What are you expected to know?

$\mathrm{N}$ : Entrance exam?

M: Yeah.

$\mathrm{N}$ : Entrance exam have reading section and writing section. And basically $80 \%$ reading section and $20 \%$ writing section. Yeah. Maybe. And we have to read a short article and there is some multiple choice. And we have to correct answer. (And there 
is like) In writing section there is like one question like "What will you do? What do you want to do?" And we have to write like 100 or 150 words. Something like that. M: Interesting. So in these classes, junior high and high school, are these mostly like lecture classes?

$\mathrm{N}$ : Yeah, just lecture.

M: Mostly just the teacher is talking and you listen. Maybe you take notes?

N: Yeah, yeah, yeah. That's right.

M: Ok. So you didn't often do activities or anything?

$\mathrm{N}$ : Hmm. Yeah, almost nothing.

M: Did you remember how you studied for class, after school. Did you study English at home?

$\mathrm{N}$ : The homework?

M: Yeah, homework.

N: Yeah, I studied a lot maybe. (In the house) At my house or cram school.

M: What kind of things did you do to study? Just use the textbook or use things like flashcards? Or what were you doing?

N: So my professor like told us to do reading for homework. Just we did and prepare for the class. And for me, if there are some words I don't know I use the flashcard. Oh yeah, and I use to read a textbook and listen to the English and I (you know) repeat the sentence. You know what I mean? It is shadowing? Hear English and repeat, repeat. Hear English and repeat, repeat. 
M: Ok. Some of the people I talked to said that to remember words they would just write them over and over again. Did you ever do anything like that?

$\mathrm{N}$ : I don't like that. I use flashcards.

M: Flashcards are better for you. Ok. So at Waseda I think they require English too, right? Two years or something like that.

N: Yeah. Two years.

M: What year are you right now?

$\mathrm{N}$ : [Misunderstands the question]. Waseda's English class was really boring. Super easy. Like much easier than high school.

M: Really?

N: (We don't have to do) We don't have to read article. We don't have homework. We don't have assignment. Just professor read a textbook. What, what did I do? Professor reads a textbook and professor read an article. And we listen to that professor talking. And sometimes answer the question. It's super boring. M: Ok. So still mostly lecture, and sometimes the professor like calls on a student? $\mathrm{N}$ : Yeah, yeah, yeah. But sometimes we have essay. Like very short essay, maybe 200 words, about like "what is right?" Something like that. We have to write 200 words.

M: How many English classes did you take at Waseda?

$\mathrm{N}$ : In one term?

M: Yeah. 
N: Only four credits. Sometimes eight credits. I mean two classes. One reading class and one speaking class. And that speaking class, the teacher is native American. Also that class is so boring. The content is so easy.

M: Ok. So what did you do in that class, in the speaking class?

N: Like presentation. But we don't use powerpoint. We just talk about what is the difference between Japan and American, for example. And what is the difference between Waseda and KEIO. Do you know KEIO? [Japanese University name] M: Yeah.

$\mathrm{N}$ : And we have to make a presentation like 3 or 5 minutes. Something like that. M: Ok. Did you ever get in groups with other students and just practice talking with them?

N: No. In Japan group work was not usual. Not common.

M: So sometimes you give presentation and the rest of the time was just lecture? $\mathrm{N}$ : Yeah, just listen to professor's talking. And sometimes the professor asks some question for us and we answer the question in very short sentence.

M: What year are you at Waseda?

$\mathrm{N}$ : Junior.

M: Ok. So you've had two years there already. So after coming back from Portland you've probably completed your English at Waseda. Do you think you'll take more classes just for fun? 
$\mathrm{N}$ : Actually I have to take one more class that is required class. So maybe I will take English class. I think maybe that is not enough for me, so maybe I will find some opportunity to speak English.

M: So, then you decided to come to Portland. Why did you want to study abroad first?

$\mathrm{N}$ : Ok. That is my personal reason, but is it ok?

M: Sure, of course. I mean unless it's too personal and you don't want to talk about it. It's up to you, anything is useful for me. But if it's too personal you don't have to say.

N: Ok. I would like to speak that. Ok first, I really want to work at trading company in Japan. So basically, in trading company in order to enter the trading company, I think I need the English speaking skill. Because my father is working at the trading company in Japan, and he said in order to enter the trading company you have to train your English skill in university. Like after you graduate from university, it is too late. But also my uncle and my uncle's father is also working at the trading company. And they said the same things for me. That is one reason. The second reason is I really like English. I really like speaking English, I really like watching movie in English. I like reading novel. So that's why; that's the second reason. And what else? Ok. And the third reason is that I did a lot of work in university, like club activity. Or something like that, but that is not exciting for me. So I really want to do more exciting things in university. So that's why I come here. 
M: That makes sense. How did you end up choosing the Portland program. Because I think Waseda has lots of programs.

$\mathrm{N}$ : Oh yeah, yeah, yeah. Ok this is my personal reason too.

M: Ok, sure.

$\mathrm{N}$ : Ok, basically whoever wants to study abroad in summer, people have to turn in application form one year before that summer. You know what I mean? When I was freshman I took the TOEFL. We need TOEFL score to enter the foreign university. (And I took) my score is not so good. So, I had no choice but to go to PSU or one more school. And my friend went to the PSU; and I asked him how is the PSU? And he said (Oh, it is not good) It is not bad. The Portland university is very diversity. And also, (there is a lot of) you can learn marketing or economics or psychology or politics, or whatever you want. So the atmosphere was not bad also. And PSU is near from downtown. So he kind of recommend me go to PSU.

M: Ok. So there's two Waseda programs. Is yours the TNP or? What does that stand for, do you know?

$\mathrm{N}$ : Ok. TNP program starts in March and ends in December. It's a nine months program. This is more focused on English. There is ESL, so there are two professor in Waseda Oregon office: Kerry and Grant. And they teach more English for TNP students. But (Lohas is) Lohas starts in September and finish at June. And LOHAS student have to take environment class, that is required. (So we have to take like) last term every LOHAS student has to take environmental and sustainability class. But this term some people take environmental and economics class, some people take 
environmental health, and some people take environmental society. There are three class right now.

M: Ok. And then Waseda students all take English classes together, right?

N: Yeah.

M: Is it separate? TNP and Lohas. There are separate English classes?

N: Separate. Yeah.

M: Ok. So you've had some English classes here in Portland already. What did you think of those?

N: ESL? Last term we learned how to write a paper: introduction, summary and response. Something like that. Also we used a textbook that is called American Ways. So we learned about American culture, American society, American education, or American history. Yeah, that is last term. And this term, we are now doing research paper. So we are writing a paper, which for me is "Why Sony became popular." The topic, we can choose whatever you want, the topic. Right now that's it.

M: Ok, so sound like a lot of writing focus?

N: Yeah, a lot of writing.

M: Ok. So the textbook teaches you about American culture. Does it also teach you English, or is just about learning culture?

$\mathrm{N}$ : Learning culture. Yeah just learning culture.

M: Ok, so not so much about teaching English? 
N: Um. Yeah. Not so much. Like maybe the professor don't care about the grammar. Mostly like reading. And the professor asks some question to us, so we like answer the question. Something like that.

M: And is that class mostly lecture or do you guys get an opportunity to work with other students sometimes?

N: Um. Maybe professor really focus on group work. So in the lecture the professor say “Ok, let's divide into three groups." And we have discussion. Yeah.

M: Have you been studying outside of class of while you've been in Portland? Studying on your own time?

$\mathrm{N}$ : Outside means like except class?

M: Yeah.

N: Oh. You mean like...

M: Like do you ever study on your own sometimes, just to improve your English? Not necessarily homework. But just outside of class you want to work on your English. (So you just study) or not even study, but do you do anything that you think is helping your English.

N: Alright. If I have time, I hang out with American people. Just only American people, not Japanese people. To train my English skill. I avoid Japanese people recently, because if I hang out with them I speak Japanese. That is a waste of time. M: That makes sense. Besides that, (do you ever) some people have a vocab book that they use just to learn new words. Do you ever do something like that? 
N: Oh yeah. Before I go to bed, I read a vocabulary book or I read novel or I watch movie or news in English on laptop.

M: Ok. That's good. And do you think that's helpful?

N: So far, I don't think so.

M: So far you don't think so?

$\mathrm{N}$ : (It is really, you know) when I'm watching movie, the people really talk fast, so I can't hear. But I use subtitle, so when I read it and I'm like "Oh yeah."

M: That makes sense. (Ok, so that's) Oh, one more question I forgot to ask you. Before you came to Portland did you do anything in particular to improve your English skills?

N: Oh yeah. So last summer, I went to café. That café is like there are a lot of foreigners, and we have to speak only English in that café.

M: Oh yeah?

$\mathrm{N}$ : That café is really interesting. It's really cheap. Like maybe 1,000 yen per hour $\{$ Roughly $\$ 10$ per hour in USD\}. And like three or four tables and there are already foreigners and one teacher in there. Just we talk about everything: politics or economics or. And there are French people or Italian people and American people and Japanese people. Mostly Japanese people, and mostly business people. So I drop in and speak English, before I come here.

M: I've never heard of that before.

$\mathrm{N}$ : Yeah, I haven't known that café, but my friend is working there, just part time job. And she is introduced me to go. It's really good. 
M: Do you remember the name of the place?

N: Leafcup. Maybe you can search on google.

M: Leafcup? Ok. Like a leaf on a tree?

N: Yeah. In Shibuya and in Idabashi.

M: $\{$ Starts looking for website $\}$ Interesting. I'll see if I can. \{Finds website quickly\} Oh yeah. English school and conversation café. So the one you went to is in Shibuya.

N: Yeah. It's very cheap. 1,000 yen for one hour.

M: So, that's like $\$ 10$ for one hour.

N: \$10 for one hour. And free coffee, free tea. And sometimes free snack.

M: Oh wow. That's seems pretty cool. Ok, so those are all the questions about experience. Now I just want to get your opinion about some things. So starting with what you think the best ways to study are, in your experience, for various things. $\mathrm{N}: \mathrm{Ok}$.

M: So let's say specifically, we'll start with vocabulary. If you are working to improve your vocabulary, what do you think is the best way to do that?

N: Flashcards. That is the best, I think.

M: Ok. And when you do flashcards, do you write just English on one side, and Japanese on the other?

N: That's right.

M: Do you ever do English on one side, like the word, and on the back what it means in English? Have you ever done it like that? 
$\mathrm{N}$ : Ok. That is sometimes meaningless. Sometimes, I wrote down word, and the backside is meaning and the sentence. Like how to use that word. Yeah, something like that.

M: That makes sense. What about (to study) to improve your speaking skills? What do you think is t he best way to do that?

N: Talk with foreigners. Talk with Americans, especially.

M: Ok. Just make friends?

$\mathrm{N}$ : Yeah make friends.

M: Ok. And what about listening skills?

$\mathrm{N}$ : Um. Also talk with foreigners. And sometimes it is beneficial to watch movie, or listen to music.

M: Ok watch movies, listen to music. What about to get better at reading?

N: Reading? Textbook? Or sometimes newspaper. I've never tried that.

M: You've never tried that? So, you said you like to read novels, right? Do you think that helps to improve your English?

$\mathrm{N}$ : I think so yeah.

M: What kind of novels do you like to read?

N: Now I am reading a really easy one for like elementary or junior high school. So that is not difficult for me, so I can read very quickly.

M: And what about spelling? Do you ever have trouble remember how to spell words?

N: Spelling? Spelling. Spelling. 
M: Sometimes spelling I think is difficult in English. Sometimes (our words) we don't always spell them how they sound. We can have letters in there that you might forget. Like the word "often," you know there's a " $t$ " there. Or "restaurant," there's a " $u$ " and even I can't remember where to put it sometimes.

$\mathrm{N}$ : Like "knife?"

M: Yeah, yeah.

N: Um. Spelling. What I do usually? Spelling. I don't know how to train spelling skilling.

M: Ok. That's ok. You don't have to. Ok. The last skill then really is grammar.

$\mathrm{N}$ : Grammar?

M: If you just want to work on your grammar skills. How do you think would be the best way to improve them?

$\mathrm{N}$ : Grammar textbook.

M: Just use a textbook. Read through it, and?

$\mathrm{N}$ : And if I find grammar that I don't know, use flashcard.

M: Ok. Flashcards for grammar? How would you make a flashcard for grammar?

N: For example, "hang out." And then backside, "I hang out with my friend."

M: Ok, so just use it in a sentence?

$\mathrm{N}$ : Yeah.

M: So thinking about all your experience learning English. You know, all of your classes in the Philippines, Japan, US, what do you think has been the most helpful? Made the biggest difference for you? 
$\mathrm{N}$ : Most helpful? Of course, the US.

M: In the US? The classes, or just the experience? Living here has been what made the difference?

$\mathrm{N}$ : Oh ok. Well, maybe living here, I think. Because (maybe in Japan), when I was in Japan I learn English a lot, but that was just in English class. In everyday life, I only speak Japanese. But in here, I have to speak English in everyday life, and also in the class. So what is the difference is, the everyday life in Japan and in America.

M: What's been the most fun in terms of learning English?

$\mathrm{N}$ : What is fun?

M: Yeah, what did you enjoy the most? Did you always enjoy learning English? In junior high and high school classes, did you think it was fun?

N: Yeah, I always enjoy my English. What is fun for me is if I feel that my English skill is improving, I feel very fun.

M: Anytime you feel you're learning?

$\mathrm{N}$ : Yeah, yeah. But now, I think my English skill has stopped?

M: Stopped?

$\mathrm{N}$ : Yeah, the curve is not so...flat. So I really worry about that.

M: I don't think you need to worry about that.

N: But (my friends said) my American friends said all Japanese students say that. Also my friends said don't care about that. M: I don't think you need to worry about that. $\mathrm{N}$ : Really? 
M: Yeah it makes sense. At the beginning there's so many things to learn. And then you get better and you know this is the part where you work on little things. Little pronunciation bits, little grammar things that you're missing. It's not big changes anymore, just little bits.

$\mathrm{N}$ : Really?

M: Yeah, I wouldn't worry about it. Ok. Let's see. Let's say you go back to Japan in a couple months and you meet a student there who is just starting to really study English. What kind of advice would you give them. What would be your advice to help them do well with English?

$\mathrm{N}$ : Like the people who wants to go abroad?

M: Go abroad, or just really want to improve their English. What would you say to them?

$\mathrm{N}$ : Ah. Well, maybe I will give advice for them that first you need remember the word and grammar, because that if really basic one. And also, that is input, right? Also, you have to do output. If you learned a couple words and grammar, and after that you have to go to some kind of café, like Leafcup, and you have to do output. M: Ok, so build a base with grammar and vocabulary. And once you do that you think it's important to start speaking. N: Yeah, yeah, yeah. That's right. M: Ok, I think that is most of my questions I have. So the last thing, what I'm studying about in my paper is basically I'm talking to people and hearing about their experiences. Trying to figure out what they did to learn English in the past and what 
they believe about language learning. And then I'm really interested in things like you're talking about going to Leafcup. Things like that are really interesting for me. So the things that people do by themselves to learn English, so outside of school. That's kind of what my paper is about. So I think it's really interesting when people tell me that they use movies to study English or the café you went to to study English? Is there anything else you can think of that you've done outside of class to study English?

$\mathrm{N}$ : Ok. I have a good experience. In Waseda there is a club, we call ISS.

International Student Society, maybe. ISS usually hold a party or sports event. And if I applied them, we can play badminton or basketball or something. And also there is English hour, so we discuss about politics, economics with foreigners in English.

That is a good program in Waseda.

M: So there's a lot of international students?

$\mathrm{N}$ : Yeah.

M: So those people are also students at Waseda?

N: Yeah.

M: What countries do they come from usually?

N: French people. And also Korean, and American. Saudi Arabian?

M: So most of the time you're just doing some casual activity like sports?

N: Yeah. Yeah.

M: So you talk during that time in English?

$\mathrm{N}$ : Yeah. 
M: And sometimes you just sit down and have conversation?

N: Yeah.

\section{M: Ok. Cool.}

$\mathrm{N}$ : And also in Waseda there is an international club. We call niji no kai.

M: Niji no kai?

N: Yeah. Niji is rainbow.

$\mathrm{M}$ : Niji is rainbow? Kai is meeting right?

$\mathrm{N}$ : Yeah, like rainbow meeting.

M: Ok.

$\mathrm{N}$ : Yeah, there is an international club. Maybe Marina belonged to that club. Did she say?

M: She didn't mention it.

N: Really? She belonged to niji no kai.

M: You didn't do that though?

N: No. I belonged to Waseda Advertising Society.

M: Cool. Anything else you can think of before you finish?

N: Um. Norio \{other participant\} said (that what is the best way to learn English) maybe he said we have to make girlfriend right?

M: He talked a little bit about that, yeah.

$\mathrm{N}$ : That is a good way, I think.

M: Whatever motivates you is good, right?

$\mathrm{N}$ : Yeah. Is that interesting for you? 
M: Sure. Yeah, I'm not as interested in school learning. Like you said, (school learning is) vocabulary and grammar, a lot of times school classes help you with that. But after that, I think a lot of the best ways are just to talk to people. Do things that are fun for you, to motivate you to learn English, whether that is clubs or girls, or whatever it is. It's all good stuff.

$\mathrm{N}$ : Yeah, I think so. Just hang out with foreigner is the best way.

M: Ok. Cool. That's everything.

\section{Hanako}

Interview transcription

M: Ok, so the first questions are mostly to do with describing your experience in English classes.

$\mathrm{H}$ : English classes.

M: And then later on at the end I'll ask some questions about your opinion about the best way to do things.

H: Ok.

M: So, first we can just talk about experience...

H: Experience I have? (So you know) in Japan or here?

M: Yeah, starting with in Japan.

H: Junior high. 
M: Do you remember when you first started learning English?

H: I think junior high. Like alphabet, ABCD. We have to memorize ABCD. And vocab, grammar. I hate it. Did I tell you I hated English class? And my score is always low. (So kind of) junior high and high school, mandatory English. So I hate it. I like math, but. In college, some requirement, but I took like audio listening something English course, so I liked it. And I also took conversation course, more interactive. And here two years ago I took academic speaking/academic writing. I don't know if I learned a lot. I don't feel like I studied hard.

M: So I know this was a while ago, but the junior high classes, do you remember what you did in those classes?

H: Maybe translate English into Japanese or (like) grammar. Like structure. Like passive or PP.

M: PP?

H: Like "I have been."

M: Like present perfect?

H: Yeah, like present perfect. Yeah PP. We know some grammatical term, but I couldn't find point why I have to study PP or passive form. Grammar exercise. M: Do you remember your teacher in that class at all?

H: Yeah. Junior high, yeah.

M: (And the teacher was) was the teacher Japanese or... H: Japanese. 
M: And was it structured like mostly like lecture class or did the students participate a lot?

$\mathrm{H}$ : No participate, more like lecture. But maybe she wanted us to translate before come to class. A kind of dialogue or something.

M: Yeah. And what about in high school. Was it similar or different?

H: High school was grammar. I don't remember story or anything. No, just grammar. In college we did (like) a children's book. (I forgot) like Matilda or something.

M: Matilda?

H: Yeah, it was ok, but not great. Because like translate English into Japanese. Oh, one class was (English practicum) practical English. (Like) we learned how to write (like) formal letter in English, or just memorize how to write sentence. Just short memory, I couldn’t use now.

M: And then, did you go to a juku, at all? Cram school?

H: For English?

M: Well anything.

H: Yeah, I went to.

M: There weren't English classes though?

H: Math, only math.

M: Oh really?

H: Yeah, in junior high. (But before high school) I went to cram school only math, I think, 14 to 15 . But before entrance exam for high school, I went to summer term. 
Like short period cram school. So I studied English too. English, math, Japanese.

History?

M: History?

H: History? No, no history. Only three: Japanese, English, math.

M: Ok. And do you remember those English classes?

H: Just for (like) study. We have like study guide. Not study guide. (Previous study) previous exam, like last year. So we just do kind of similar exercise.

M: Ok.

H: Just workbook.

M: A workbook that prepares you for exams.

H: Yeah. I don't remember anything.

M: Ok.

H: \{laughing $\}$ Yeah.

M: Did you like any of those classes: junior high, high school, cram school? Did you enjoy any of them?

H: No.

M: Not really?

H: Never. I can't tell never.

M: Do you think any of it was helpful? I mean, do you think that you learned anything?

H: I learned that I hate English \{laughing . 
M: \{laughing $\}$ Ok, you learned that you hate English. Ok, and then college. (You said) I think the classes were a little different in college.

H: A little different. More something meaningful. Ok, I have to speak English now because we have conversation class. But if the English teacher can speak Japanese, I didn't want to speak (Japanese, uh) English. Because I cannot see point why I have to use English.

M: I see.

H: Can you see?

M: Yeah. Did you ever have ALT, like assistant language teacher from a western country?

H: Yeah, yeah in high school.

M: In high school you did?

H: So he didn't speak Japanese at all during in class, or maybe no one can use (like) Japanese. But he can speak Japanese. But he finally (like) gave up. He talked to me in Japanese \{laughing\}. I don't know why.

M: So when he was teaching, he taught in English?

H: Yeah. Maybe he shouldn't speak Japanese, right?

M: I see. But did he just lecture?

H: No. We have textbook, like conversation or communication or something. And we just do exercise. So boring. Yeah, textbook.

M: And in college you said you read story books, like Matilda. Did you have more conversation in that class? 
H: No. We just remember Matilda. But I couldn't have fun for learning. Just requirement. But it was easy class because sitting and sometimes translate. And also professor didn't expect us to speak English. The learning (like internet) like audio was fun. I don't know. There are many internet audio program, right?

M: You did that during class?

H: Yeah.

M: During class? I see. Interesting. Ok, so you came to the US first about three years ago.

H: Yes.

M: (Did you before you came to the us) well, how long after you graduate college before you came?

H: One year.

M: And you were just working?

H: Yes, working hotel.

M: And then you just decided to do the ALLEX program \{Japanese teaching exchange program $\}$ ?

H: Yes. No, before. After I graduated from university I decided maybe I need English skills, if I get a job. So I was looking for something, but not ALLEX. I was going to graduate school, US. I wanted to study social psychology, I wanted to continue, but (you know) ALLEX. And then "Ok. This sounds ok." M: Did you do anything, as far as studying English, before you came to the US to prepare? 
H: Yeah. When I went to travel in New York or Bali. Kind of (not like) not Japanese country. We studied like "How much is it?" or "excuse me." Yeah, we did.

M: Ok. Who's we?

H: Like friend. My friend from my part time job. She can speak English really well, so she taught me.

M: She taught you?

H: Yeah, and then ALLEX program we had English interview too. I think I told you. M: I don't remember that part.

H: Ok, so I couldn't say like English (introduce) introduction. I said like "My name is ___ _ _ That's all, so \{nervous noise\} I couldn't say anything. So before interview I prepared with my friend. She can speak English. So she asked me "Why do you want to do this program?" and we just practiced. So I have no idea what I want to say. Just English.

M: Ok, (so you were) you've been at three different universities here. Did you take English classes?

H: English, English classes? Like ESL or something?

M: Yeah.

H: Wellesley College, no I didn't take. I just took undergraduate class, so it was really difficult for me to follow what they say. I couldn't understand. Like writing course and second language acquisition class I take. The first year I took ESL. So I took (academic), no, TOEFL participate. Do you know TOEFL?

M: Yeah. 


\section{H: TOEFL...}

M: Like preparation course?

$\mathrm{H}$ : Yeah, preparation course. And both (for the graduate student) kind of requirement for graduate student, before they start class. So (writing) academic writing and academic speaking, I took.

M: And was that (mostly) for people who English was their second language? H: Yeah.

M: Ok. And what did you think of those classes?

H: Maybe writing was kind of good (like) helpful, because I have no idea how English writing organized. I could use my assignment, like application, so we can check with teacher. But not so much feedback, I think. Grammatical mistake. But speaking. Yeah, pronunciation, we practice it. But I don't know. But so much better than junior high or high school class. The academic speaking course the teacher focus more on, not English. How we use language or voice or be confident. Not like grammar, not vocab.

M: Was that helpful?

$\mathrm{H}$ : I think the opportunity was good, because I have to speak in front of people. But simultaneously I took public speaking (like) undergraduate course. I think this class was so much better, because I had to research what I wanted to say. I talked about US bases in Okinawa. I had no idea the history, so I studied by myself. And then I had to memorize like sentence script. So I had to practice before the class. I think the 
class was much better than ESL academic speaking course. But before my friend checked my grammar or how I say these sentence.

M: Ok. So you took those courses at Vanderbilt, right? So no English classes really at Wellesley, and you don't have to take anything at PSU, right?

H: Yeah. Yeah. PSU. But I was conditional acceptance. But just I had to keep my grade " $\mathrm{B}$ " or better, the first summer term.

M: Ok, so if you didn't keep a "B” or better they would make you take English classes?

H: Maybe. Or I cannot get in.

M: Ok, I see. (Um) So, let's see. Have you been studying, like trying to improve your English by yourself the last couple of years? While you've been in the US?

H: The last couple of years? Yes, I have. (I tried to read) I am still doing, but I tried to read book. And not listening a lot. Because I hate reading too, but I want to learn (like) fun reading, not like a textbook, something interesting. So I start reading. (Um) by myself? Only myself?

M: Yourself or with other people, or...

H: When I was in Vandy, the first year, I tried to read children's book out loud, and then somebody corrected me.

M: Ok. Just one of your friends?

H: Yeah. But I think you know my English is so much better than three years ago, right?

M: Yeah. 
H: Because I couldn't communicate. This is big problem. I remember in 2008 in Boston, I couldn't read email too, because I cannot write email either. So I was so frustrated.

M: So what did you do to improve then? What do you think made a difference between 2008 and now?

H: Now? I think I met (many) not many, but. Of course I met many interesting people, but I met people who I really want to be friend with them. (So, I still like) when I was in Boston, I was Japanese TA. So my friend was (I think) Spanish TA, (French TA) not French TA \{laughing . Spanish TA, German TA, Italian TA. We were really close friend, we still talk now too. But I thought their English is (really good) really perfect for me. I don't know but their still learning. (They're graduate) kind of exchange program. Yeah, I met them so I wanted to communicate with. So (tried to) I used my body language.

M: So beside reading books, is there anything else you've been doing by yourself? H: Now?

M: Or the last couple of years too?

H: I do listen how they say. And but not now. (Now maybe) but this years is kind of my English study time, because finally I am full time student. But last year, I was not. I don't know. Watching movie? TV shows.

M: Do you think those are helpful, like listening/speaking?

H: I don't know. Just for fun. Because I never understand everything perfectly. But I can understand story, so. 
M: Do you ever feel like you learned something?

H: Maybe. Maybe. Yeah, like listening. Legendary \{quoting TV Show . Do you know the "How I Met Your Mother?"

M: Yeah, I love "How I Met Your Mother" \{laughing\}!

H: \{laughing\} "Wait for it, wait for it."

M: "Wait for it, wait for it....dary. Legendary" \{laughing\}.

H: Yeah, I learned some phrase. Yeah, maybe.

M: Ok, so you learned some phrases. Casual speech. The way people talk casually to each other.

H: Yeah.

M: That's good. (Um) So now I'm going to ask a couple questions just about what you think the best way to do things is.

H: Best way.

M: So, I'll make them more specific though. So let's say next week you have a test on vocabulary. And you can study for it however you want to?

H: Vocab?

M: What do you think the best way to study vocabulary is? Or what do you do?

$\mathrm{H}$ : Test is going to be writing or meaning?

M: Meaning.

H: Meaning? So I don't have to correct spell, right?

M: Well, for now let's say it's about meaning. 
$\mathrm{H}$ : Vocab is kind of, I'm going to try to make sentence. And make some kind of meaningful sentence. And if it's easy maybe just picture.

M: You mean, think about the picture in your head.

H: Yeah, vocab. I think.

M: (What if one of the words is) let's say one of the words is "legendary." And you don't know what the word "legendary" means. So you have to study that word. How are you going to remember what that means?

H: Legendary?

M: What techniques?

H: Ok. I'm going to ask a native, (what) maybe they can describe what is legendary.

M: Ok. And then after they tell you how do you memorize it.

H: Maybe, I'm sure he or she will give me some example.

M: Ok, try to remember examples of things that are legendary or something like that.

Ok. So (did you ever) have you ever used flashcards or anything to memorize vocabulary?

H: Maybe I shouldn't say yes, because I told you I'm not good student. I'm now a good student, but I was not a good student.

M: That's ok.

H: So after I wrote, (you know) I tried once, flashcard. After I finish making flashcard, it's done. \{laughing\} I won't use this.

M: You don't use them, just...

H: Just satisfied, making them. 
M: You just made them? Ok. So you didn't think it was a good way? Or?

H: No, not for me.

M: Ok. Not for you.

H: Some people, right? Patient, or good students.

M: (So you said) So far you said, like if the word is recorder, you picture this, right? Will you look at a picture, or just think about what it is?

H: Noun is easy to see, like a thing. But "legendary," more meaningful, I need more description.

M: So you need examples?

H: Yeah, examples.

M: From someone who is a native speaker, you said. What if the test is going to be on, like it's a speaking and listening exam?

H: So the TOEFL speaking exam, have you heard before?

M: Yeah.

$\mathrm{H}$ : So you have to speak to a computer. And judge is not like, who is like native. Judge is if we can organize well. So before I took TOEFL, I talked to international friend because she knew the TOEFL. Just practice. She asked questions, so I'm gonna reply. Listening skill is kind of, I don't how we can improve listening skill. I still don't know. If you don't know the vocab, you cannot listen. Maybe you can figure it out, if you can see the picture. For me, I don't have to understand everything. Speaking and listening, for me is difficult. Speaking is more interact. But For TOEFL it is not interact, just one way. Yeah presentative communication. 
M: What if it is like an exam like they do in JSL \{referencing curriculum we are both familiar with \} where you walk into a situation and you interact with somebody? And then someone is grading. So instead of talking to a computer.

$\mathrm{H}$ : The interact exam.

M: Yeah.

H: If I have friend, or. But I don't want to use friends for study. (This is my) I'm gonna ask friend if I need help, but I don't want to use them only my study. Do you understand?

M: I understand. But do you think it would be helpful if you used your friends? (Let's pretend) ignore whether you think it's nice to ask them or rude to ask them. Just if you think it's helpful.

H: I think so, yeah.

M: Ok it sounds like, you can correct me if I'm wrong, but it sounds like for studying speaking/listening you think the best way is to just talk with friends and if you make a mistake, just ask them to correct you.

H: Yeah, but the friends doesn't correct me, usually. But it's ok.

M: Yeah, friends don't usually.

$\mathrm{H}$ : Correction is a really big topic in learning language, you know?

M: Yeah.

H: I don't know. Maybe not friend, but interact is really important for me. Doesn't matter friend. Because if I go to Safeway and interact with cashier I can learn something. 
M: Yeah, sure.

$\mathrm{H}$ : I think, but friends is really important. Not acquaintances, friends.

M: Like good friends?

H: Yeah.

M: Ok, what about for reading? Let's say the test is like you have a certain amount of time and you have to read a passage and answer questions.

$\mathrm{H}$ : So, I have already the material?

M: (Uh) no, you don't have the material. You don't know what it will. You know the format, and let's say you know you'll have five minutes to read some text and then answer questions.

H: I'm going to read by myself. That's I did before. But I didn't improve my score. Maybe I did wrong way \{laughing .

M: I don't know \{laughing\}. Did you ever try any reading exercises where you read the first sentence of every paragraph first, to get the topic sentence? After that, then you read everything. Ever tried anything like that?

H: I tried, yeah. But I don't know if it was successful, for me. I'm really bad reading. M: Ok, last one. What about if it's a writing test? So, you have to do spelling? How do you study to remember how to spell things?

H: Spell. Write, write.

M: Over and over again?

H: Uh huh. Sentence I'm gonna speak sentence many times.

M: But for spelling. 
H: Spelling I'm gonna write.

M: So like "legendary, legendary, legendary, legendary..."

H: "legendary, legendary."

M: Ok. So those are most of the questions I have. (But if you can think of anything else interesting) I'm really interested in the ways people study by themselves.

Especially, instead of using textbooks, they use TV shows or things like that. Can you think of anything you've done that might be of interest?

$\mathrm{H}$ : Not me, but my student. He studied Japanese anime. He loves it, so he watched many times. So his pronunciation is really good. But he is also Korean. You know Korean is kind of well behaved in class, I think. But what is your goal for the foreign language study?

M: My goal?

H: No, no, no. (You're asking) you're talking about study, right?

M: Yeah.

$\mathrm{H}$ : I think studying language has goal for me. Ok. You want to go to graduate school in the US or just travel conversation for fun, or you want to get a job. I think (there's) the requirement for proficiency is different. You know, (my experience is) maybe you can use my experience, right?

M: Sure, yeah.

H: Maybe some people, you know, “Ok I'm going to New York,” you know. "So I'm going to study how to buy clothes." So I have to take grade "B" or better, so I have to study. 
M: Yeah.

H: My friend is sometimes really helpful. But friends are friends. But 2008, they helped me a lot. Before presentation, giving presentation, I practice with them. It was really good.

M: (So do you think, in general) Ok here's a question first, when you're studying by yourself, have you ever used a textbook for that?

H: No.

M: No. And why not?

H: I was in middle school and high school, right? Because I didn't want to study, or I couldn't find the meaning to study English. But after, in Boston and here, I have people who I speak with. Especially, in Boston, I wanted to communicate with them even though my English is horrible. So then kind of motivate me to study. Of course myself to, I want to improve my English. But every day, 10 months, we had dinner together. It was really helpful.

M: So even if you had a textbook at that time you don't think you would have used it to study? It sounds like for you the more effective way is just to communicate with friends.

H: But, no. I did grammar structure notebook in Japan before. Like during ALLEX and graduate. But that's all. But I hated, so I just stopped.

M: You just stopped?

H: It's boring! It was so boring! I'm not linguist, maybe. 
M: Was it just boring or was it not helpful? Or do you think it was helpful, but just too boring?

H: I think it might help, but my friends said if you try like three or four times the same textbook or (like) workbook. Again, again, again, you can do. I think she's true, but I was not patient enough. It's like exercise, writing, translate. \{unintelligible\}. I don't have any memorable textbook. You know, some English teachers say "this is really good textbook," but I don't know. It's so funny right? M: No, it's not funny. It's interesting. It's always interesting. Everybody studies language differently, I think. OK. I don't think I have any more questions.

H: Did I say too much?

M: No, you were in the middle, I think. Some people were longer, some people were shorter. Unless you can think of anything else interesting, then I don't think I have any more questions.

\section{Follow up communication}

M: First of all, I wanted to say thank you again so much for your help with my thesis research. I have one more question I wanted to ask: If you were giving advice to someone who is just starting to study English, what would you say? Can you think of 3-5 pieces of advice? Thanks again.

H: 1: Desire 
find out what you like, what you are good at, what you want to share with someone and your goal of studying English.

2:Plan

make sure your daily schedule.

depends on your goal, there is many chance to improve your skills.

so I would say that if you are in school(ELC), hang out with classmates.find out people who have the same ideas like you: want to improve own English but also want to be friends.

3: study English with the contexts= use English in the real situation. Remember English is just a tool. (communication)

4: improve your communication or an interaction skill in native language. English is tool of the communication.

5: be patient, learning language is a long life process.

from my experiences, I was good at communication in Japanese, love to talk to people, share own experience, learn from each other etc (1), so I became friends with other TAs, and also our schedule or condition was quite similar, so we had time to get together. we had dinner almost everyday, and watch a movie, travel together(2)(3)(4). 


\section{Yoshito}

Interview transcription

M: Ok. I'm just going to look at this real fast \{examining study log $\}$. So you were mostly just studying for class?

Y: Yeah.

M: Oh Longman. That's a grammar book, right?

Y: Yeah.

M: Is that for class?

Y: No. My program is kind of exchange student. So we must pass the TOEFL test.

So if we pass the TOEFL test, in winter we can register for elective class. So we must pass the TOEFL test. So we must study a lot.

M: Ok, but this book, did they recommend it?

Y: Yeah, recommend it.

M: Can I see it? I have one of these too, Longman. It's smaller than this though. Oh this is for TOEFL specifically.

Y: It's so heavy.

M: Ok, so these are like practice questions?

Y: Reading, listening, grammar. 
M: I see. How much do you usually do at one time? Each day how much do you study?

Y: Average one hour.

M: One hour? So maybe like one section, or?

Y: Skill 1 to 6 or skill 2 to 5 \{pointing to sections in the book\}.

M: I see. So that looks like most days you're using Longman. This study guide from the US, what's that like?

Y: I don't have it now.

M: Oh, thats ok.

Y: But we are given from my professor.

M: I see. So those are homework. Listening, listening, reading, grammar, writing, grammar. This one was not succesful, you thought $\{$ examining study log $\}$. Why? Just because you maybe were tired, or?

Y: Yeah, because my weak point is listening and speaking. And so, I'm good at reading and writing, (it's not) I don't think it's study is... \{can't understand\}. M: That's ok. Sometimes it's not. You usually study at home or the library. And usually by yourself?

Y: Yeah.

M: Ok. Thank you for filling that out. I'm just going to go through some questions that I've prepared. Mostly just describing your experience. So, let's get started with those. First of all, when did you first start studying English.

Y: Thirteen. 
M: Thirteen years old?

Y: My junior high school. (It's my) most Japanese start English from junior high school, because it's compulsory.

M: Compulsory? Yeah, you have to.

Y: Yeah. But maybe most Japanese started form 13.

M: In junior high school, you started having English classes at school. And what were those like? Can you kind of describe those classes?

Y: It's beginner grammar. For example "It's a pen" or "this is a pen" and "you are a doctor" or "my name is blah blah blah." Kinds of very beginner grammar, we learn. From high school its more complicated grammar and many reading/writing, we studied.

M: Ok. So, (in junior high did you most do) what kind of skills? When I say skills, it means reading, writing, grammar, speaking, listening. Those are the five skills, usually.

Y: In junior high school we focused on grammar and listening.

M: Ok. Grammar and listening. So not much speaking practice.

Y: Yeah. (Japan) I think many Japanese don't study speaking. So I think most

Japanese is not good at speaking. Many of them must study reading and grammar. Because we have a test to enter university. It's focused on reading and listening. So many Japanese must study them.

M: I see. So, do you think those classes mostly just prepared you for (examinations) entrance examinations? 
Y: Yeah.

M: (Do you think) at that time did you want to learn English? Or only because you had to take an exam.

Y: At that time, it was only prepare.

M: Yeah. And did they help you prepare for the exam?

Y: Sometimes.

M: I see. Do you remember anything about the kinds of textbooks you used? It's ok if you don't, I know that's a long time ago.

Y: It's kind of conversation. For example, the boy: "hi, hello.” The girl: "hello.” Boy: "My name is blah.” Girl: "My name is blah." Kind of simple conversation. And we learn from that the grammar.

M: Ok. (Did you) you just looked at those as examples? Did they ever ask you to (maybe) you and a student next to you to practice back and forth? Did you do that? Y: Yeah.

M: What did you think about that?

Y: At that time, it's kind of shy. Because we speak only Japanese, so English is difficult to speak, I mean the pronunciation. So many of my friends feel shy, I think. M: Let's see. What about your teachers? Still thinking about junior high.

Y: Junior high?

M: Yeah. Were they good teachers? Did they speak English well? Y: Um. (It depends on) some teacher is good. But some teachers pronunciation is not good; how to teach is not good. 
M: Ok. Were they usually Japanese?

Y: Yeah, Japanese teachers. (But some) do you know TA?

M: TA, yeah. Teacher's assistant. TA.

Y: Only one TA, she is from...can't remember. And she assist sometimes. For

example, it's kind of recreation. It's a game to remember English.

M: (So sometimes you had) so at that time would you say that you like that class? Or didn't like it?

Y: I liked. Because it's simple and...kantan \{Japanese word for easy\}.

M: Easy?

Y: Yeah, easy. I can get good score on the exam.

M: So you liked it because you could get an "A" in the class?

Y: Yeah.

M: And what about high school?

Y: High school is more complicated, but still focused on grammar and reading. Then a little listening. (We don't talk) we don't study writing and speaking. But I think speaking and listening is more important skill than reading and grammar.

M: Speaking and listening is more important than reading and grammar? Yeah. And the teachers there are still Japanese? No TA's?

Y: Yeah, Japanese.

M: And (um so you still think) would you say that the classes were still designed to prepare you for examinations? 
Y: Yeah. Most high school students must take the exam, it's a exam to pass the university. It's kind of...It's focused on grammar. Half of grammar and half of reading, and a little listening. So we must study kinds of skill. It's not exam speaking and writing. So, most of us don't study speaking and writing.

M: Did you, at any point go to (I think in Japanese you call them juku) cram school? Y: Ah. No.

M: You never did.

Y: No.

M: Did many of your friends do that?

Y: Not many. A little my friends went to juku.

M: Ok.

Y: But my hometown is country side so there is (little) a little juku. So I didn't go and many of my friends didn't go, maybe.

M: Which city are you from again?

Y: What?

M: What's the name of your city?

Y: Kakoshima. It's in kyushu.

M: Kyushu.

Y: And my hometown is island. It's a little island, the name is Amami. It's located half Okinawa and Kyushu, in the half. So it's really countryside. So there are (little) a little juku.

M: So did you ever study English outside of class? 
Y: You mean preparation for the exam?

M: Yeah, maybe preparation for the exam.

Y: Yeah, but only senior.

M: Senior yeah of high school?

Y: Yeah, because we have important exam. Junior and freshman (we only did) I only did homework.

M: (So how did) senior year, how did prepare for that?

Y: I asked my teacher to give me (some) some question. It's kind of test. And I did in home and I (watasu \{Japanese word for handing something over\}) gave my teacher. And my teacher is...

M: Correcting?

Y: Uh huh. And then I receive. It's your winning point. Then next...sorry \{struggling for the word $\}$.

M: It's ok, take your time.

Y: Then next question, I received.

M: Ok. It sounds like it's like a practice exam.

Y: Yeah.

M: Practice exam? So your teacher

Y: It's not homework. I ask my teacher.

M: Ok. So your teacher would give you a practice exam, and you would take that and then the teacher would correct it. And then new practice exam. Y: Yeah. 
M: So, why did you ask your teacher for the practice exam.

Y: Um. I wanted to get high school on the exam.

M: Was that your idea? Or maybe your parents suggested?

Y: Um, my idea.

M: (Cause you wanted to) Just cause you wanted to get into a good university?

Y: Huh?

M: Maybe because you knew a good, high school means you could go to a good university?

Y: Ah yeah!

M: Um. Ok. So you used practice exams. And do you think those helped?

Y: Helped?

M: Did they prepare you for entrance exams?

Y: Say one more please.

M: (Did the practice exams) were they helpful?

Y: Yeah. Helpful.

M: (And then) ok, so you got into university. You were accepted at university, at

Waseda. And then do you take English classes at university?

Y: I just took compulsory.

M: Only the ones you have to?

Y: Yeah.

M: What do they require? What are the compulsory classes? 
Y: Uh, it's twice in a week. One class is 90 minutes. We have two class in a week. It's compulsory, but it's also still focused on reading.

M: Reading? Ok. Not much speaking or listening. And the teacher is...

Y: Teacher is American.

M: Teacher are American?

Y: Class is taken by English, only English.

M: Only English? And what do you think of those classes?

Y: It's a little difficult. Because it's my first time to learn in English, so I can't catch up them. It's a little difficult, so I was supported by my friends.

M: So it was harder for you? The other students, you think it was easier for them?

Y: (It depends on) some of my friends it's easy, but some it's not easy but not hard.

But for me it's hard, really hard. Some of friends, my class... \{gets out electronic dictionary\}

M: Returning student \{reading electronic dictionary entry\}? Which one?

Y: Returning student, which means only high school they went to foreign high school. University, they returned and study. So they are good at English. Some of them, it is very easy. But for me it is very hard.

M: Ok. I see, so some of them were exchange in the US, maybe, during high school. Y: Yeah US or Australia or...

M: So their English is pretty good?

Y: Yeah. So I was supported by them. 
M: I see. (Is there much) so at Waseda there are compulsory English classes, but (I think) I'm wondering for how many years. Every term?

Y: Ah. One year and half. No, no, sorry, two.

M: Two years?

Y: By sophomore we must study English. It's compulsory. After that it's free to choose or don't choose.

M: Ok. And what year are you now? At Waseda are you sophomore or junior or senior?

Y: Junior.

M: Ok. So obviously you are here now, so you're still taking English.

Y: Uh huh.

M: What about when you go back to Waseda?

Y: Yeah, I will take.

M: You'll take?

Y: To keep my English skills.

M: And why did you choose to come to the US? Was it mostly for fun? Or because you wanted to improve English? Or just a good experience? Or?

Y: Um. Why did I choose to come to America?

M: Yeah.

Y: In Waseda program there are two application time. Spring and fall. This program is in spring application. Spring application is mainly Asia, Australia, and South America. And other countries like America, Europe is in fall application. We 
applied for spring application, (so) and PSU is only one school in America that's in spring application. Other school is in fall application. I wanted come America, so I choose this.

M: Ok. So why did you want to go to America.

Y: \{laughing\} Sorry. Uh. Australia is a little accent, strong accent. So I don't like that. So English and America I'm thinking. But Europe is a little far, so I choose this one.

M: Ok. But the reason for studying abroad was to improve English? Or you just thought it would be fun?

Y: No. Improve English.

M: Like 100\% improve English? Or 70\% improve English, 30\% fun? Or you know...It's ok.

Y: \{laughing $60 \%$ improve English and others is I want to experience foreign living. M: Yeah, I understand. I understand that. (Um) So before you came to the US, did you do anything special to increase your English skill, to prepare?

Y: Ah. Yeah. I took (class) two class. Listening class and speaking class.

M: Ok. So these ones are not compulsory?

Y: Yeah. Not compulsory. My choose.

M: Ok. So you decided to take extra speaking listening classes so that when you get to the US, you don't have (too many) too much trouble, right? Y: Yeah.

M: Ok. So, you've been in the US for about one month. 
Y: Yeah one month.

M: How many weeks of classes? Cause probably the first week was no classes, I bet. Right?

Y: Um. Core class is very difficult. We have two class. It's core class and one more is English class. And it support this content. So, I think core class is very hard because we (must learn) must listen in English and write English, read English and understand content. It's very hard work.

M: What's the subject of core classes?

Y: Environment.

M: Ok. This is the (oh I know this) the name of the program is LOHAS?

Y: That's right.

M: Ok. The English class. Is it one English class this quarter?

Y: No. (Monday,Tuesday) Monday, Wednesday, Friday.

M: Ok. But is that the same class, just three times a week?

Y: Yeah.

M: And can you describe what you do in that class?

Y: In English class?

M: Yeah.

Y: Oh, it support core class content. And (we must) we practice pronunciation and conversation.

M: Ok. (So maybe the) when you say it supports the core class, maybe you learn vocabulary that's... 
Y: Uh. No vocabulary. \{Looking for word $\}$ content?

M: Content.

Y: We ask our professor where didn't I understand. Then he told me that.

M: Ok. So they answer your questions. Ok. And then you have this book, which is recommend by English teacher?

Y: Yeah. Uh, English teacher?

M: Or just (program) somebody from your program?

Y: English teacher.

M: And do you use this in (your class) English class?

Y: Yeah.

M: You do?

Y: Yeah, we use.

M: Ok. (And so this) thinking again about the different skills: (so) reading, writing, speaking, listening, pronunciation, that kind of thing. The English class here in the US, what's the main focus?

Y: Oh. Reading and speaking. A little writing.

M: A little writing? (Besides, you said) so you told me that your teacher will answer your questions if you don't understand something. Besides that, what else happens in that class.

Y: Ah. We have a text. It's a reading text. And the homework. We must read in home, the chapter one or two. And in class we correct and talk about the chapter. And discuss my opinion and listen other friend opinion. 
M: Ok. Yeah, and do you like that?

Y: Yeah. Because it's practice, speaking.

M: Ok. Speaking and listening. So thinking about your whole English experience, so junior high, high school, Waseda, the US, what have you liked the most?

Y: Um. US.

M: Because it's speaking and listening?

Y: Yeah.

M: And what have you liked the least?

Y: High school, Waseda, and junior high.

M: All of it?

Y: Waseda's class, you know, Japanese students don't study?

M: At unversity?

Y: So some of my friends sleeping during class, and absent. So, even it's compulsory, many students is not serious.

M: Ok. So (my friends) my Japanese friends have told me that Japanese students work really hard in high school to prepare for college exams. And then once they are in college, they relax a little bit. Is that?

Y: What do you mean? Say one more?

M: So they work hard in high school, study, prepare for examinations and then you get accepted into university. And then when you go to university, you don't study very much. Is that accurate?

Y: \{laughing \} Yeah. 
M: I see.

Y: Because of the exam, we study. So library is so many people before exam. But except for that, in library there aren't the people.

M: So a lot of my (friend) Japanese friends have told me in (high school) especially high school they went to juku. So they studied at school and then after school, still studying hard. But you said you didn't go to cram school. But were you still studying after school?

Y: Yeah.

M: Just by yourself, or?

Y: Uh. It's compulsory. My high school is in countryside, so our teacher supported after class. Because there aren't the juku. If was ask my teacher, they could help. M: (So they just give you) your teacher at school gives you extra work to do at home? Y: Yeah. Uh huh.

M: What about now. I mean, my guess is probably after class you want to have fun and explore. Or do you still study outside of class sometimes?

Y: Half and half.

M: Half and half?

Y: Yeah.

M: (And when you do study outside is it) when you study outside class is it just mostly this book. Like here you were studying...

Y: Uh. Yeah and study guide.

M: (And that study guide) where did you get that study guide? 
Y: My teacher gave us.

M: Your teacher gave you the study guide.

Y: Yeah

M: Um. So. You've had a fair amount of experience studying English. You studied in junior high, high school, university, US. So I just want to ask some questions to get your opinion on some of the best ways to study. (Um, let's see) So let's pretend that next week you have an exam and it's a vocabulary exam. How would you study for that?

Y: (Um). Look many times. In the bus or before sleeping, I look many times. And if I think I remember, I write.

M: Ok, so to learn new words you just study often. And would you use any kind of materials? Or what would you look at? Dictionary?

Y: I would write. Pick up. Pick up words which I don't understand.

M: And those words you would write down?

Y: Yeah. And I would look many times. And then write.

M: Ok. So let's use this as an example \{getting paper out $\}$. So let's say we have the word (I can't think of a good word). Let's pretend you haven't heard the word restaurant.

Y: Restaurant?

M: Yeah. Just pretending. So how would you prepare to study for that? Y: Ah ok. Firstly, I write. Then I write Japanese meaning. And then next days I look in the bus or before sleeping. Then when I remember the meaning, I write again. 
M: And then write Japanese again underneath? Or just?

Y: It's just English. Just English.

M: Ok. (So this) First you're just studying this. Looking restaurant. Then you look at the Japanese. On the bus you do that and at home you do that. And you think you remember the meaning finally and you write this down.

Y: Yeah.

M: Ok. Have you ever used (like) flashcards? You know what those are? One side is English, one side is Japanese. You use those too?

Y: Yeah.

M: So you think those are both effective? Good ways to study for vocabulary?

Y: I think so.

M: Where did you learn those methods.

Y: Many friends did, so I imitate. Yeah, I imitate.

M: So you saw you friends doing similar things and you tried it?

Y: Yeah.

M: What about studying for speaking and listening. Let's say next week we have a speaking/listening exam. How would you prepare for that?

Y: Actually we haven't had a speaking and listening test, so I don't know how to prepare for that. (But listening is) Listening kind of test, similar kind of test I listen. It's preparation.

M: Ok.

Y: Ah. First listen, then see the script, and listen. 
M: Listen and see the script, and then listen. Do they have something like that in here \{pointing to textbook\}?

Y: Yeah.

M: Ok, what if it's not for a test. (It's just) you came to the US now and really want to work on your speaking and listening. How would you do that?

Y: (I think it's) conversation. With foreign students. Not foreign, American. M: Ok.

Y: It's practice I think. Best way to improve my speaking and listening skills. M: Sure. That makes sense. (What about) do you ever watch English TV shows? Y: Ah. Yeah. When I watch English TV or movie, there are subtitle. Because there is no subtitle, we don't understand. They speak so slowly, so it's need subtitle.

M: Ok. Do you think watching English TV helps?

Y: I don't think so.

M: Not really? Ok. So best way for you to improve speaking/listening skills is to find somebody to practice with, some native speaker of English.

Y: Yeah.

M: Makes sense. (Um) Ok, what about reading and writing? Thats the last one. If you want to improve your reading and writing.

Y: Firstly, we make list of vocabulary for this reading. Then we learn how to read quickly.

M: Ok. How do you practice reading quickly? 
Y: (Uh) read many times. Or firstly I read first sentence of each paragraph. After that we read all of them. I think it's a correct way.

M: Where did you learn to do that?

Y: My teacher from high school taught me.

M: Ok, so reading the first sentence, sometimes we call that the topic sentence. And that sort of gives you an idea of the rest. That makes sense.

Y: Yeah.

M: What about for spelling? Cause in English sometimes we spell things kind of funny?

Y: Spelling?

M: (Have you ever just tried) Do you just memorize? Cause like this word "restaurant," I have trouble spelling restaurant.

Y: Maybe many Japanese student remember restaurant \{pronuncing in Japanese\}. It's an easy way. For example \{writes the word "line" $\}$. It's line, but we just li-ne \{pronunces in Japanese\}.

M: I see. So you remember kind of how you would pronounce this in Japanese. Ok. Y: Yeah. So maybe many Japanese pronunciation is not good, I think.

M: So how did you learn to do that? I think that's interesting. Y: How?

M: Yeah. Because if you look at restaurant. This "u" \{making sound $\}$ is not there. But you put it there, right? You put it there to remember how to write it in English. How did you learn this strategy? 
Y: Ah. I don't remember. Sorry.

M: You don't remember. Could be maybe one of your friends, or one of your teachers?

Y: Not one of my teachers? Maybe my friend.

M: Not a teacher. Maybe one of your friends or maybe it just made sense to you. You thought: "ok how do I remember this?" And you remember how you pronounce in Japanese.

Y: Yeah.

M: Interesting. I wouldn't have guessed that. That works though. I think it's a good strategy, for spelling.

Y: \{laughing $\}$ For spelling. Just only spelling.

M: Just spelling. As long as you don't pronunce it that way \{laughing $\}$. That's good though. Let's see. So that's actually most of the questions have. Let me think for just a second to think if there's anything else. While I'm doing that, is there anything else you think is interesting about your English study? Or anything you think I should know or would want to know?

Y: What?

M: Can you think about anything else that I didn't ask about? About your experience studying English?

Y: Um. Nothing.

M: Has it been a mostly positive experience?

Y: I think so. 
M: I'm going to look at my questions real fast to make sure I didn't miss anything, but I think we're probably done. Oh, one more question. I don't know how to describe this very well, to make it easy to understand. (Um) Your classes in Japan: junior high school, high school, waseda. How much time does the teacher spend speaking?

Y: Teacher?

M: The teacher, yeah. Mostly, the whole class the teacher is talking to you?

Y: Yeah, almost talking. So we just sitting and writing.

M: You just sit, and write what the teacher says. Do you ask questions?

Y: Sometimes.

M: Sometimes you ask questions. But mostly you're listening to what the teacher says. At Waseda is that te same?

Y: Yeah. And sometimes the teacher asks us to answer the question. But almost they are talking.

M: What about now in the US.

Y: Half and Half.

M: And what do you think about that?

Y: US is better.

M: Ok.

Y: Japanese class is boring because it's just sitting and listening. So sometimes students are sleeping. It's not the correct way, I think.

M: So the US way is better because it's more interesting? 
Y: Uh huh.

M: And then, do you think it's better just because it's more interesting? Or?

Y: Ah no. It's practice to speaking. I need to speak English. I need to practice speak English. So it's better than Japanese class. Japanese class if really just sitting and listening. So we don't practice speaking.

M: Ok, that makes sense. I think (that's) that's everything.

\section{Follow up communication}

M: First of all, I wanted to say thank you again so much for your help with my thesis research. I have one more question I wanted to ask: If you were giving advice to someone who is just starting to study English, what would you say? Can you think of 3-5 pieces of advice? Thanks again.

Y: Okay! I would give advice...

1make chance to talk native speaker!

2be active!( don't be shy!) $\rightarrow$ I mean try to talk more people!( It's similar to 1 st advice though)

3increase vocaburary! 


\section{Appendix D: Codes}

\begin{tabular}{|l|c|c|c|}
\hline Master Codes & Experiences & Beliefs & Informal Learning \\
\hline \multirow{5}{*}{ Subcategories } & Childhood Lessons & Repetition & TOEFL \\
& Teacher Fronted & Order of Study & Textbook \\
& Student Participation & Motivation & Conversation Partner \\
& Grammar Class & Demotivation & Friends \\
& Grammar Translation & Persistence & Movies/TV \\
& Conversation Class & Acquisition & Books/Novels \\
& Reading Class & Social Nature of & Music \\
& Grammar translation & Language & Skype \\
& Homestay/Study Abroad & Trust in Formal Ed. & Conversation Café \\
& Cram School & Distrust in Formal Ed. & Vocab Book \\
& Entrance Exams & Native Instructors & Web Resource \\
& Assistant Language & & Boyfriend/Girlfriend \\
& Teacher & & Flashcards \\
& Presentation & & Dictionaries \\
& Pronunciation & & Non-compulsory Class \\
& Instruction & & Repetitive Writing \\
& Non-ESL Language Class & & \\
& Audio Laboratory & & \\
& American Culture Class & & \\
\hline
\end{tabular}

